\title{
WestVirginiaUniversity
}

THE RESEARCH REPOSITORY @ WVU

Graduate Theses, Dissertations, and Problem Reports

2003

\section{Treatment outcome for male adolescents in residential placement}

Taji Tortorello

West Virginia University

Follow this and additional works at: https://researchrepository.wvu.edu/etd

\section{Recommended Citation}

Tortorello, Taji, "Treatment outcome for male adolescents in residential placement" (2003). Graduate Theses, Dissertations, and Problem Reports. 1901.

https://researchrepository.wvu.edu/etd/1901

This Dissertation is protected by copyright and/or related rights. It has been brought to you by the The Research Repository @ WVU with permission from the rights-holder(s). You are free to use this Dissertation in any way that is permitted by the copyright and related rights legislation that applies to your use. For other uses you must obtain permission from the rights-holder(s) directly, unless additional rights are indicated by a Creative Commons license in the record and/ or on the work itself. This Dissertation has been accepted for inclusion in WVU Graduate Theses, Dissertations, and Problem Reports collection by an authorized administrator of The Research Repository @ WVU.

For more information, please contact researchrepository@mail.wvu.edu. 
Treatment Outcome for Male Adolescents in Residential Placement

Taji Tortorello, M.S.

\title{
DISSERTATION
}

Submitted to the College of Human Resources and Education at West Virginia University in partial fulfillment of the requirements for the degree of

\author{
Doctor of Philosophy \\ in \\ Counseling Psychology
}

David J. Srebalus, Ed.D., Chair

Richard T. Walls, Ph.D.

Ken Weigand, Psy.D.

Robert Marinelli, Ed.D.

Roy Tunick, Ed.D.

Department of Counseling Psychology

\author{
Morgantown, West Virginia \\ 2003
}

Copyright 2003 Taji Tortorello 


\section{ABSTRACT \\ Treatment Outcome for Male Adolescents in Residential Placement}

Taji Tortorello

The purpose of the study was to assess archival data to determine what variables are related to successful discharge from a residential treatment program for adolescents with behavioral disorders. The records of 120 residents of a Northern Virginia residential treatment program were reviewed from January 1999 to January 2001. The researcher was interested in determining what predictor variables, such as: intake demographic and intake assessments relate to outcome, such as: discharge assessments, discharge planning, and discharge GPA. Results indicated that students who are successfully discharged from this program at intake are typically: 1) older, 2) less oppositional, 3) engage in less externalizing behaviors, 4) receive fewer restrictions, and 5) improve achievement scores while at the facility.

Keywords: Adolescents, Residential Treatment, and Treatment Outcome, Discharge Planning, Behavioral Disorder, and Assessments 


\section{Table of Contents}

CHAPTER

Page

ABSTRACT

1. Problem in Perspective .......................................................................

Development of Behavior Disorders ................................................ 3

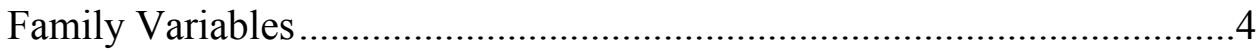

Description of Variables to be Studied .................................................5

Deviant Peer Associations .........................................................6

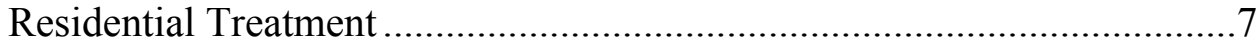

Multisystemic Treatment Models .................................................. 9

Statement of the Problem............................................................... 11

Purpose of the Study .................................................................... 12

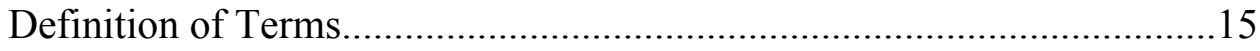



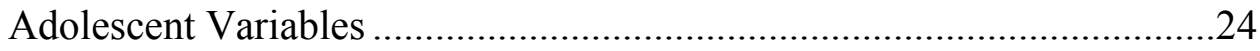



Treatment Outcome .......................................................................29

Premature Termination of Treatment.......................................................33



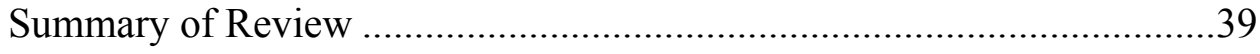

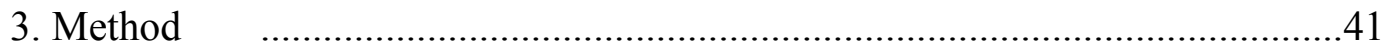

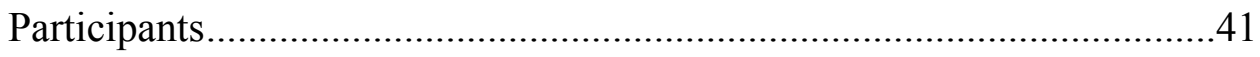

The Residential Treatment Facility......................................................42 
Measurement of Independent Variables

Treatment Characteristics ...................................................4 46

Measurement of Dependent Variables ........................................................47

Beck Depression Inventory................................................4

Norwicki-Strickland Locus of Control Scale for Children ............48

Millon Adolescent Clinical Inventory .....................................49

State-Trait Anger Expression Inventory ..................................50

Woodcock-Johnson Test of Achievement ................................51

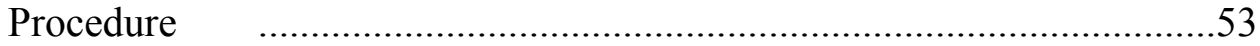



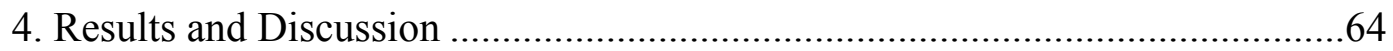

Description of the Sample................................................................64

Demographic Characteristics .......................................................64

Psychometric Characteristics ........................................................67

Treatment Characteristics ............................................................ 70

Outcome Characteristics ......................................................... 77

Zero-Order Pearson Product-Moment Correlation ..................................80

Research Question 1 .............................................................. 81

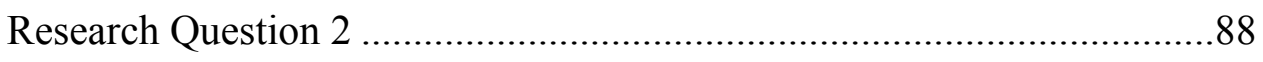

Research Question 3 ............................................................... 91

Research Question 4 ................................................................99

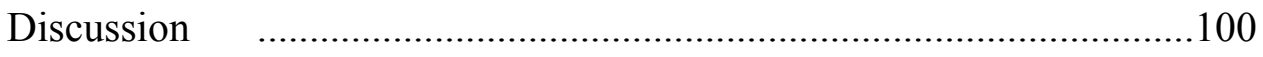

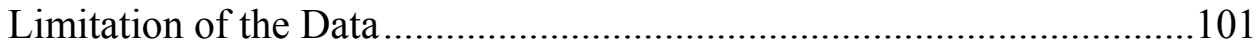


Future Research

Implication for Practice.

5. Summary

References

Appendix A: Data Record Sheet.

Appendix B: Description of Psychometric Measures

Appendix C: Behavioral Management System. 150

Appendix D: Supplemental Tables 159

Table 1: Demographic Variables: Definition of Variables 56

Table 2: Independent Variables: Definition of Variables 57

Table 3: Dependent Variables: Definition of Variables .58

Table 4: Independent, Dependent, \& Intake Demographic Variables 59

Table 5: Statistical Analysis for Research Question 1 60

Table 6: Statistical Analysis for Research Question 2 61

Table 7: Statistical Analysis for Research Question 3 62

Table 8: Statistical Analysis for Research Question 4 63

Table 9: Demographic Characteristics of Residential Treatment Participants .65

Table 10: Intake Scores for Residential Rx Pt. for MACI, BDI, LOC, STAXI \& WJ-R..68

Table 11: Frequency of Treatment Received by Residents in Adolescent Rx Facility .....71

Table 12: Treatment Variables: Individual \& Group Therapy ..... 73

Table 13: Treatment Variables: Family Therapy vs. No Family Therapy .75

Table 14: Treatment Variables: Masters Level Therapist vs. Doctorate Level Psych.......76

Table 15: Treatment Variables: Residential Rx that Received Psychotherapy . .78 
Table 16: Mean Scores for Outcome Variables.

Table 17: Age Related to Intake \& Discharge For Research Question 1 ........................82

Table 18: Significant Correlations of Clinical Psychopathology .................................86

Table 19:Significant Correlations of Demographic Variables with Outcome Variables ..89

Table 20: Significant Correlation of Psychometric Measures with Outcome Variables ...93

Table 21:Significant Correlation of Types of Rx Received with Outcome Variables ......98 


\section{Problem in Perspective}

\section{CHAPTER 1}

\section{$\underline{\text { Introduction }}$}

The school shootings in the media, such as Columbine, Colorado, Jonesboro, Arkansas, and Santee, California have sparked many researchers' interests into the study of adolescents with behavioral problems (Garbarino, 1999). Behavioral disorders are the fastest growing disorders of childhood, and account for $2 \%$ to $9 \%$ of all clinic referrals (McMahon \& Wells, 1998). Childhood behavioral disorders have been found to significantly correlate with later delinquency, criminality, and substance abuse in adolescents and adulthood (Anasari, Gouthro, Ahmad, \& Steele, 1996; Eme \& Kavanaugh, 1995; McMahon \& Wells, 1998). Moreover, oppositional defiant disorder is the most common diagnosis made for children; about 5 percent of all children are diagnosed with it (Naiken, 2002). A recent study has estimated that more than 10 percent of the nation's youth, age 10-17 years, are engaging in behaviors that seriously jeopardize their futures, including poor academic performance, substance abuse, delinquency, and unprotected sex.

The specific behavioral problems addressed in this study include: conduct disorder (CD), oppositional defiant disorder (ODD), and disruptive behavioral disorder (DBD); which are all classified in this study as behavioral disorders. Additional student diagnoses, within the special education profession are: emotional disorders (ED) and learning disorders (LD). Behavioral disorders (BD) in general are characterized by conduct problems, aggressive tendencies, and antisocial behavior. Behavior disorders may be chronic. There may be events that perpetuate the onset of CD or ODD symptoms; for example, maladjustment to stressful life events, reactions to 
traumatic situations such as sexual/physical abuse, neglect, multiple foster placements, and parental substance abuse (Frauenglass \& Routh, 1997).

Within the United States, it is reported that juveniles are responsible for committing $17 \%$ of violent crimes (Schrere, Brondino, Hennggeler, Melton, \& Hanley, 1994). Of the 717, 700 persons arrested in 1997 for violent crimes, 17\% were juveniles (122,009) (Uniformed Crime Report, 1998). From 1993 to 1997 the overall juvenile arrest rate rose 14\%. Six percent of all persons arrested were under age of 15 with 19\% under age 18, and 32\% under age 21 . Specifically, 17-year-old males accounted for the highest arrest rates (Uniformed Crime Report, 1998).

Since 1967, the overall arrest rate for juveniles has increased 26\%. However, the juvenile arrest rate for violent crimes reveals a 143\% increase from 1967 to 1996 (Uniformed Crime Report, 1998). Moreover, the nature of the crimes committed by juveniles has drastically changed. For example, in 1967 nine percent of male juveniles were arrested for violent crimes, while the remaining $91 \%$ were for property crimes. In 1996, $18 \%$ of juvenile arrests were for violent crimes, while the remaining $82 \%$ were for property crimes. Furthermore, juvenile males display a progressively higher rate of arrests as they age. For instance, 16 and 17-year-old males account for the majority of juvenile crimes committed, while thirteen to fourteen-year-old males' account for the smallest proportion (Uniformed Crime Report, 1998).

The statistics cited are alarmingly high numbers, yet it significantly underestimates the actual rates of crimes committed by juveniles. It has been reported that many crimes go unreported, or juveniles are simply reprimanded for bad behavior. Youths committing violent acts have been an ever-increasing phenomenon. 


\section{$\underline{\text { Development of Behavioral Disorders }}$}

Behavioral disorders have been the topic of research for several decades (Richters \&

Cicchetti, 1993, p. 2). Adolescents' behavioral problems have historically been presumed to be a normal part of the developmental process. Literature is accumulating that describes our understanding of the etiology, course, and the treatment of behavioral disorders (Coie \& Jacobs, 1993). Moreover, many disciplines including: developmental, child, forensic, social, and neuropsychology, psychobiology, epidemiology, criminology, and sociology have become involved in the quest to develop a clinical representation of behavioral disorders (Coie \& Jacobs, 1993).

Richters and Cicchetti (1993) agree with the notion that the study of childhood behavioral problems has developed along multidisciplinary lines in which professionals from a variety of educational fields are interested in the study of behavioral disorders. Many researchers argue that what is missing within the research community is the necessary theoretical and conceptual connective tissues which serve to integrate knowledge among the multitude of scientific disciplines involved in the study of behavioral disorders (Richters \& Cicchetti, 1993).

Researchers are aware of several predictor variables that have been associated with the onset of behavioral problems. However, more research is needed to develop a consensus within the field to understand the interplay among these factors (Richters \& Cicchetti, 1993). Among the predictors found to contribute to the onset of behavioral problems are familial issues. Many researchers agree that delinquency and violent actions are, in part, the outcome of adolescents socioeconomic status and poor parenting practices (Heimer, 1997). 


\section{$\underline{\text { Familial Variables }}$}

What is less clear is exactly how familial factors exert their effects on childhood behavioral disorders. For example, McMahon and Wells (1998) questioned how these factors directly place the child at risk for developing conduct problems, or do these risk factors exercise their effects by disrupting the home and parenting practices? Some research indicates that these risk factors are in fact the result of conduct problems in children, rather than a potential cause (McMahon \& Wells, 1998).

An overall review of the literature suggests that there are a number of familial variables have been associated with the development of delinquent behavior, such as poor parent-child bonding and affection, poor parental monitoring of behavioral practices, lack of supervision, and poor discipline practices (Borduin, Mann, Cone, Henggeler, Fucci, Blaske, \& Williams, 1995; Kazdin, Siegel, \& Bass, 1992; McCord, 1993; Reid, 1993; Schrere, Brondino, Hennggeler, Melton, \& Hanley, 1994). Moreover, family discord, marital distress and conflict, single-parent families, large family size, parental deviance in behavior and attitude, and ineffective parenting strategies also have been associated with the development of behavioral disorders in children (Kazdin, Siegel, \& Bass, 1992; McCord, 1993; Reid, 1993). Although, evidence does suggest that marital discord is not the primary cause of behavioral problems; typically these problematic behaviors are present prior to the divorce (McCord, 1993).

In addition, it has been documented that variables, such as maternal age, socioeconomic status, and parental antisocial behavior, each were found to correlate significantly with childhood behavioral problems. Furthermore, it has been suggested that teenage motherhood, parental antisocial personality, and socioeconomic status each contribute distinctively to conduct problems when these factors are analyzed using a path analytical approach. It was further 
reported that socioeconomic status and parental antisocial personality accounted for the greatest variance (Christ, Lahey, Frick, Russo, McBurnett, Loeber, Stouthamer-Loeber, Green, 1990).

Frick, Lahey, Loeber, Stouthamer-Loeber, Christ, and Hanson (1992) documented that their results were consistent with a large body of research that indicates that a high rate of parental antisocial personality and substance abuse are typically found with the parents of behaviorally disordered children. It was also determined that children with much less severe behavioral problems, such as those diagnosed with ODD, also are parented by persons with antisocial personality and substance abuse histories. Moreover, children with behavioral problems are more likely to be parented by fathers diagnosed with antisocial personality and maintain a history of substance abuse (Frick, Lahey, Loeber, Stouthamer-Loeber, Christ, \& Hanson, 1992).

It seems likely that within dysfunctional families, family members themselves inadvertently reinforce violent behavior by themselves engaging in violent forms of behavior (McMahon \& Wells, 1998). This form of modeling encourages the child to engage in aggressive behaviors. In any case, it is important to note that, poor parental modeling, along with other parental behaviors, may be the result of a multitude of difficulties the parents face. These include, stress, poor health care, unemployment, socioeconomic disadvantage, educational difficulties, mental health concerns, and a history of drug and alcohol abuse (Borduin, Mann, Cone, Henggeler, Fucci, Blaske, \& Williams, 1995; Kazdin, Siegel, \& Bass, 1992; Schrere, Brondino, Hennggeler, Melton, \& Hanley, 1994).

Description of Variables to be Studied

Research indicates that children with behavioral disorders are more likely to drop out of school, be unemployed, and have poor interpersonal relationships (Coie \& Jacobs, 1993). 
Children diagnosed with behavioral disorders often exhibit many non-normative behaviors, such as aggression, deceitfulness, and destruction. Unfortunately, aggressive adolescents use threats and physical threats as a means to achieve personal goals. Peers inadvertently reinforce these aggressive tendencies by backing down and allowing these aggressive adolescents to succeed. Therefore, children with behavioral problems are likely to think that aggressive behavior has positive functional consequences and are likely to utilize this form of behavior (Coie \& Jacobs, 1993).

Children with behavioral disorders often engage in high-risk activities, such as illegal drug-use, alcohol use, and early sexual behaviors (Atkin \& Brown, 1994). They typically show little empathy for others, have limited insight into their behaviors, poor self-control, an inability to delay gratification, demonstrate little to no remorse for their action, and have minimal concern for the feelings, wishes, and well being of others (Atkin \& Brown, 1994; Coie \& Jacobs, 1993). Behavioral disordered children tend to have academic problems, problems at home and in the community, a high rate of suicidal ideation, and suicidal attempts and completion (Atkin \& Brown, 1994). They have poor relationships with peers as well as adults, and significant selfesteem problems (Cole \& Jacobs, 1993). In addition, peer associations were also discovered among the predictors found to contribute to the onset of behavioral problems. Many researchers agree that behavioral problems are, in part the outcome of youth's association with aggressive peers and socioeconomic status (Heimer, 1997).

\section{Deviant Peer Associations}

Research indicates that there is a significant association between the maintenance of behavioral problems and association with deviant peer groups. Research suggests that, children that do not display behavioral problems often reject children with behavioral disorders (Eme \& 
Kavanaugh, 1995). These adolescents are then forced to participate with the only group that will accept him/her, which typically tends to be other behaviorally disordered youths. Acceptance into this delinquent subgroup ultimately serves as the training ground for future delinquent acts. These more problematic peers are thought to supply the adolescent with attitudes, motivations, and rationalizations to support further antisocial acts, as well as, the opportunity for continued delinquent behavior (Eme \& Kavanaugh, 1995). By the time the child reaches 10 to 11 years of age there is an increased risk of association with a deviant peer group (McMahon \& Wells, 1998). Therefore, treatment of this population must encompass, not only treating the resultant behavioral problems, but also serve to reduce the extrafamilial factors, such as deviant peer associations. Subsequently, for rates of behavioral problems among adolescents to decline there has to be a change in the way that mental health professionals approach the treatment of these behavioral disorders. Research is needed to identify those groups of children and adolescents for whom the benefits of residential care outweigh the potential risks. Which at-risk youth are best served by residential care rather than community-based care and how residential care should be combined with community-based care to best serve at-risk youth over time?

\section{$\underline{\text { Residential Treatment }}$}

Over the last ten years there has been an increase in the number of behavioral disordered adolescents placed in residential care settings (McMahon \& Wells, 1998). In light of the increasing number of school shootings, there is a movement toward more effectively treating those adolescents with behavioral disorders. The need remains for continued research on effective forms of treatment for this population (Henggeler, Melton, Brindino, Scherer, \& Hanley, 1997). Researchers are still trying to pinpoint the components that need to be included in a treatment program (Borduin, Mann, Cone, Henggeler, Fucci, Blaske, \& Williams, 1995; 
Henggeler, Melton, Brindino, Scherer, \& Hanley, 1997). Researchers have conclusively determined that adolescents who have been classified with a behavior disorder have been considerably resistant to currently available modes of treatment (Henggeler, Melton, Brindino, Scherer, \& Hanley, 1997).

Adolescents who are placed in residential treatment centers clearly constitute a difficult population to treat effectively. The most effective programs typically involve intensive training or behavior modification techniques aimed at reducing risk behavioral difficulties. Overall there is some evidence for the effectiveness of a variety of approaches. Since there is an increasing number of adolescent with behavioral problems being placed in residential treatment settings, the range of placement types include: community-based family-style group homes, cottages in larger institutional settings, larger group living situations with shift staff, and therapeutic foster care. Residential treatment for troubled adolescents is expensive, typically assuming a substantial portion of a state's child welfare, mental health and education budgets. Despite high costs, little is known about the effectiveness of this intervention. Longer-term data are needed to test the endurance of treatment effects (Chamberlain, 1999).

Given the growing use of residential placement and the large amount of Medicaid dollars that are spent to place adolescents in residential treatment centers, there remains a tremendous need for additional research to examine long-term effectiveness. Chamberlain (1999) cites a need to bridge the gap between research on effectiveness and practical application of these empirically validated treatment in residential facilities. Several reviews of residential treatment programs have produced promising findings, but do these studies address what components need to be implemented in residential settings to successfully treat the adolescent with a behavioral disorder? 
Researchers are aware of several positive findings associated with residential treatment of behavioral disorders. For example, Ansari, Gouthro, Ahmad, and Steele (1996) evaluated shortterm residential placement in which behavior modification was utilized. Behavioral techniques, such as positive reinforcement, and behavioral contracts were found to produce improvements in prosocial behaviors. The increased success of treatment when the family is involved is widely acknowledged by therapists. Most therapists are acutely aware of the damage that a family can do to client's therapeutic progress, if the family is not supportive of the treatment goals or are unaware of their impact on the client (Kumpfer, 1999). Garrett (1985), in a meta-analytic review, reports that individual and group therapy with adolescents in residential care, had no effect; while family therapy appeared to be more effective, with this population. It is strongly recommended from the literature on residential treatment that the family be involved in the treatment process. Family-focused interventions have shown positive impacts on child and family functioning, delinquent behavior, and recidivism.

The amount of family involvement is also thought to have some bearing on treatment outcome (Mann-Feder, 1996). Whether family therapy should be a necessary component of routine residential treatment remains a controversial issue (Chamberlain, 1999). What is clear is the fact that failure to include parents in the treatment process may be the single largest factor that impedes the generalization of treatment success from the residential setting to home. The problem is generalizing treatment gains noted within the residential setting back into the community. A review of the literature identified a number of studies that found that some adolescents leaving residential facilities have a difficult time maintaining treatment gains.

\section{Multisystemic Treatment Models}

Encouragingly, there is no longer a consensus in the literature that nothing works, as was 
reflected in the 1970's (Borduin, Mann, Cone, Henggeler, Fucci, Blaske, \& Williams, 1995; Henggeler, Smith, \& Schoenwald, 1994). There is also growing evidence for the effectiveness of multifaceted programs to prevent development of disorder in at-risk youth. Multisystemic therapy is an intensive family and community-based treatment that addresses the multiple determinants of serious antisocial behavior in juvenile offenders. Multisystemic therapy developed in response to the need for efficacious and cost-effective treatment for the behaviorally disordered population. Treatment efforts, in general, have failed to address the complexity of adolescents needs. Given overwhelming empirical evidence that suggests that serious antisocial behavior develops as a result of the interchange of individual, family, peer, school, and neighborhood factors, it is not surprising that previous treatments of serious antisocial behavior have been largely ineffective (Borduin, Mann, Cone, Henggeler, Fucci, Blaske, \& Williams, 1995; Henggeler, Melton, Brindino, Scherer, \& Hanley, 1997).

Developers of multisystemic treatment approaches argue that restrictive out-of-home placements, such as residential treatment, psychiatric hospitalization, and incarceration, fail to address the known determinants of serious antisocial behavior and fail to alter the home environment to which the adolescent will inevitably return. The ineffectiveness of out-of-home placement, coupled with extremely high costs, has led many mental health professionals to seek out feasible alternatives. Multisystemic therapy has a well-documented capacity to address the aforementioned difficulties (Borduin, Mann, Cone, Henggeler, Fucci, Blaske, \& Williams, 1995; Henggeler, Melton, Brindino, Scherer, \& Hanley, 1997).

The first controlled study of multisystemic therapy with adolescents with behavioral disorders was conducted in 1986. Since that time, three randomized clinical trials with violent and chronic behaviorally disordered adolescents have been conducted. In these trials, 
multisystemic therapy has demonstrated promising long-term results. Preliminary successful results has led to additional randomized trials and quasi-experimental studies designed to further reproduce efficacious outcomes with adolescents presenting with serious behavioral problems (Borduin, Mann, Cone, Henggeler, Fucci, Blaske, \& Williams, 1995; Henggeler, Melton, Brindino, Scherer, \& Hanley, 1997).

The goal of multisystemic therapy is to provide an integrative, cost-effective, familybased treatment approach that results in positive outcomes for adolescents with serious behavioral issues. It focuses first on improving psychosocial functioning for adolescent and their families so that the need for out-of-home child placements is reduced or eliminated. It is based on the philosophy that the most effective and ethical route to helping behaviorally disordered adolescents is through helping their families.

\section{Statement of the Problem}

Many authors address the need for continued research into effective treatments for behavioral disordered population, yet to date, there is not a general consensus within the research community in terms of the components that need to be included in residential treatment programs for this population (Henggeler, Smith, \& Schoenwald, 1994; Scherer, Brondino, Hennggeler, Melton, \& Hanley, 1994). More information is needed regarding what the role of residential treatment and what contributes to its effectiveness. To date, much of the research supports the proposal that adolescents who are behaviorally disorder need to be treated in a multidetermined fashion, acknowledging multiple predictors responsible for the developmental of behavioral disorders. Therefore, there is a need for multifaceted approaches to intervention (Henggeler, Schoenwald, Borduim, Rowland, \& Cunningham, 1998). 
Research indicates that treatments that are longer in duration and involve more contact hours are often associated with better outcomes (Borduin, Mann, Cone, Henggeler, Fucci, Blaske, \& Williams, 1995). In general, the most effective residential programs are highly structured, emphasize the development of basic social skills, and provide individual counseling that directly addresses behavior, attitudes, and perceptions. The introduction family-focused interventions have shown positive impacts on child and family functioning, delinquent behavior, and recidivism. This study will begin to address the need for individual, group, family, therapy combined with medication management are necessary to produce effective outcomes when treating adolescents in residential treatment settings.

\section{Purpose of the Study}

The current study proposes to conduct an analysis of archival data to assess the contributions of demographic variables, family issues, and peer associations on treatment outcome in a residential treatment setting. Specifically, what demographic characteristics and behavioral disorders, receiving what form of therapeutic intervention achieve what level of success? This question adequately characterizes the intent of the investigation. The purpose of the study is to determine what variables are related to success upon completion of a residential treatment program. The study will answer the following questions:

1. How does the age of residents of a Northern Virginia residential treatment facility, relate to intake and outcome levels of: (a) depression, (b) internal - external locus of control, (c) state anger, (d) trait anger, (e) angry reaction, (f) anger in (g) anger out, (h) anger control and (i) anger expression?

2. What relationship exists among demographic variables ?: (a) age, (b) grade, (c) number of siblings, (d) verbal IQ, (e) performance IQ, (f) full scale IQ, (g) GPA, (h) substance abuse 
history, (i) ethnicity, (j) religious denomination, (k) parents' marital status, and (1) legal guardianship? How did the demographic variables relate to the following outcome variables? : (a) number of AWOL's, (b) weeks at level 1, (c) weeks at level 2, (d) weeks at level 3, (e) weeks at level 4, (f) Progression Score level 1, (g) Progression Score level 2, (h) Progression Score level 3, (i) Progression Score level 4, (j) type 1 restriction, (k) type 2 restriction, (l) type 3 restriction, (m) current GPA, (n) broad reading discharge, (o) broad math discharge, (p) broad writing discharge, (q) broad knowledge discharge, ( r) skills discharge, and (s) discharge criteria?

3. What relationship exists between scales of the Millon Adolescent Clinical Inventory, Beck Depression Inventory, the Locus of Control Scale for children, the State-Trait Anger Expression Inventory, the, and the Woodcock-Johnson Achievement Test and outcome variables: (a) number of AWOL's, (b) weeks at level 1, (c) weeks at level 2, (d) weeks at level 3, (e) weeks at level 4, (f) Progression Score level 1, (g) Progression Score level 2, (h) Progression Score level 3, (i) Progression Score level 4, (j) type 1 restriction, (k) type 2 restriction, (1) type 3 restriction, (m) current GPA, (n) broad reading discharge, (o) broad math discharge, (p) broad writing discharge, (q) broad knowledge discharge, (r) skills discharge, and (s) discharge criteria?

4. What relationship exists between the treatment variables of: (a) individual therapy, (b) family therapy, (c) group therapy, (d) therapist's degree, (e) therapist's style, and (f) current medication; and the, outcome variables of: (a) number of AWOL's, (b) weeks at level 1, (c) weeks at level 2, (d) weeks at level 3, (e) weeks at level 4, (f) Progression Score level 1, (g) Progression Score level 2, (h) Progression Score level 3, (i) Progression Score level 4, (j) type 1 restriction, (k) type 2 restriction, (1) type 3 restriction, (m) current GPA, (n) broad 
reading discharge, (o) broad math discharge, (p) broad writing discharge, (q) broad knowledge discharge, ( r) skills discharge, and (s) discharge criteria? 


\section{Definition of Terms}

\section{$\underline{\text { Level Systems }}$}

The residential treatment facility utilizes a Behavioral Management/Change system, in which they incorporate a Level System approach. For advancement from level to level at the residential treatment facility used in the study, criteria are established. It is important to note that the criteria are meant as general guidelines. Transition from one level to the next is based on the discretion of staff members. Advancement to a new level presents new challenges, graduated levels of freedom, and greater responsibility for the student. Therefore, students are always encouraged to meet the challenges and supported throughout the process. The ultimate goal is to teach the students to effectively meet his need for power, belonging, fun, and freedom by making choices that comply with prosocial group rules (Glasser, 1984) (See Appendix C, pg. 150).

1. Level I: Adjustment - This level serves to introduce the student to the facility and its staff. Students are expected to learn the rules and daily routines. A minimum time requirement for advancement to the next level is two weeks.

2. Level II: Personal Compliance - Students learn what behaviors are expected. Student must demonstrate 85 percent compliance with all the rules and treatment expectations over a minimum of several weeks. A minimum time requirement for advancement to the next level is four weeks. Knowing and complying with rules on a relatively consistent basis are the expectations for successful outcome on Levels I and II.

3. Level III: Setting goals - Here, students learn that it is not enough to change their thoughts and comply with rules; rather, the students learn they must set goals and reach them. Students must demonstrate 90 percent compliance with all the rules and treatment expectations over a minimum of several weeks. Furthermore, they learn to set goals for themselves as well as 
develop strategies to reach those goals. A minimum time requirement for advancement to the next level is six weeks.

4. Level IV: Goal achievement - "Nearly perfect compliance" with rules and treatment is expected; the program defines compliance no more precisely. At this level, staff begins to slowly assess student ability to be successful. Control over ones behavior gradually is given over to the students. A minimum time requirement for advancement to the next level is eight weeks.

5. Level V: Responsibility - "Nearly perfect compliance" with rules and treatment is expected; the program defines compliance no more precisely. Greater emphasis is place on students internal drive to maintain responsible behavior. There are more opportunities for independent decision-making: 1) living off campus, 2) getting a job off campus, etc. A minimum time requirement for advancement to the next level is eight weeks, six weeks with complete compliance. Transition back to the larger community now starts to become a prominent theme in treatment.

6. Level VI: Reintegration - "Nearly perfect compliance" with rules and treatment is expected; the program defines compliance no more precisely. At this level the student is preparing for discharge. Generally, completion of this level is eight weeks.

\section{$\underline{\text { Progression Score }}$}

Progression score in this study is defined as the difference between the actual time that it took the resident to progress through the level and the prescribed amount of time that the resident will take to progress through the levels (as determined by the treatment facility) (actual timeprescribed time $=$ progression score). This difference score is the progression score for each resident. For example, on level 1 the minimum criterion for advancement to next level is two 
weeks, if a given resident advanced in six weeks then the progression Score would reflect a +4 . A positive number reflects that it took that student longer than the prescribed amount of time to complete that level. Whereas, for level 2 a minimum criterion for advancement to next level is four weeks. If a given resident progresses in three weeks, then the progression score for that resident would be $\mathrm{a}-1$. A negative number would represent that a given student went through that particular level faster or under the amount of time prescribed to complete that level. Whereas, for level 3 the minimum criterion for advancement to next level is four weeks, if a given resident progresses in four weeks then the progression score would be zero which would reflect that a student went through the levels in exactly the amount of time that it was prescribed by the residential treatment facility.

\section{$\underline{\text { Behavior Disorders }}$}

Behavioral disorders are acting out behaviors that have occurred for a long period of time, goes against what is socially acceptable for the individual's age and situation, and is selfdestructive and adversely affects the family.

\section{$\underline{\text { Learning Disorders }}$}

Learning disorders are defined by a child's unexpected poor academic achievement. "Specific learning disability is a chronic condition of presumed neurological origin which selectively interferes with the development, integration, and/or demonstration of verbal, and/or nonverbal abilities. Specific learning disabilities exist as a distinct condition that may vary in degree of severity. Throughout the adolescents' life, the condition can affect self-esteem, education, vocation, socialization, and/or daily living activities" (Swanson, 1991). 


\section{$\underline{\text { Emotional Disorders }}$}

Emotional disorders can be defined as a mental disorder in which chronic, inappropriate emotional reactions predominate (Chaplin, 1985). Most children with emotional disorders exhibit externalizing behaviors (e.g., noncompliance, aggression, tantrums), but many exhibit internalizing behaviors (e.g., excessive shyness, depression).

\section{Comorbidity}

Comorbidity exists within this context when the co-occurrence of two or more disorders is greater than one would expect by chance; i.e., when there is a higher than expected rate of emotional disturbance or psychopathology in children (Nieves, 1991).

\section{$\underline{\text { Restrictions }}$}

1. Type 1 - Type 1 Restriction is a punishment for a behavioral infraction. A Type 1 Restriction can be earned for the following behaviors: not attending an off-campus activity after having committed to it, behavior in a vehicle that causes the vehicle to return to campus, misbehavior on a vehicle that threatens the safety of other passengers; while on an off-campus activity not reporting to check-in within 5-minutes of designated check-in time; while on an off-campus activity leaving the designated parameters without staff permission, while on an off-campus activity behaving in a manner that brings shame to other students, without permission or a valid parental excuses not returning to campus on a scheduled day after a home/community visit, and without permission using the telephone. As a result of these behavioral infractions, the student is restricted to campus, such restrictions will provide him with a more controllable and predictable environment. Type 1 Restrictions are coded on a "Restriction Record Sheet". This sheet is also used to 
record successful completion of the restriction period. Each of the above stated behaviors are carefully recorded and tracked on demerit cards, progress cards, and level cards. These forms/cards are maintained in each student file. (See Appendix C, pg. 150) for behavioral record forms.

2. Type 2 - A Type 2 Restriction is a more serious form of a behavioral infraction. Examples of behaviors that would earn a student a Type 2 Restriction are as follows: borrowing or lending money in any form, buying or stealing property without a written agreement between the buyer, the seller, and a staff member, deliberate damage to property, either personal or belonging to others, estimated at less than $\$ 50.00$, accidental damage to property belonging to others through misuse after being told how to use it properly, leaving the assigned area when directed to serve a time-out, refusing to serve a time-out and requiring that assistance be called, overt and persistent defiance of authority, refusing to report to the assigned area, etc... As a result of these behavioral infractions, the student is restricted to campus. Such restrictions will provide him with a more controllable and predictable environment. Type 2 Restrictions are coded on a "Restriction Record Sheet". This sheet is also used to record successful completion of the restriction period. Each of the above stated behaviors are carefully recorded and tracked on demerit cards, progress cards, and level cards. These forms/cards are maintained in each student file. (See Appendix C, pg. 150) for behavioral record forms.

3. Type 3 - A Type 3 Restriction is a punishment for the most severe level of behavior infraction. Examples of Type 3 Restrictions are as follows: holding, concealing, or otherwise possessing a weapon; supplying tobacco products to other students, threatening to harm another person with a weapon, the use of possession of illegal drugs, drug 
paraphernalia, and/or alcohol, fighting, physical assault, being absent without leave, and intentional damage to property estimated at over $\$ 50.00$. As a result of behaviors that warrant a Type 3 Restriction, the student is restricted to his room, providing him with a more controllable and predictable environment. The students are restricted to the unit for 7 consecutive days. Type 3 restrictions are assigned using a "Restrictive Record Sheet". This sheet is also used to record successful completion of the restriction period. Each of the above stated behaviors are carefully recorded and tracked on demerit cards, progress cards, and level cards. These forms/cards are maintained in each student file. (See Appendix C, pg. 150) for behavioral record forms.

\section{Outcome:}

Outcome was measured by four variables: treatment process variables, discharge assessments (Beck Depression Inventory, the Locus of Control Scale for children, the State-Trait Anger Expression Inventory, the Millon Adolescent Clinical Inventory, and the WoodcockJohnson Achievement Test), successful discharge planning, and discharge GPA. A description of the behavioral rating scales can be found in Appendix B (pg. 137-149). The behavioral rating scales utilized in this study allowed the researcher to determine if the treatment program had an effect on residents' behavioral symptoms.

Treatment outcome was also measured by four factors: 1.) The number of weeks a particular resident spends on any given level, the progression score a student has obtained (which is described below); 2.) The number of AWOL's a resident has accumulated; 3.) The resident engages in socially acceptable behaviors in school, home, and community (number of Type Restrictions); 4.) The resident complies with facility, parental, and societal rules (number of Type Restrictions). 


\section{Clinical Psychopathology}

The Million Adolescent Clinical Inventory (MACI) measured clinical pathology in this study. The MACI is a measure of general and specific kinds of pathology. The MACI is made up of 31 scales. Any elevated MACI scale has the potential to slow down advancements through the level system; hence, effecting outcome in the treatment program. A detailed explanation of these scales can be found in Appendix B (pg. 146-158).

Therapist Style

Therapist style is the particular orientation a given therapist reported utilizing within the residential treatment setting. Therapist at the residential facility reported the following styles: cognitive, family systems/object relations, psychodynamic, cognitive-behavioral, or eclectic. Therapist Degree

Highest level of degree obtained.

\section{$\underline{\text { AWOL's }}$}

AWOL is defined by the residential treatment facility as being absent without leave (i.e., unauthorized departures from the facility), typically for instances in which the student is known to be out of area and not seen around campus for more than thirty minutes. Individual Therapy

A 1 to1 session utilizing either: cognitive, family systems/object relations, psychodynamic, cognitive-behavioral, or eclectic.

\section{Family Therapy}

Sessions can be held with the parents individually, or with the student. There are some residents who do not receive family therapy. In those circumstances, because many family members live a great distance from the facility, a telephone discussion between the student, 
counselor, and the parent can be arranged. Typically, family therapy is offered once every 4 to 5 weeks to residents.

Character Education Groups

These groups occur an average of 40 times annually all by themselves. The other groups listed occur an additional 35-40 times yearly.

\section{Group Therapy}

Therapeutic modalities include weekly group psychotherapy, which is approximately forty sessions per year. Groups offered include: Weekly substance abuse, anger management, physical and/or sexual abuse groups. Other areas for group counseling intervention are developed as indicated by student needs. 


\section{CHAPTER 2}

\section{Review of Relevant Literature}

$\underline{\text { Introduction }}$

This chapter reviews the relevant literature that addresses adolescent behavioral disorders. First, is a review of adolescent predictor variables that have been shown to attribute to behavioral disorders. Second, is a review of familial predictor variables, followed by a review of the treatment/outcome research and the efficacy of residential treatment.

\section{$\underline{\text { Biological Predisposition }}$}

There are many allied fields within the behavioral sciences that have been intensively studying various dimensions of behavioral disorders. They include, but are not limited to: behavioral genetics, neurobiology, physiology, cognitive neuroscience, endocrinology, and forensic psychiatry. To date, findings have provided evidence to suggest that individuals vary to the degree in which they are susceptible to develop behavioral problems in early childhood.

Researchers in these fields are studying the predispositions to engage in criminal behavior by trying to identify genetic and biological mechanisms that underlie or contribute to these problem behaviors. "The antecedents or conditions that underlie some types of criminal behavior are psychological traits and behaviors that highly correlate with the development of antisocial behavior and occur early in a child's life; thus, they are believed to be important in a developmental sense. For example, hyperactivity, attention and other cognitive deficits, conduct disorder, aggressiveness, and negative affect all tend to co-occur with and predict criminal behavior. Each of these so-called antecedents, among others, has been associated with various disturbances or irregularities in brain function, physiological and neuropsychological processes, and biochemical balance. In interaction with certain conditions in the physical and social 
environment, these disturbances are thought to increase the likelihood for an antisocial outcome" (Fishbein, 1990; Reiss \& Roth, 1993).

\section{Adolescent Variables}

Adolescents suffering from behavioral disorders constitute the largest percentage of atrisk adolescents for future criminal activities. In 1992, prevalence rates indicate that between 2 to $6 \%$ of school-aged adolescents are affected by behavioral disorders. This percent reflects 1.3 to 1.8 million cases within the United States (Kazdin, Siegel, \& Bass, 1992). In 2002, Teplin reported that among teens in juvenile detention, nearly two thirds are males. More than 40 percent of these males were diagnosed with a disruptive behavior disorder, namely: conduct disorder. Overall, behavioral disorders are more prevalent among older adolescent males. More than 106,000 adolescents are currently placed in the custody of many U.S. juvenile residential facilities. Of the 106,000 teenagers in juvenile detention, it is estimated that 60 percent have behavioral, mental and/or emotional problems (Teplin, 2002). It was further reported that as many as 1 in 10 children and adolescents not remanded to juvenile residential facilities may have conduct disorder (Teplin, 2002).

In order to begin to more effectively treat this population researchers must first begin to understand the etiology, course, and predictor variables associated with the development of this class of disorders. The sociological theory of differential association offers a tangible explanation for the development of behavioral disorders.

The sociological theory of differential association (Sutherland, 1947) highlighted the importance of family and child variables on the development of deviant behavior. This theory suggests that deviant behavior is learned. Moreover, adolescents who typically associate with conforming peers will themselves tend to be conforming in their behavior. The primary 
component of problem behavior occurs during associations with one's intimate primary group. Adolescents who associate with peers with behavioral problems are more likely themselves to display behavioral problems (Paetsch \& Bertrand, 1997).

Heimer (1997) also suggests that behavioral disorders are the result of learning. By direct association with other problem peers, the behaviorally disordered child learns to display a new array of negative and coercive behavioral patterns. These behaviorally disordered adolescents respond by creating subcultural classes in which they are positively valued (Heimer, 1997). These subcultural classes are often found within a lower socioeconomic stratum. Researchers have indicated that conduct disorder is more common for lower socioeconomic families and adolescent males whose parents display antisocial tendencies (Lahey, Loeber, Hart, Frick, Applegate, Zhang, Green \& Russo, 1995). Many sociologists report that behavioral disorders are learned through interaction with delinquent parents and in a family environment that promotes nonconforming behavior.

Miller and Prinz (1990) suggest that before one can begin to change existing parenting techniques, one must first address the child involved. Each child is unique and responds in a variety of ways to different types of intervention techniques. Therefore, one must thoroughly explore the literature to fully understand the behaviorally disordered child. It seems apparent that socialization practices have a different effect on various types of children. There is much that remains to be learned regarding the interaction between childhood behavioral disorders and parental socialization practices (Frick, Lahey, Loeber, Stouthamer-Loeber, Christ \& Hanson, 1992). 


\section{$\underline{\text { Familial Variables }}$}

Research frequently discusses the need to further examine familial factors as relating to behavioral disorders in adolescents (Quinsely, Harris, Rice \& Cormier, 1998). Many researchers have observed factors believed to contribute to the development of behavioral disorders, such as harsh discipline and lack of parental warmth. Heimer (1997) argues that variables, such as socioeconomic status and poor parenting practices can be attributed to problem behavior in adolescents. He further suggests that these latter variables can also be attributed to the development of negative attitudes and coercive behavioral patterns. McMahon (1994) has discovered several predictor variables associated with long-term treatment success with behaviorally disordered adolescents, which consisted of: (a) socioeconomic status (b) familial characteristics (one-parent or two-parent home), (c) parental behavior, and (d) personal and marital distress (McMahon, 1994).

Likewise, Cohen (1955) argues that parents from lower socioeconomic status lack the appropriate resources to adequately prepare their children for success in middle-class institutions. As a result, these behaviorally disordered adolescents respond by defiantly creating subcultural classes in which they are positively valued (Heimer, 1997). For several years, broken homes and marital dysfunction have been blamed for adolescent behavioral problems, since correlations have been found between rates of single parent families and crime (McCord, 1993). Yet, studies that control for familial variables have failed to support this notion (McCord, 1993).

Many researchers are interested in the effects of single parent families, parental criminality, and parental conflict on adolescent behavioral disorders (McCord, 1993). In controlled studies, parental criminality predicted both the adolescents' misbehavior and subsequent parental conflict. In addition, parental conflict and adolescent behavioral problems 
were reported to correlate with one another; but were also found to be significant predictors of subsequent crime (McCord, 1993). Overall, studies that examine child-rearing practices seem to indicate that child's noncompliant behavior, influences parental behavior in the short term; whereas, it is not so clear how the relationship works on a long-term basis (McCord, 1993). Klein, Forehand, Armstead, and Long (1997) studied 132 families to determine which variables predict later delinquency (i.e., marital status, interparental conflict, mother-adolescent relationship, and maternal depressive mood). Regression analysis revealed that a significant relationship existed between delinquency, arrests/convictions, and predictor variables. Predictor variables consisted of lack of maternal communication with children, poor problem-solving skills, and high family stress. Klein et. al (1997) further indicated that the highest number of arrests/conviction occurred in the group with the worst combination of familial factors. Whereas, families with good maternal communication, and low family stress (i.e., intact marriage, low maternal depression, and low interpaternal conflict) were typically associated with lower incidences of behavioral problems in adolescents. This study supports the notion that parenting practices are influential in predicting behavioral problems and overall treatment outcome (Klein, Forehand, Armistead \& Long, 1997).

McCord (1993), however, indicated that males from single parent families were no more likely to display behavioral problems then those from two parent homes. Rather, parental alcoholism, lack of supervision, and poor socialization practices within the home seem to be responsible for elevated rates of behavioral disorders (McCord, 1993). In addition, Farrington (1978) found that boys, who had not exhibited previous behavioral problems, began to exhibit signs of highly agitated forms of behavior following the emergence of parental marital difficulties. 
Researchers have proposed that children's misbehavior can create a parental response to which the misbehavior could be mistakenly attributed. This hypothesis gained support through a study that was conducted in which boys between the ages of six and eleven interacted with their own mothers as well as surrogate or foster mothers. Half of these boys were previously classified as having a behavioral disorder. Results revealed that mothers of both the boys (both the behavioral disordered and normals) tended to display harsher discipline strategies toward the behaviorally disordered children, for similar acts of noncompliance (McCord, 1993).

Frick, Lahey, Loeber, Stouthamer-Loeber, Christ, and Hanson (1992) conducted extensive literature reviews and discovered a substantial body of literature, which indicates that several types of familial dysfunction have been highly correlated with childhood conduct problems. Parental psychopathology, high rates of antisocial personality disorder, substance abuse, and maternal depression are among the increasingly growing numbers of mental health issues noted in many parents of boys referred to mental health clinics for behavioral problems (Frick, Lahey, Loeber, Stouthamer-Loeber, Christ \& Hanson, 1992; Wagner \& Cohen, 1996). Loeber and Stouthamer (1986) reported that the two strongest predictors of conduct problems and subsequent treatment outcome were poor parental supervision and lack of parental involvement.

To further examine these predictors Frick, Lahey, Loeber, Stouthamer-Loeber, Christ, and Hanson (1992) studied 177 clinic-referred children between the ages of 7-13 in three university outpatient clinics during the first year of a three-year longitudinal study. Parents were assessed along four parenting constructs: (a) maternal supervision; (b) maternal persistence/consistency in discipline; (c) time spent with child; and (d) frequency of discussion between mother and child. Three groups were established which consisted of: Conduct Disorder 
youths, Oppositional Defiant Disorder youths, and clinic control. The diagnosis of conduct disorder was found to correspond with several conditions of family functioning. Lack of maternal supervision, parental persistence/consistency, and/or paternal substance abuse were found to significantly contribute to the diagnosis of conduct disorder (Frick, Lahey, Loeber, Stouthamer-Loeber, Christ \& Hanson, 1992). Results revealed that $40 \%$ of conduct disorder, $23 \%$ oppositional defiant disorder, and $8 \%$ of the control groups had a parent with antisocial personality disorder. Moreover, $50 \%$ of conduct disorder, $40 \%$ of oppositional defiant disorder, and $23 \%$ of control group had parents that abused substances.

Familial and child variables have been significantly associated with the development of behavioral disorders. Yet, consistent research is not available that addresses how these specific factors can be attributed to treatment success with the behavioral disordered population. In fact, studies that address treatment effectiveness fail to consistently present methodologically sound research or research findings, in regard to the development and maintenance of behavioral disorders.

\section{$\underline{\text { Treatment Outcome }}$}

Juveniles who have been classified as serious offenders have been considerably resistant to currently available modes of treatment (Henggeler, Melton, Brindino, Scherer, \& Hanley, 1997). Treatments have shown minimal effectiveness. Moreover, there are still a number of methodological problems evidenced in the literature. McMahon (1994) revealed several predictor variables that have been associated with the long-term treatment success. These variables consisted of: (a) the nature of the conduct problems, (b) the child's age, (c) sex, (d) race, (e) problem solving abilities, (f) the nature of the referral, and (g) the therapists' characteristics (McMahon, 1994). 
For example, Kazdin, Bass, Ayers, and Rodgers (1990) studied the results of empirical research on child and adolescent psychotherapy. Meta-analytic research was utilized to answer the research question that drives many research endeavors. "What treatment, by whom, is most effective for this individual, with that specific problem, under which set of circumstances?" (Kazdin, Bass, Ayers \& Rodgers, 1990, p.730; Paul, 1967) Out of 3,086 original articles reviewed, 218 articles were evaluated. Three domains of interest were reviewed: (a) "the substantive research questions that guided the study as reflected in the types of groups and group comparisons included to evaluate treatment; (b) characteristics of the patients, clinical problems, therapists, and treatments; (c) selected methodological features related to the evaluation of treatment outcome such as the method of assigning cases to conditions, assessment domains and methods, criteria for evaluating change, and evaluation of follow-up" (Kazdin, Bass, Ayers \& Rodgers, 1990, p.733).

The behavioral problems presented at the onset of treatment consisted of $50.7 \%$ actingout behaviors and $22 \%$ problem behaviors at home. When treatment was compared to no treatment, the effect size for posttreatment and follow-up were .88 and .72 , respectively, indicating that some form of treatment is better than no treatment at all. When treatment was compared to an active control group, effect sizes for posttreatment and follow-up were .57 and .31 , respectively (Kazdin, Bass, Ayers \& Rodgers, 1990).

Kazdin and Weisz (1998) also found through meta-analytic research that the mean effect size was .71, which indicated that the average adolescent was less symptomatic on outcome measures after having received some form of treatment. However, Weisz, Walter, Weiss, Fernandez and Mikow (1990) indicate that research conducted on various interventions utilized with juvenile delinquents produced mixed findings. Meta-analysis of 91 cases revealed that 
intervention for adolescents with delinquent, antisocial, and violent behavior varies from study to study. For example, " $60 \%$ of the studies yielded some evidence of positive intervention effects, but when the actual size of the effect is considered, a radically different conclusion is reached...namely.. there are no interventions with juvenile delinquents that produce positive effects" (Weisz, Walter, Weiss, Fernandez and Mikow, 1990, p. 721).

An additional study conducted by Kazdin (1991) provides a meta-analytic review of the efficacy of various forms of treatment with children and adolescents. Moreover, Kazdin's research reviews the alternative treatments that are being used to work with conduct disorder children and its outcome. Kazdin reported deficiencies in research, which he believes are due to weak statistical power (Kazdin, 1991). Moreover, developing and identifying empirically validated treatments for children with emotional disorder is needed given the alarmingly high rates of juvenile offenses, a number continuing to rise (Kazdin, 1991). Henggeler, Smith, and Schoenwald, (1994) also address the need for more controlled studies on empirically validated treatments of conduct disorder children.

Kazdin, Bass, Ayers and Rodgers (1990) argued that there is a significant discrepancy between treatment studies in research and the form of intervention being applied in community mental health agencies. The literature frequently addresses this broad gap between outcome research, systematically applied treatments developed through the use of experimental rigor, and community mental health agencies where interventions typically develop as a result of a trial and error processes that tend to be independent of any scientific investigation (Weisz, Han \& Valeri, 1997).

Kazdin, Bass, Ayers, and Rodgers (1990) report that currently available treatments are too brief to make a lasting difference in these children's lives. Kazdin and Weisz (1998) indicate 
that child outcome studies are significantly limited in a variety of ways. For example, the majority of treatment studies focuses on nonreferred cases that provide relatively brief treatment conducted in a group format. Moreover, "they tend to evaluate treatment almost exclusively in relation to symptom reduction without assessing impairment or adaptive functioning, they do not evaluate the clinical significance of symptoms changes, and do not conduct follow-up research" (Kazdin \& Weisz, 1998, p. 23).

The Fort Bragg study is a study that was conceived to address the need for outcome research. Results of the Fort Bragg study revealed that the favorable results observed from child interventions during clinical trials typically were not replicated in many community mental health agencies. The rationale given for this phenomenon was that many professionals in mental health agencies are not utilizing empirically supported intervention strategies in their treatment regimens (Weisz, Han \& Valeri, 1997). In addition, many researchers argue that the guidelines that are required for inclusion in randomized clinical trial (RTC) studies that support certain therapy procedures are unrealistic. For example, "no clients included in randomized controlled trials can maintain comorbid conditions" (Beutler, 1998, p. 115; Chambless \& Hollon, 1998).

Patients who are being included in these samples to validate treatments represent a very homogenous population. Limited representativeness of the sample can ultimately effect the external validity of many of these validating studies (Chambless \& Hollon, 1998). Very rarely, if at all, does a psychotherapist obtain the rare privilege of being presented with a client that exhibits a specific problem, which results because a specific problematic area, and the client can effectively convey that problem area to the psychotherapist. Researchers are aware that behavioral disorders occur due to a multidetermined set of variables. Multisystemic intervention serves to integrate each of the predictor variables into every aspect of the treatment process: the 
family, child, peer, school, and home of the behaviorally disordered adolescent (Henggeler, Smith \& Schoenwald, 1994).

If researchers are going to address the need to approach treatment from a multifaceted approach, then researchers also need to address how these same familial factors, that are essential to treatment outcome, can become barriers to treatment. Researchers have reported that socioeconomic disadvantage, family constellation, parental stress, parent's history of antisocial behavior, adverse family child-rearing practices, child severity, and history of aggressive and antisocial behavior can all serve as barriers to treatment and result in premature termination of services (Kazdin, Holland \& Crowley, 1997).

Barriers to treatment also become an issue in residential placement. It is often difficult to incorporate familial interventions within the scope of residential treatment. Many times the family either lives to far away to participate in treatment or, does not have the financial means to travel long distances to participate in family therapy. As a result, professionals in residential placement often are faced with premature termination due to familial dissatisfaction. Research conducted on treatment outcome and residential placement strongly suggests the involvement of the family. More important than mere involvement is the amount of contact. The amount of contact a resident has will ultimately effect treatment outcome (Mann-Feder, 1996).

\section{Premature Termination of Treatment}

Kazdin, Holland, and Crowley (1997) reviewed barriers to treatment participation and rates of attrition among oppositional, aggressive, and antisocial behavior in children referred for treatment by replicating Kazdin, Siegel and Bass' (1992) study with the exception that additional outcome measures were utilized. Two hundred and forty-two children between the ages of 4 to 14 participated in the study. Participants were obtained from the Child Conduct Clinic. Forty 
percent of the children maintained a conduct disorder diagnosis, while $32 \%$ were diagnosed with oppositional defiant disorder. Seventy-eight percent of the children met the criteria for more than one diagnosis (Kazdin, Holland \& Crowley, 1997).

Various family, child, and parent characteristics were assessed during the initial phase of the study. Factors that placed the family/child at risk for early termination consisted of: socioeconomic disadvantage, family constellation, parental stress, parent's history of antisocial behavior, adverse family child-rearing practices, child severity, and history of aggressive and antisocial behavior. Kazdin, Holland and Crowley replicated Kazdin, Siegel and Bass (1992) earlier study in which participants were randomly assigned to participate in either one of three conditions. Cognitively based problem solving skill training (PSST) and parent management training (PMT), or PSST and PMT. Treatment completion required participation for 7-10 months (Kazdin, Holland \& Crowley, 1997).

Results revealed that parents who dropped out of treatment were more likely to be socioeconomically disadvantaged, to be from a minority group, to be younger, to be a single parent, to report harsh forms of discipline and rearing practices, and to report antisocial behaviors from their own childhood (Kazdin, Holland \& Crowley, 1997). Moreover, among those who dropped out of treatment prematurely, parents reported that their children exhibited greater signs of antisocial symptoms. Regression analysis revealed that family, child, and parent variables "added significant variance to the prediction of dropping out" (Kazdin, Holland \& Crowley, 1997).

Kazdin and Wassell (1998) further reviewed the relationship between treatment completion and therapeutic change among those children referred to treatment for antisocial behavior. They predicted that family variables, such as socioeconomic disadvantage and parental distress would be associated with premature termination of treatment. In addition, several 
variables were used to predict treatment completion, such as: parental psychopathology and stress, socioeconomic disadvantages and difficult family living conditions, child dysfunction and impairment, problems in treatment attendance, and perceived barriers during the course of treatment (Kazdin \& Wassell, 1998). Three hundred and four children were studied. Of the 304 children, $40 \%$ maintained a diagnosis of conduct disorder and 34\% were diagnosed with oppositional defiant disorder (Kazdin \& Wassell, 1998).

Of those children who were being treated for behavioral difficulties between $40-60 \%$ terminated prematurely (Kazdin \& Wassell, 1998). Parents rated 62\% of the children as having improved following treatment completion. Therapists rated that $72 \%$ of the children who completed treatment improved, while only $14 \%$ of those who terminated treatment prematurely improved. Overall, a significantly higher percentage of treatment completers improved over those who terminated treatment prematurely. Those families who terminated treatment early were more likely to originate from families with greater socioeconomic disadvantages, had more difficulty with living circumstances, and showed signs of greater child deviance, when compared to those families who completed treatment.

Of the cases where there was premature termination, parents exhibited greater signs of antisocial behavior when they were younger as compared to treatment completers on outcome measures. Outcome measures were utilized to obtain the total number of antisocial behaviors noted during the diagnostic interview. To obtain parent's level of current and past delinquency the parents completed the following outcome measures: Interview for Antisocial Behavior, Parent Daily Report, the Child Behavior Checklist, and the Child Peer Contacts Scale (Kazdin \& Wassell, 1998). The study revealed the need for ongoing outcome research to confirm advances in treatment for behaviorally disordered adolescents. The ongoing assessment of progress is a 
critical feature in the effective treatment and maintenance of behavioral changes (Kazdin \& Wassell, 1998).

Mattys (1997) reviewed outcome research for residential treatment programs and outpatient therapy. Through this review Mattys addresses the effectiveness of residential treatment programs, yet questions "really how effective are residential treatment programs on a long-term basis" (Matthys, 1997, p.513). As a result, researchers are interested in understanding what is the role of residential placement, and what factors contribute to successful completion of these programs.

\section{$\underline{\text { Residential Treatment }}$}

Most commonly, residential treatment facilities utilize an eclectic approach to treating conduct-disordered children, utilizing family therapy, behavior modification, group therapy, and individual therapy. Mattys (1997) argues that only a select number of residential treatment facilities utilizes all of the above mentioned services. As a result, Matthys (1997) suggests the need for a "comprehensive and integrated program", in which the child is treated from "the perspective of a more adequate functioning of both child and parents at home". He further suggests that the treatment of these children should include: contingency management, cognitivebehavioral therapy, and parent coaching and training (Matthys, 1997, p. 513).

Ansari, Gouthro, Ahmad, and Steele (1996) examined the use of behavior modification in a short-term (10-12 weeks) residential treatment facility with 60 conduct disordered adolescents ages $12-18$. The adolescents displayed a wide variety of behavioral problems such as truancy, running away, promiscuity, aggressive acting out, poor peer relationships, drug abuse, and depression. Behavior modification principles, such as negative and positive consequences, along with a token economy system were the primary interventions used by this residential treatment 
facility. Criteria for inclusion were that participants needed to be enrolled in the behavior modification program for a minimum of eight weeks, which was a sufficient time frame to produce a measurable impact on participant's oppositional behaviors. Participants' files were reviewed to obtain relevant information. Behaviors were measured according to the number of points earned daily for compliant behavior and those lost for displays of noncompliance (Ansari, et. al, 1996).

The utility of behavior modification programs is questioned since unfortunately, the rates of recidivism remain discouraging (Ansari, et. al, 1996). Results of Ansari et. al (1996) study revealed that the behavior management plan utilized was generally effective for female participants and for those non-conduct disordered individuals. Furthermore, "behavioral techniques such as positive reinforcement, behavioral contracts, modeling, and role playing resulted in improvement in prosocial behaviors as demonstrated by point increases within the token economy" (Ansari, et. al, 1996, p. 471). Age was also related to outcome levels. For example, age of onset before six years of age resulted in better outcome; however, those who developed symptoms of behavioral disorders at a later age resulted in a poorer prognosis (Ansari, et. al, 1996).

Mann-Feder (1996) reviewed the effects of two groups of conduct disorder adolescents in two distinct programs. There was a therapeutic community (TC), located a publicly financed psychiatric hospital, which promotes self-regulation, peer confrontation, and the development of insight as necessary for behavior change; and a public psychosocial agency that provides out-ofhome care and wrap around services $(\mathrm{BU})$. The $\mathrm{BU}$ program utilizes a residential treatment basis and a modified Token economy system. Twenty-eight conduct disorder adolescents between the ages of 14 and 18 participated in the study. Instruments utilized as outcome measures included: 
Wechsler Intelligence Scale for Children-Revised (Wechsler, 1974), Jesness Inventory (Jesness, 1972), Conceptual Level Paragraph Completion Test (Hunt, Butler, Ney \& Rosser, 1979), Internal Locus of Control Scale (Levenson, 1981), Tennessee Self-Concept Scale (Fitts, 1965), the Devereux Adolescent Behavior Rating Scale (Spivack, Spotts, \& Haines, 1967), and demographic information was collected (Mann-Feder, 1996). Data was collected just prior to admission, three months after admission, and six months after admission (Mann-Feder, 1996). Upon childrens' admission, both TC and BU conditions exhibited serious emotional and behavioral disturbances.

Statistical analysis revealed little differences between the program results, despite an overall trend toward success. Mann-Feder (1996), however, also discovered small differences between dropouts and non-dropouts. When dropouts were compared to non-dropouts on demographic characteristics no differences were noted. The difference noted in those residents that dropped out or went "AWOL", were in regard to the amount of familial involvement during placement. The residents that dropped out of treatment had far less family contact during treatment. Research conducted on treatment outcome and residential placement strongly suggests the involvement of the family. More important than mere involvement is the amount of contact. The amount of contact a resident has will ultimately effect treatment outcome (MannFeder, 1996). In addition, on outcome measures (Devereux Scale 6) dropouts had poorer emotional control and were more emotionally volatile $(\mathrm{F}=5.89, \mathrm{p}<.02)$.

From the research conducted it appears that there is a need for qualitative studies. As the author suggests, qualitative studies go far beyond test scores and review client's attributes, perceptions, and the underlying mechanisms of various treatment modalities (Mann-Feder, 
1996). To develop a profile of what type of adolescents with behavioral disorders are the best candidates for future success.

$\underline{\text { Summary of Review }}$

Several predictor variables have been associated with treatment success of behavior disorders. These variables consisted of: familial, child, and predictors of premature termination. The familial characteristics associated with treatment outcome include: high family stress, adverse family child-rearing practices, poor parenting practices, harsh discipline, lack of maternal communication with children, lack of parental warmth, socioeconomic status, parental criminality, personal/marital distress, parental substance use/abuse, maternal depression, and parental conflict (Frick, Lahey, Loeber, Stouthamer-Loeber, Christ \& Hanson, 1992; Klein, Forehand, Armistead \& Long, 1997; Heimer, 1997; Loeber \& Stouthamer, 1986; McMahon, 1994; \& Wagner \& Cohen, 1996).

The child predictor variables associated with treatment outcome include: the child's age, sex, race, comorbid issues, history of aggression and juvenile delinquency, poor problem-solving skills, substance use/abuse, the nature of the conduct problems, nature of the referral, and association with delinquent peers (Heimer, 1997; Lahey, Loeber, Hart, Frick, Applegate, Zhang, Green \& Russo, 1995; \& Paetsch \& Bertrand, 1997).

Several predictors of premature termination of treatment have also been discovered, such as: socioeconomic disadvantage, to be from a minority group, family constellation, parental stress/distress, psychopathology, difficult family living conditions, problems in treatment attendance, to be a single parent, to report antisocial behaviors from their own childhood (parents), to report harsh forms of discipline and rearing practices, child severity, history of 
aggressive and antisocial behavior, oppositional, and age of the adolescent (Kazdin, Holland \& Crowley, 1997; Kazdin \& Wassell, 1998; \& Kazdin, Siegel \& Bass, 1992).

Research indicates a significant need for the development of reliable and valid treatment. As well as empirically based treatment strategies, the knowledge of what variable predicted better outcomes, and a way to better address what is the best way to prevent and treat behavioral disorders (McMahon \& Wells, 1998). Researchers are becoming aware that more attention needs to be paid toward the therapies that are being utilized in mental health settings, such as family therapy, eclectic, and psychodynamically oriented treatments.

The current study proposes to conduct an analysis of archival data to determine what predictor variables are related to successful discharge upon completion of a residential treatment program. Specifically, what demographic characteristics and behavioral disorders, receiving what form of therapeutic intervention, achieve what level of success? This question adequately characterizes the intent of the investigation. Where earlier studies frequently used child predictor variables taken from intake interview checklists, the current study used standardized personality inventories, such as the Millon Adolescent Clinical Inventory, the State-Trait Anger Inventory, the Locus of Control Scale for Children, the Beck Depression Inventory for Children, and the Woodcock-Johnson Achievement Test, to generate and measure child predictor variables. 


\section{CHAPTER 3}

\section{Method}

Introduction

Kazdin, Bass, Ayers and Rodgers (1990) argued that there is a significant discrepancy between treatment outcome studies in research and the form of intervention being applied in community mental health agencies. More attention needs to be paid toward the therapies that are being utilized in mental health settings, such as family therapy, eclectic, and psychodynamically oriented treatments. Residential treatment facilities also employ an eclectic approach to treating conduct-disordered children; utilizing family therapy, behavior modification, group therapy, and individual therapy. Matthys (1997) suggests the need for "comprehensive and integrated programs", which should include: contingency management, cognitive-behavioral therapy, and parent coaching and training (Matthys, 1997, p. 513).

The consensus in the literature is that researchers need to be aware of what variables predicted better outcomes (McMahon \& Wells, 1998). Research should be pointed at answering the research question that drives many research endeavors "What treatment, by whom, is most effective for this individual, with that specific problem, under which set of circumstances?" (Kazdin, Bass, Ayers \& Rodgers, 1990, p.730; Paul, 1967)

For the purposes of this study the researcher was interested in looking at treatment outcome. The current study conducted an analysis of archival data to determine what predictor variables are related to successful discharge upon completion of a residential treatment program.

\section{$\underline{\text { Participants }}$}

The records of 120 adolescents who were admitted to a residential treatment facility in Northern Virginia and were served by the facility from January 1999 to January 2001 were 
reviewed. First, the investigator obtained permission from the Director of the facility to review charts. Secondly, the investigator agreed that none of the charts would be removed from the premises. In addition, permission was obtained from West Virginia University's Institutional Review Board.

The criterion for inclusion in this study was based on residents submitting to some form of psychometric testing, namely, the Beck Depression Inventory (BDI), the Locus of Control Scale for children (LOC), the State-Trait Anger Expression Inventory (STAXI), the Millon Adolescent Clinical Inventory (MACI), and the Woodcock-Johnson Achievement Test (WJ$\mathrm{ACH})$. Participants included male adolescents between the ages of 11 to 18 . It is important to note that there are age ranges for different measures used (ages 11-12 and ages 13-14). The average age of residents at the facility was 15.5 years. Residents represent various racial backgrounds (i.e. white, black, hispanic, and biracial). Many of the residents came from broken homes, and had not been exposed to a structured environment. Approximately $40-50 \%$ of the residents were classified by the facility as behaviorally disordered (BD), and 60\% were classified as emotionally disordered (ED); some residents met the criteria for more than one disorder.

Several comorbid issues were noted with this current population, such as: depression, substance abuse problems, history of parental neglect, and physical and/or sexual abuse. Aggressive tendencies, deceitfulness, truancy, repeated school suspensions, minor legal altercations, and vandalism were common in the histories of participants.

\section{The Residential Treatment Facility}

The residential treatment facility used in this study is located on 126 acres, and is about 20 minutes from the nearest town. At any given time the facility houses $70-80$ residents. The 
residents are primarily from Virginia; however, there are some residents from West Virginia, Maryland, New Jersey, and Philadelphia.

Adolescents at the facility were referred to the facility by one of three sources: (a) the court, (b) the division of social services, or (c) the school system. Typically, the residents' presenting problem was chronic, and often this was the residents' third to fifth placement. Yet, for some residents this may have been the first out-of-home placement. Every resident in the facility manifests some form of a behavior disorder. However, at the facility emphasis is not placed on a DSM-IV diagnosis. Therefore, the only real distinction made among residents is between the behaviorally disordered and the emotionally disordered population.

Family involvement starts at admission. The family and staff immediately embark on a collaborative process to assist the adolescent in adjusting to their placement at the facility. Moreover, parent groups are offered that provide psychoeducational information. In the community, these support sessions center more on sharing and parenting training. "Parent to Parent" techniques are used to improve parenting skills. General support from staff and other parents was also offered to ensure an easier transition period for the resident from the facility back to the home.

Before a resident began the program an individualized service plan was prepared for each resident. The family participated in writing the student's Individualized Service Plan. This plan described the residents needs, goals, services one can expect to receive, and ongoing evaluation techniques. The students' service plan also includes character development. Goals are defined within the residents' service plan. While the emphasis was different in each plan, there are a number of central themes: 1) To follow the rules and expectations at the treatment facility; 2) To understand and explain the need for rules and laws in a community; 3) To state his personal 
standards that govern his behavior; 4) To demonstrate support for the rules and laws of the communities to which he belongs; 5) To contribute to common group goals, either as a leader or as a team member; 6) To describe how he will face the challenges of living in his home community; and 7) To behave consistently with rules and laws wherever he finds himself.

Therapeutic modalities include weekly individual and group psychotherapy, which was approximately forty sessions per year. Weekly Character education groups were another aspect of treatment. Weekly character education groups were utilized to teach virtues/morals to the residents.

Family therapy was provided to those residents for whom it was feasible for family members to attend. Typically, family therapy was offered once every 4 to 5 weeks to residents. Family counseling was offered to families. Family sessions are also held in the student's home community. This is especially true when the student is preparing to return home.

The facility employs an intensive behavioral management program in which a level system approach is utilized as a measurement of successful completion. Level systems are a multi-level approach in which residents are required to engage in specific behaviors in order to gain privileges. Theoretically, this approach is supposed to teach the adolescent that he has responsibilities that must be completed and maintained in order to achieve rewards and increased levels of freedom. The more compliant the adolescents are with the rules of the facility, and following through with socially acceptable behaviors, the higher levels they gain.

The multi-level system at this facility employs six levels. The program requires residents to remain on any given level, with the exception of Level 1 and 2, for a six to eight weeks. Completion of the first two levels typically occurs during the initial intake phase. Level 1 consists of becoming acclimated to the facility by learning the rules and expectations of 
residential life. Each student is required to pass a written and oral examination in order to advance to Level 2 of the program.

Successful completion of Level 2 requires a demonstration of $85 \%$ compliance with all rules and expectations over "a minimum of several weeks". The minimum requirement for advancement to Level 3 is four weeks.

Level 3 requires a demonstration of $90 \%$ compliance with all rules and treatment expectations. Moreover, active participation in setting goals is encouraged. As stated earlier, goals are defined within the resident' service plan. The goals identified in each student's plan are different. Students are further encouraged to learn that through setting goals, they are reaching for and achieving productivity. As a result, residents learn to set goals and to develop strategies that will better help them to attain those goals. The minimum requirement for advancement to Level 4 is six weeks.

Level 4 requires "nearly complete compliance" with all rules and treatment expectations; the program defines compliance no more precisely. Opportunities are provided to participate in various activities outside the direct supervision of staff. For the first time during the treatment program, the resident's potential for treatment success is evaluated. The minimum criterion for advancement to Level 5 is eight weeks, however, complete compliance with the rules and expectations can allow residents to advance in six weeks.

Level 5 also requires "nearly complete compliance" with treatment expectations as well as rules; the program defines compliance no more precisely. At this level, greater emphasis is placed on the residents displaying initiative and beginning to take more responsibility for their behaviors. More opportunities are provided for independent decision-making, such as living in the on-campus independent unit, acquiring and successfully maintaining an off-campus job, and 
scheduling and participating in off-campus independent activities. Theoretically, several displays of responsible behavior over a given period of time are thought to be the most effective measure of success. As with level 4, the minimum criterion for advancement to the Level 6 is eight weeks, however, complete compliance with the rules and expectations can allow residents to advance in six weeks.

Finally, Level 6 also requires "nearly complete compliance" with treatment expectations and rules; the program defines compliance no more precisely. Typically, discharge planning has begun prior to the residents reaching this level. Movement to a less restrictive setting is overwhelming for residents. Therefore, irresponsible behaviors begin to occur with greater frequency during the last several weeks of their stay. Staff view these violations as a manifestation of discharge anxiety and treat them therapeutically, rather than punitively. Measures of the Independent Variable

This study was performed in an ex post facto manner, in which there was very little control over the independent variables. The independent variables in this study are as follows: age, grade, number of siblings, verbal IQ, performance IQ, full scale IQ, GPA, substance abuse history, ethnicity, religious denomination, and parents marital status.

Treatment Characteristics. Treatment variables were additional independent variables. These treatment variables included: whether students received individual, group, and/or family therapy, what orientation was the therapist, what was the degree level of the therapist, and was the resident on any kind of medication, and if so, what type? This aspect of the study was designed to be descriptive and shed more light on what characteristics play into successful outcomes. Again, demographic characteristics and behavioral disorders are addressed, receiving what form of therapeutic intervention, and achieving what level of success? 


\section{Measurement of the Dependent Variable}

The dependent/outcome variables are overall improvement on behavioral rating scales, and they are as follows: number of AWOL's (temporary), weeks at Level 1, weeks at Level 2, weeks at Level 3, weeks at Level 4, Progression Score Level 1, Progression Score Level 2, Progression Score Level 3, Progression Score Level 4, Type 1 Restriction, Type 2 Restriction, Type 3 Restriction, current GPA, broad reading discharge, broad math discharge, broad writing discharge, broad knowledge discharge, skills discharge, and discharge (successful versus not successful).

The behavioral rating scales utilized in this study allowed the researcher to determine if the treatment program had an effect on residents' behavioral symptoms, as evidenced by differences between intake psychometric measures and discharge administration on the following variables: (a) depression, measured by the Beck Depression Inventory; (b) internal/external locus of control, measured by the Locus of Control Scale for children; (c) state anger, (d) trait anger, (e) angry reaction, (f) anger in, (g) anger out, (h) anger control, and (i) angry expression, all measured by the State-Trait Anger Expression Inventory; and (f) clinical psychopathology, measured by the Millon Adolescent Clinical Inventory. Detailed information regarding these instruments will be provided in a subsequent section of the chapter.

Beck Depression Inventory. The Beck Depression Inventory (BDI-II) is a 21-item selfreport measure. It was developed to measure the severity of depression in adults and adolescents. Each item is rated on a four-point scale, ranging from 0-3 in terms of severity (Beck, Steer, \& Brown, 1996). The maximum total score is 63. This maximum total score is consistent with the DSM-IV criteria for Severe Depression. Total scores that range from 0-13 indicate minimal depression, 14-19 indicates mild depression, 20-28 moderate depression, and 
29-63 indicates severe depression. Statements covered on the BDI-II refer to the past two weeks (Beck, et. al, 1996).

Beck, Steer, \& Brown (1996) reported the following reliability coefficients for the BDIII: coefficient alpha was .92 for the outpatient population and .93 for internal consistency. The test-retest correlation of .93 was significant $(\mathrm{p}<.001)$.

Nowicki-Strickland Locus of Control Scale for Children. The Nowicki-Strickland Locus of Control Scale for children (LOC) is a 29-item scale. The LOC utilizes a yes-or-no format. The LOC scale is used to measure childrens' perceived level of control over their own lives. The items focus on the individual's belief in personal will and action as the primary causal driving force in determining events central to one's life, versus luck or external agents (Nowicki and Strickland, 1973).

The LOC refers to two characteristics or personality subtypes. Internal LOC refers to individuals who attribute events to internal processes and would be reflective of a lower score on the LOC. For example, a juvenile with the desired internal control would indicate that luck has little to do with getting a good grade in school. External Locus of Control refers to individuals who view events as occurring because of external events. The higher the score, the more the individual externalizes locus of control. A lower score is desirable because it indicates more internal control (Enger \& Howerton, 1994; Nowicki and Strickland, 1973). Sound statistical finding have been reported for the LOC.

Test-retest reliability has been reported as being stable and consistent, with internal consistency reliability of .68 , sampled at three grade levels: $(6,7$, and 8$)$. Split-half reliability was reported at .63 for the $3^{\text {rd }}$ grade, .66 for the $6^{\text {th }}$ grade, and .71 for the $10^{\text {th }}$ grade (Nowicki \& Strickland, 1973). Reportedly, this measure has satisfactory concurrent validity when compared 
to other measures of locus of control (DeMar, 1997). Test-retest reliability has been reported as consistently averaging .68. Moreover, the author of this instrument reported that this measure is highly related to academic competence and social maturity (Nowicki \& Strickland, 1973).

Millon Adolescent Clinical Inventory. The Millon Adolescent Clinical Inventory (MACI) is a 160 -item inventory, 31 -scale, self-report inventory that is adapted to a sixth grade reading level. This measure was developed specifically for assessing personality characteristics and clinical syndromes (Millon \& Davis, 1993). Personality characteristics are defined by the manner in which personality traits and features merge to form a distinct pattern. Clinical syndromes are defined as disorders that are exhibited in somewhat specific forms, such as anxiety or depression. Clinical syndromes can be seen as a basic extension or distortion of the adolescent's fundamental personality (Millon \& Davis, 1993).

The 31-scales of the MACI can be further subdivided into three overall categories: 12 personality patterns scales, eight expressed concern scales, and seven clinical syndrome scales. An in-depth review of each scale can be found in Appendix B, pgs. 142-153. The first 12-scales "make up the personality patterns and reflect the way in which personality traits and features combine to form a pattern" (Millon \& Davis, 1993, pg. 7). The eight expressed concern scales focus on feelings and attitudes about issues that tend to distress most troubled adolescents. The following seven clinical syndrome scales "relate to disorders that manifest themselves in relatively specific form; that is, the symptomatology will cluster into clear-cut and well-defined clinical syndromes, such as anxiety and depression. They are usually the initial focus of treatment, standing out as relatively dramatic and notable behavior, thoughts, or feelings that call attention to the person as one who requires professional help" (Millon \& Davis, 1993, p. 7, 12, 17). The intensity of the adolescents' experiences is reflected by elevations on each scale. In 
addition, procedures were added for correcting various response styles, such as random responding, faking good, or faking bad. Therefore, the final three scales: disclosure, desirability, and debasement are defined as "modifier" scales.

Norms for the MACI were established on 13 to 19 -year olds in various clinical settings. Millon and Davis (1993) reports a range of internal consistency reliability coefficient for the 31 scales from .57 to .90 . Test-retest reliability ranged from 0.57 to 0.92 . The median range stability coefficient was 0.82 . This inventory underwent "item selection and scale development.... progressed through three sequential validation stages: a) theoretical-substantive, b) internalstructural, and c) external-criterion. Rather than attempt to establish validity after instrument construction, this approach builds validity into the instrument from the beginning." (Millon \& Roger, 1993 p. 571). Using instruments purported to measure similar construct as subscales of the MACI, correlations were obtained for scaled scores of both measures to determine validity of the instrument. The correlation obtained among the eating dysfunction subscale of the MACI, and the Thinness and Body Dissatisfaction subscale of the Eating Disorder Inventory-2, were .75 and .88, respectively. The correlation between the, MACI subscale depressive affect, and scores on the Beck Hopelessness scale, were both .59 (Millon \& Roger, 1993).

State-Trait Anger Expression Inventory. The State-Trait Anger Expression Inventory (STAXI) is a 44-item self-report inventory. Each item is rated along a four-point Likert scale, ranging from $1=$ almost never to $4=$ almost always. The STAXI measures state anger, trait anger, and anger expression. State is defined as "an emotional state marked by subjective feelings that vary in intensity from mild annoyance or irritation to intense fury and rage." (Spielberger, 1991, p.1) Trait is defined as "the disposition to perceive a wide range of situations as annoying or frustrating and the tendency to respond to such situations with more frequent elevations in state 
anger" (Spielberger, 1991, p.1). Ten items measure trait anger. Anger expression is measured by twenty-four items related to the frequency that one tends to express anger.

There are eight scale scores on the STAXI are as follows: State-Anger, Trait-Anger, Trait-Temperament, Trait-Reaction, Anger-In, Anger-Out, Anger-Control, and AngerExpression. In addition, the Trait-Temperament and Trait-Reaction scales consist of two additional subscales of four items from the Trait-Anger scale. Moreover, the Anger-In, AngerOut, and Anger-Control scales consist of three subscales derived from eight items from the Anger-Expression scale (Spielberger, 1991).

The STAXI reports coefficient alphas for the State-Anger and the Trait-Anger that range from .84 to .93 . For the Trait-Temperament scale the reported coefficient alphas range from .84 to .89. For the three anger expression scales (Anger-In, Anger-Out, and Anger-Control) the reported coefficient alpha ranges from .73 to .85 (Spielberger, 1991).

Boyle and Siegman (1992) administered the STAXI to male college students. Anger was provoked in certain students who worked on serial subtraction tasks. It was found that the AngerOut scale correlated .41 with systolic blood pressure, .45 with diastolic blood pressure, and .39 with heart rate reactivity. For those students who were not provoked the correlations of the anger-out scale were not significant (Spielberger, 1991).

Woodcock-Johnson Test of Achievement. The Woodcock-Johnson Test of Achievement (WJ-R) contains two parallel forms containing nine items, each of which measures various aspects of achievement (Woodcock \& Johnson, 1989). The WJ-R Test of Achievement is an overall measure of cognitive ability. The WJ-R provides a complete assessment of reading, mathematics, written language, and knowledge. The WJ-R examines basic skills in each area as well as application of those skills. The eight areas of cognitive abilities measured in the WJ-R 
are: long-term retrieval, short-term memory, processing speed, auditory processing, visual processing, comprehension-knowledge, fluid reasoning, and quantitative ability (Woodcock \& Johnson, 1989).

The Standard Battery of the Woodcock-Johnson Achievement Test contains nine tests and yields five cluster scores. These achievement clusters can be obtained from the administration of certain combinations of the nine tests. The Broad Reading cluster is a combination of the Letter-Word Identification and Passage. Its median reliability is .94 in the Kindergarten to grade 12 ranges, and .97 in the adult range. The Broad Mathematics cluster is a combination of the Calculation and Applied Problems test and indicates a broad measure of math achievement. Its median reliability is .93 in the Kindergarten to grade 12 ranges, and .97 in the adult range. The Mathematics Reasoning cluster is a combination of the Dictation and Writing Samples. Its median reliability is .91 in the Kindergarten to grade 12 ranges, and .94 in the adult range. The Broad Written Language cluster is a combination of the Dictation and Writing Samples. Its median reliability is .91 in the Kindergarten to grade 12 ranges, and .94 in the adult range. The Broad Knowledge cluster is a combination of the Science, Social Studies, and Humanities tests. Its median reliability is .94 in the 2 to 4 -year old range, .94 in the Kindergarten to grade 12 ranges, and .97 in the adult range. The Skills cluster is a combination of the LetterWord Identification, Applied Problems, and Dictation tests. Its median reliability is .96 in the 2 to 4-year old range, .96 in the Kindergarten to grade 12 ranges, and .98 in the adult range (Woodcock \& Johnson, 1989).

The Supplemental Battery, used in conjunction with the Standard Battery, yields the following cluster scores: Basic Reading, Reading Comprehension, Basic Mathematics, Basic Writing Skills, and Written Expression, as well as scores for Punctuation, Spelling, Usage and 
Handwriting (Woodcock \& Johnson, 1989).

The following correlation coefficients "were determined by data collected from 6359 subjects in over 100 geographically diverse communities," aged 2 to $90+$ years old (Woodcock \& Mather, p. 93). Sampling did take into account a diverse population, such as: age, location, community size, gender, ethnicity, and occupation (for adults). Tests were administered to these participants over a two-year period. Median reliabilities generally exceed .90 for clusters scores, indicating respectable reliability coefficients for broad cognitive and broad achievement clusters. Concurrent validity studies report correlations in the .60 to $.70+$ range when the WJ-R is compared to other achievement tests. There is adequate concurrent and content, but not construct validity (Woodcock \& Johnson, 1989).

\section{Procedure}

Permission was obtained from the residential treatment facility in Northern Virginia to review only resident records. Subsequently, there was no need to gain consent forms from individual residents. Both the researcher and the agency agreed to confidentiality prior to any review of records. In addition, permission was obtained from West Virginia University's Institutional Review Board.

The records of 120 adolescents who resided in a residential treatment facility in Northern Virginia and were served by the facility from January 1999 to January 2001 were reviewed. This date was selected since there was a mass administration of psychometric measures during that time. The criterion for inclusion in this study was that residents must have submitted to psychometric testing, namely, the Beck Depression Inventory (BDI), the Locus of Control Scale for children (LOC), the State-Trait Anger Expression Inventory (STAXI), the Millon Adolescent Clinical Inventory (MACI), and the Woodcock-Johnson Achievement Test (WJ-ACH). 
For the purposes of this study a data record sheet was develop to gather and code all information obtained from the residents' chart. The data sheet can be found in Appendix A, page 139. The majority of the information was gathered directly from the residents chart and was immediately entered into an electronic database for further analyses.

$\underline{\text { Statistical Analysis }}$

Multivariate analysis would have been desirable to allow simultaneous interpretations of effects. Such analyses, however, were prohibitive because of missing data in all student records. Descriptive statistics were obtained for variables related to intake demographics. Following the analysis of descriptive statistics, a zero-order Pearson Product Moment Correlation was run to determine what relationship exists between: demographic and treatment variables (independent variables); intake psychometric measures; namely, the Beck Depression Inventory, the Locus of Control Scale for children, the State-Trait Anger Expression Inventory, and clinical psychopathology, measured by the Millon Adolescent Clinical Inventory, and outcome variables (dependent variables): number of AWOL's, weeks at Level 1, weeks at Level 2, weeks at Level 3, (e) weeks at Level 4, Progression Score for Level 1, Progression Score for Level 2, Progression Score for Level 3, Progression Score for Level 4, Type 1 Restriction, Type 2 Restriction, Type 3 Restriction, current GPA, broad reading discharge, broad math discharge, broad writing discharge, broad knowledge discharge, skills discharge, and discharge criteria. The rationale for using grade equivalency scores is to allow one to easily note and compare any progress made while in the program.

The researcher was also interested in determining if any relationship existed between the use of medication versus no medication and the treatment variables: individual, group, and family therapy, therapist degree, and therapist style. In an effort to try and answer this question, 
the research conducted a bivariate tabular analysis. This approach was utilized as a method to try and understand the relationship between medication and treatment variables. Therefore, contingency tables were created and cross categorized according to two variables: 1) individual therapy vs. no individual therapy (dependent variable) and medication vs. no medication (independent variable); 2) group therapy vs. no group therapy (dependent variable) and medication vs. no medication; 3) Family therapy vs. no family therapy (dependent variable) and medication vs. no medication; 4) Master Degree vs. Doctorate Degree and medication vs. no medication; and 5) Therapist Style vs. medication vs. no medication. 
Table 1

Demographic Independent Variables: Definition of Variables

\begin{tabular}{|c|c|}
\hline $\begin{array}{l}\text { Demographic } \\
\text { Variables }\end{array}$ & Definition \\
\hline Age & The chronological age of the adolescent at test administration. \\
\hline $\begin{array}{l}\text { Number of } \\
\text { Siblings }\end{array}$ & The number of siblings a resident reports having. \\
\hline Grade & Residents' academic year both at intake and discharge. \\
\hline Verbal IQ & $\begin{array}{l}\text { A WISC-III index of the child's relative brightness in verbal areas, as } \\
\text { compared with their age. }\end{array}$ \\
\hline $\begin{array}{l}\text { Performance } \\
\text { IQ }\end{array}$ & $\begin{array}{l}\text { A WISC-III index of the child's relative brightness in performance areas, as } \\
\text { compared with their age. }\end{array}$ \\
\hline Full Scale IQ & $\begin{array}{l}\text { An overall WISC-III index of the child's relative brightness as compared with } \\
\text { their age. }\end{array}$ \\
\hline $\begin{array}{l}\text { Probationary } \\
\text { Status }\end{array}$ & $\begin{array}{l}\text { A correctional status in which an officer of the court in lieu of serving jail time } \\
\text { supervises the adolescent. }\end{array}$ \\
\hline $\begin{array}{l}\text { GPA @ } \\
\text { Admission }\end{array}$ & A score that reflects an individual's academic performance at admission. \\
\hline Race & Pertai \\
\hline Religion & Whether or not the individual identifies with any religious organization. \\
\hline $\begin{array}{l}\text { Parent's } \\
\text { Marital } \\
\text { Status }\end{array}$ & $\begin{array}{l}\text { Pertaining to whether or not the parents are still married, separated, divorced, } \\
\text { never married, unknown, or single parent status. }\end{array}$ \\
\hline Diagnosis & $\begin{array}{l}\text { Conduct disorder (CD), oppositional defiant disorder (ODD), and disruptive } \\
\text { behavioral disorder (DBD); which are all classified in this study as behavioral } \\
\text { disorders). Additional student diagnoses, within the special education } \\
\text { profession are; emotional disorders (ED) and learning disorders (LD). } \\
\text { Behavioral disorders (BD) in general are characterized by conduct problems, } \\
\text { aggressive tendencies, and antisocial behavior. }\end{array}$ \\
\hline Guardianship & $\begin{array}{l}\text { Who maintains legal custody of the child, the court, division of social services, } \\
\text { or the parent? }\end{array}$ \\
\hline $\begin{array}{l}\text { Intake } \\
\text { Psychometric } \\
\text { Measures }\end{array}$ & $\begin{array}{l}\text { Intake administration of the following measures: Beck Depression Inventory } \\
\text { (BDI), Locus of Control Scale for children (LOC), State-Trait Anger } \\
\text { Expression Inventory (STAXI), Millon Adolescent Clinical Inventory (MACI), } \\
\text { and Woodcock-Johnson Achievement Test (WJ-ACH). }\end{array}$ \\
\hline
\end{tabular}


Table 2

Independent Variables: Definition of Variables

\begin{tabular}{|l|l|}
\hline $\begin{array}{l}\text { Independent } \\
\text { Variables }\end{array}$ & Definition \\
\hline $\begin{array}{l}\text { Individual } \\
\text { Therapy }\end{array}$ & $\begin{array}{l}\text { A 1 to 1 session utilizing either: cognitive, family systems/object relations, } \\
\text { psychodynamic, cognitive-behavioral, or eclectic }\end{array}$ \\
\hline $\begin{array}{l}\text { Family } \\
\text { Therapy }\end{array}$ & $\begin{array}{l}\text { Sessions can be held with the parents individually or with the student. } \\
\text { Measured according to notes taken in chart, as to whether family participated in } \\
\text { family therapy. }\end{array}$ \\
\hline $\begin{array}{l}\text { Group } \\
\text { Therapy }\end{array}$ & $\begin{array}{l}\text { Groups offered include: Weekly character education groups, substance abuse, } \\
\text { anger management, physical and/or sexual abuse }\end{array}$ \\
\hline $\begin{array}{l}\text { Therapist's } \\
\text { Degree }\end{array}$ & Highest level of degree obtained. \\
\hline $\begin{array}{l}\text { Therapist } \\
\text { Style }\end{array}$ & $\begin{array}{l}\text { The orientation a given therapist reported using within the residential treatment } \\
\text { setting. }\end{array}$ \\
\hline $\begin{array}{l}\text { Meds vs No } \\
\text { Meds }\end{array}$ & Current psychotropic medication taken. \\
\hline
\end{tabular}


Table 3

Dependent Variables: Definition of Variables

\begin{tabular}{|c|c|}
\hline $\begin{array}{l}\text { Dependent } \\
\text { Variables }\end{array}$ & Definition \\
\hline $\begin{array}{l}\text { AWOL's } \\
\text { (temporary) }\end{array}$ & Unauthorized departures from the facility \\
\hline Weeks@Level1 & Number of chronological weeks spent Level 1. \\
\hline $\begin{array}{l}\text { Weeks@ } \\
\text { Level } 2\end{array}$ & Number of chronological weeks spent Level 2. \\
\hline $\begin{array}{l}\text { Weeks@ } \\
\text { Level } 3\end{array}$ & Number of chronological weeks spent Level 3. \\
\hline $\begin{array}{l}\text { Weeks@ } \\
\text { Level } 4\end{array}$ & Number of chronological weeks spent on Level 4. \\
\hline $\begin{array}{l}\text { Progression Score } \\
\text { Level } 1\end{array}$ & $\begin{array}{l}\text { The difference between the actual time that it took the resident to progress } \\
\text { through levels versus the prescribed amount of time that the resident will } \\
\text { take to progress through Level } 1 \text { (as determined by the treatment facility) } \\
\text { (actual time - prescribed time = progression score). }\end{array}$ \\
\hline $\begin{array}{l}\text { Progression Score } \\
\text { Level } 2\end{array}$ & $\begin{array}{l}\text { The difference between the actual time that it took the resident to progress } \\
\text { through levels versus the prescribed amount of time that the resident will } \\
\text { take to progress through Level } 2 \text { (as determined by the treatment facility) } \\
\text { (actual time - prescribed time = progression score). }\end{array}$ \\
\hline $\begin{array}{l}\text { Progression Score } \\
\text { Level } 3\end{array}$ & $\begin{array}{l}\text { The difference between the actual time that it took the resident to progress } \\
\text { through levels versus the prescribed amount of time that the resident will } \\
\text { take to progress through Level } 3 \text { (as determined by the treatment facility) } \\
\text { (actual time - prescribed time = progression score). }\end{array}$ \\
\hline $\begin{array}{l}\text { Progression Score } \\
\text { Level } 4\end{array}$ & $\begin{array}{l}\text { The difference between the actual time that it took the resident to progress } \\
\text { through levels versus the prescribed amount of time that the resident will } \\
\text { take to progress through Level } 4 \text { (as determined by the treatment facility) } \\
\text { (actual time - prescribed time = progression score). }\end{array}$ \\
\hline $\begin{array}{l}\text { Type } 1 \\
\text { Restriction }\end{array}$ & Type 1 Restriction is a punishment for a behavioral infraction. \\
\hline $\begin{array}{l}\text { Type } 2 \\
\text { Restriction }\end{array}$ & $\begin{array}{l}\text { Type } 2 \text { Restriction is a punishment for a more severe behavioral } \\
\text { infraction. }\end{array}$ \\
\hline $\begin{array}{l}\text { Type } 3 \\
\text { Restriction }\end{array}$ & $\begin{array}{l}\text { Type } 3 \text { Restriction is a punishment for the most severe behavioral } \\
\text { infraction. }\end{array}$ \\
\hline Discharge GPA & A score that reflects an individual's academic performance at discharge. \\
\hline $\begin{array}{l}\text { Discharge } \\
\text { Psychometric } \\
\text { Measures }\end{array}$ & $\begin{array}{l}\text { Discharge administration of the following measures: Beck Depression } \\
\text { Inventory (BDI), Locus of Control Scale for children (LOC), State-Trait } \\
\text { Anger Expression Inventory (STAXI), Millon Adolescent Clinical } \\
\text { Inventory (MACI), and Woodcock-Johnson Achievement Test (WJ- } \\
\text { ACH). }\end{array}$ \\
\hline
\end{tabular}


Table 4

$\underline{\text { Independent, Dependent, \& Intake Demographic Variables }}$

\begin{tabular}{|l|l|l|}
\hline $\begin{array}{l}\text { INDEPENDENT } \\
\text { (DEMOGRAPHIC) }\end{array}$ & $\begin{array}{l}\text { INDEPENDENT } \\
\text { VARIABLES }\end{array}$ & DEPENDENT \\
VARIABLES \\
\hline Age & Individual Therapy & AWOL's (temporary) \\
Number of Siblings & Family Therapy & Weeks @ Level 1 \\
Grade & Group Therapy & Weeks @ Level 2 \\
Verbal IQ & Therapist's Degree & Weeks @ Level 3 \\
Performance IQ & Therapist Style & Weeks @ Level 4 \\
Full Scale IQ & Meds vs. No Meds & Progression Score Level 1 \\
Probationary Status & & Progression Score Level 2 \\
GPA @ Admission & & Progression Score Level 3 \\
Race & Progression Score Level 4 \\
Religion & & Type 1 Restriction \\
Parent's Marital Status & Type 2 Restriction \\
Diagnosis & & Type 3 Restriction \\
Guardianship & & Discharge GPA \\
Intake Psychometric & Discharge Psychometric \\
Measures & & Measures \\
& & \\
\hline
\end{tabular}


Table 5

Design of Statistical Analysis for Research Question 1

\begin{tabular}{|c|c|c|}
\hline Predictor & Intake Psychometric Variables & $\begin{array}{c}\text { Outcome Psychometric Variables } \\
\text { (Discharge) }\end{array}$ \\
\hline Age & $\begin{array}{l}\text { Depression (BDI) } \\
\text { Locus of Control (LOC) } \\
\text { State Anger (STAXI) } \\
\text { Trait Anger (STAXI) } \\
\text { Angry Reaction (STAXI) } \\
\text { Anger In (STAXI) } \\
\text { Anger Out (STAXI) } \\
\text { Anger Control (STAXI) } \\
\text { Anger Expression (STAXI) } \\
\text { Disclosure (MACI) } \\
\text { Desirability (MACI) } \\
\text { Debasement (MACI) } \\
\text { Introversion (MACI) } \\
\text { Inhibited (MACI) } \\
\text { Doleful (MACI) } \\
\text { Submissive (MACI) } \\
\text { Dramatizing (MACI) } \\
\text { Egotistic (MACI) } \\
\text { Unruly (MACI) } \\
\text { Forceful (MACI) } \\
\text { Conforming (MACI) } \\
\text { Oppositional (MACI) } \\
\text { Self-demeaning (MACI) } \\
\text { Borderline (MACI) } \\
\text { Identity diffusion (MACI) } \\
\text { Self-devaluation (MACI) } \\
\text { Body disapproval (MACI) } \\
\text { Sexual discomfort (MACI) } \\
\text { Peer insecurity (MACI) } \\
\text { Social insensitivity (MACI) } \\
\text { Family discord (MACI) } \\
\text { Childhood abuse (MACI) } \\
\text { Eating dysfunction (MACI) } \\
\text { Substance abuse proneness } \\
\text { (MACI) } \\
\text { Delinquent predisposition (MACI) } \\
\text { Impulsive propensity (MACI) } \\
\text { Anxious feelings (MACI) } \\
\text { Depressive affect (MACI) } \\
\text { Suicidal tendency (MACI) } \\
\text { (MAnA }\end{array}$ & $\begin{array}{l}\text { Depression (BDI) } \\
\text { Locus of Control (LOC) } \\
\text { State Anger (STAXI) } \\
\text { Trait Anger (STAXI) } \\
\text { Angry Reaction (STAXI) } \\
\text { Anger In (STAXI) } \\
\text { Anger Out (STAXI) } \\
\text { Anger Control (STAXI) } \\
\text { Anger Expression (STAXI) } \\
\text { Disclosure (MACI) } \\
\text { Desirability (MACI) } \\
\text { Debasement (MACI) } \\
\text { Introversion (MACI) } \\
\text { Inhibited (MACI) } \\
\text { Doleful (MACI) } \\
\text { Submissive (MACI) } \\
\text { Dramatizing (MACI) } \\
\text { Egotistic (MACI) } \\
\text { Unruly (MACI) } \\
\text { Forceful (MACI) } \\
\text { Conforming (MACI) } \\
\text { Oppositional (MACI) } \\
\text { Self-demeaning (MACI) } \\
\text { Borderline (MACI) } \\
\text { Identity diffusion (MACI) } \\
\text { Self-devaluation (MACI) } \\
\text { Body disapproval (MACI) } \\
\text { Sexual discomfort (MACI) } \\
\text { Peer insecurity (MACI) } \\
\text { Social insensitivity (MACI) } \\
\text { Family discord (MACI) } \\
\text { Childhood abuse (MACI) } \\
\text { Eating dysfunction (MACI) } \\
\text { Substance abuse proneness (MACI) } \\
\text { Delinquent predisposition (MACI) } \\
\text { Impulsive propensity (MACI) } \\
\text { Anxious feelings (MACI) } \\
\text { Depressive affect (MACI) } \\
\text { Suicidal tendency (MACI) } \\
\text { Progression Score Level 1 } \\
\text { Progression Score Level 2 } \\
\text { Progression Score Level 3 } \\
\text { Progression Score Level } 4 \\
\text { (M) }\end{array}$ \\
\hline
\end{tabular}


Table 6

Design of Statistical Analysis for Research Question 2

\begin{tabular}{|l|l|}
\hline \multicolumn{1}{|c|}{ Intake (Demographic) } & \multicolumn{1}{c|}{ Outcomes } \\
\hline Age & Number of AWOL's \\
Grade & Weeks @ Level 1 \\
Number of Sibling & Weeks @ Level 2 \\
Verbal IQ & Weeks @ Level 3 \\
Performance IQ & Weeks @ Level 4 \\
Full Scale IQ & Progression Score Level 1 \\
GPA & Progression Score Level 2 \\
Substance abuse history & Progression Score Level 3 \\
Ethnicity (Race) & Progression Score Level 4 \\
Religious Denomination & Type 1 Restriction \\
Parents Marital Status & Type 2 Restriction \\
Legal Guardian & Type 3 Restriction \\
& Current GPA \\
& Broad Reading Discharge \\
& Broad Math Discharge \\
& Broad Writing Discharge \\
& Broad Knowledge Discharge \\
& Skills Discharge \\
& Discharge Criteria \\
\hline
\end{tabular}


Table 7

Design of Statistical Analysis for Research Question 3

\begin{tabular}{|c|c|}
\hline Intake (Psychometrics) & Outcomes \\
\hline $\begin{array}{l}\text { Depression (BDI) } \\
\text { Locus of Control (LOC) } \\
\text { State Anger (STAXI) } \\
\text { Trait Anger (STAXI) } \\
\text { Angry Reaction (STAXI) } \\
\text { Anger In (STAXI) } \\
\text { Anger Out (STAXI) } \\
\text { Anger Control (STAXI) } \\
\text { Anger Expression (STAXI) } \\
\text { Disclosure (MACI) } \\
\text { Desirability (MACI) } \\
\text { Debasement (MACI) } \\
\text { Introversion (MACI) } \\
\text { Inhibited (MACI) } \\
\text { Doleful (MACI) } \\
\text { Submissive (MACI) } \\
\text { Dramatizing (MACI) } \\
\text { Egotistic (MACI) } \\
\text { Unruly (MACI) } \\
\text { Forceful (MACI) } \\
\text { Conforming (MACI) } \\
\text { Oppositional (MACI) } \\
\text { Self-demeaning (MACI) } \\
\text { Borderline (MACI) } \\
\text { Identity diffusion (MACI) } \\
\text { Self-devaluation (MACI) } \\
\text { Body disapproval (MACI) } \\
\text { Sexual discomfort (MACI) } \\
\text { Peer insecurity (MACI) } \\
\text { Social insensitivity (MACI) } \\
\text { Family discord (MACI) } \\
\text { Childhood abuse (MACI) } \\
\text { Eating dysfunction (MACI) } \\
\text { Substance abuse proneness (MACI) } \\
\text { Delinquent predisposition (MACI) } \\
\text { Impulsive propensity (MACI) } \\
\text { Anxious feelings (MACI) } \\
\text { Depressive affect (MACI) } \\
\text { Suicidal tendency (MACI) } \\
\text { Broad Reading Time 1 (WJ-R) } \\
\text { Broad Math Time 1 (WJ-R) } \\
\text { Broad Writing Time 1(WJ-R) } \\
\text { Broad Knowledge Time 1(WJ-R) } \\
\text { Skills Time 1 (WJ-R) }\end{array}$ & $\begin{array}{l}\text { Number of AWOL's } \\
\text { Weeks @ Level } 1 \\
\text { Weeks@ Level } 2 \\
\text { Weeks @ Level } 3 \\
\text { Weeks @ Level } 4 \\
\text { Progression Score Level } 1 \\
\text { Progression Score Level } 2 \\
\text { Progression Score Level } 3 \\
\text { Progression Score Level } 4 \\
\text { Type 1 Restriction } \\
\text { Type 2 Restriction } \\
\text { Type } 3 \text { Restriction } \\
\text { Current GPA } \\
\text { Broad Reading Discharge } \\
\text { Broad Math Discharge } \\
\text { Broad Writing Discharge } \\
\text { Broad Knowledge Discharge } \\
\text { Skills Discharge } \\
\text { Discharge Criteria }\end{array}$ \\
\hline
\end{tabular}


Table 8

Design of Statistical Analysis for Research Question 4

\begin{tabular}{|l|l|}
\hline \multicolumn{1}{|c|}{ Treatment Variables } & \multicolumn{1}{c|}{ Outcomes } \\
\hline Individual Therapy & Number of AWOL's \\
Family Therapy & Weeks @ Level 1 \\
Group Therapy & Weeks @ Level 2 \\
Therapists Degree & Weeks @ Level 3 \\
Therapist Style & Weeks @ Level 4 \\
Current Medications & Progression Score Level 1 \\
& Progression Score Level 2 \\
& Progression Score Level 3 \\
& Progression Score Level 4 \\
& Type 1 Restriction \\
& Type 2 Restriction \\
& Type 3 Restriction \\
& Current GPA \\
& Broad Reading Discharge \\
& Broad Math Discharge \\
& Broad Writing Discharge \\
& Broad Knowledge Discharge \\
& Skills Discharge \\
& Discharge Criteria \\
\hline
\end{tabular}




\section{CHAPTER 4}

\section{Results \& Discussion}

Introduction

This investigation was designed to determine what demographic and treatment variables have a reliable effect on outcome variables of adolescents with behavioral disorders in residential facilities. What students, with what demographic characteristics, from what environmental circumstances, receiving what forms and methods of treatment, achieve what levels of success? Research questions were designed to address these above-stated issues.

\section{Description of the Sample}

The records of 120 adolescents, who were admitted to a residential treatment facility in Northern Virginia, and were served by the facility from January 1999 to January 2001, were reviewed. Only those participants whose medical records included psychometric testing were used, namely, the Beck Depression Inventory (BDI), the Locus of Control Scale for children (LOC), the State-Trait Anger Expression Inventory (STAXI), the Millon Adolescent Clinical Inventory (MACI), and the Woodcock-Johnson Achievement Test (WJ-R). Limitations of this data set consisted of missing data in all student records.

\section{$\underline{\text { Demographic Characteristics }}$}

Table 9 (pages 65-66) includes means, standard deviations, and frequencies for variables related to intake demographics. As seen in the table, the students' average age was 15 years, and the average grade was 9th. Students' IQ averaged in the normal range (97.8), and the GPA at admission showed a mean in the " $\mathrm{D}$ " range. Students' admission grades were calculated based on a 100-point scale; therefore, the obtained 74.5 reflect an average based on 100 points. 
Table 9

Demographics Characteristics of Residential Treatment Participants $(n=120)$

\begin{tabular}{|c|c|c|c|}
\hline Variable & $\mathrm{n}$ & $\mathrm{Me}$ & n SD \\
\hline Age & 120 & 14.9 & 1.5 \\
\hline Grade & 120 & 8.9 & 1.4 \\
\hline Number of Siblings & 102 & 2.1 & 1.3 \\
\hline Verbal IQ (WISC) & 87 & 95.8 & 12.8 \\
\hline Performance IQ (WISC) & 87 & 99.4 & 14.0 \\
\hline Full Scale IQ (WISC) & 91 & 97.8 & 12.6 \\
\hline GPA at Admission (out of 100 possible points) & 120 & 74.5 & 8.4 \\
\hline GPA at Discharge (out of 100 possible points) & 114 & 84.1 & 12.0 \\
\hline Variable & & quency & Percent \\
\hline Gender & & & \\
\hline Male & 120 & & 100 \\
\hline Race & & & \\
\hline African American & 30 & & 25.0 \\
\hline Caucasian & 80 & & 66.7 \\
\hline Other & 10 & & 8.3 \\
\hline Religion & & & \\
\hline Protestant & 43 & & 36.4 \\
\hline Catholic & 16 & & 13.6 \\
\hline Other & 4 & & 3.4 \\
\hline None & 55 & & 46.7 \\
\hline Marital Status of Biological Parents & & & \\
\hline Married & 29 & & 24.4 \\
\hline Divorced & 7 & & 5.9 \\
\hline Separated & 3 & & 2.5 \\
\hline Widowed & 4 & & 3.4 \\
\hline Never Married & 19 & & 16.0 \\
\hline Unknown & 17 & & 14.3 \\
\hline Either Parent Remarried & 40 & & 33.6 \\
\hline Diagnosis & & & \\
\hline Behavioral Disorder & 24 & & 22.4 \\
\hline Emotional Disorder & 51 & & 47.7 \\
\hline Leaning Disorder & 14 & & 13.0 \\
\hline $\mathrm{BD} / \mathrm{LD} / \mathrm{ED}$ Comorbidity & 18 & & 16.9 \\
\hline Guardian & & & \\
\hline Family Services & 60 & & 51.3 \\
\hline Permanent Foster Care & 2 & & 1.7 \\
\hline Relative & 5 & & 4.3 \\
\hline
\end{tabular}


Table 9 (continued)

Table continues

Frequency Percent

\begin{tabular}{lrr}
\hline Parents & 26 & 22.2 \\
Mother only & 18 & 15.4 \\
Father only & 6 & 5.1 \\
Current Medications & 6 & 8.5 \\
Antipsychotics & 7 & 9.9 \\
Antidepressants & 4 & 5.6 \\
Antianxiety & 5 & 7.0 \\
Mood Stabilizers & 12 & 16.9 \\
Stimulants & 21 & 29.4 \\
Two or more Psychotropic Meds & 8 & 11.3 \\
Other (none psychotropic meds) & & \\
Probation & 53 & 46.5 \\
No & 61 & 53.5 \\
Yes & & 51.0 \\
Substance Abuse History & 50 & 49.0 \\
No & 48 & \\
Yes & & \\
\end{tabular}


The participants were predominantly Caucasian (67\%) and from homes of remarried parents (34\%). Fifty one percent of the sample were involved with family services or were wards of the state. Seventy seven percent of the sample was on some form of psychotropic medications. Fifty four percent of the sample was on probation, and $49 \%$ reported substance abuse. "Two or more Psychotropic Meds," "Race," and "Dual Diagnosis" categories were created because the overall sample size for each of these subcategories was miniscule; therefore, the researchers concluded that it was more useful to view these figures as a combined category, rather than independently. $\underline{\text { Psychometric Characteristics }}$

Table 10 (pages 68-69) reports intake psychometric scores for residents in residential treatment. In Table 10, it may be noted that, the Millon Adolescent Clinical Inventory (MACI) consists of 30 subscores. For the MACI, the higher the base rate score ( 75 or higher), the greater the probability that the scale has accessed that syndrome. It maybe noted that students' scores tended to reveal higher means for the following subscales: Forceful (71.9), Social Insensitivity (65.1), Family Discord (70.2), Delinquent Predisposition (74.8), and Impulsive Propensity (67.0). The lowest means were Body Disapproval (29.6) and Eating Dysfunction (22.3). The Beck Depression Inventory (BDI) consists of one score. The clinically significant cut-off score for the BDI is 63 . The overall $\underline{n}$ for the BDI was 31 , which was small given the overall sample was 120 . The mean score in this sample was 13 , which is indicative of minimal depressive symptoms. 
Table 10

Intake Scores for Residential Treatment Participants for the MACI, BDI, LOC, STAXI, and WJ$\underline{\mathrm{R})}$

\begin{tabular}{|c|c|c|c|}
\hline Variable & $\mathrm{n}$ & Mean & SD \\
\hline \multicolumn{4}{|c|}{ *Million Adolescent Clinical Inventory } \\
\hline Disclosure & 74 & 54.8 & 21.0 \\
\hline Desirability & 74 & 54.8 & 21.0 \\
\hline Debasement & 74 & 62.3 & 17.0 \\
\hline Introversive & 74 & 56.9 & 19.2 \\
\hline Inhibited & 74 & 48.2 & 18.2 \\
\hline Doleful & 74 & 45.4 & 23.6 \\
\hline Submissive & 74 & 51.5 & 22.9 \\
\hline Dramatizing & 74 & 53.7 & 15.0 \\
\hline Egotistic & 74 & 59.7 & 18.6 \\
\hline Unruly & 74 & 52.5 & 16.0 \\
\hline Forceful & 74 & 71.9 & 21.0 \\
\hline Conforming & 74 & 48.1 & 18.0 \\
\hline Oppositional & 74 & 62.1 & 19.0 \\
\hline Self-Demeaning & 74 & 45.5 & 20.1 \\
\hline Borderline & 74 & 45.5 & 24.0 \\
\hline Identity Diffusion & 74 & 48.7 & 20.0 \\
\hline Self-Devaluation & 74 & 48.0 & 28.1 \\
\hline Body Disapproval & 74 & 29.6 & 30.0 \\
\hline Sexual Discomfort & 74 & 47.3 & 18.0 \\
\hline Peer Insecurity & 74 & 43.9 & 28.0 \\
\hline Social Insensitivity & 74 & 65.1 & 19.0 \\
\hline Family Discord & 74 & 70.2 & 20.0 \\
\hline Childhood Abuse & 74 & 46.0 & 27.0 \\
\hline Eating Dysfunction & 74 & 22.3 & 23.0 \\
\hline Substance Abuse Proneness & 74 & 59.3 & 34.2 \\
\hline Delinquent Predisposition & 74 & 74.8 & 21.0 \\
\hline Impulsive Propensity & 74 & 67.0 & 25.0 \\
\hline Anxious Feelings & 74 & 51.9 & 18.0 \\
\hline Depressive Affect & 74 & 53.1 & 29.0 \\
\hline Suicidal Tendency & 74 & 35.6 & 24.0 \\
\hline \multicolumn{4}{|c|}{ **Beck Depression Inventory 2nd Edition } \\
\hline Beck Depression Inventory & 31 & 13.4 & 12.0 \\
\hline \multicolumn{4}{|c|}{ ***Locus of Control Scale for Children } \\
\hline Locus of Control Scale & 82 & 14.5 & 5.0 \\
\hline \multicolumn{4}{|c|}{$* * * *$ State-Trait Anger Expression Inventory } \\
\hline State Anger & 25 & 53.5 & $\begin{array}{l}21.0 \\
\text { continues }\end{array}$ \\
\hline
\end{tabular}


Table 10 (continued)

\begin{tabular}{lrll} 
Variable & $\mathrm{n}$ & Mean & SD \\
\hline Trait Anger & 24 & 35.0 & 29.0 \\
Angry Temperament & 25 & 47.0 & 27.0 \\
Angry Reaction & 25 & 30.0 & 23.0 \\
Anger In & 25 & 45.9 & 23.0 \\
Anger Out & 25 & 64.6 & 28.0 \\
Anger Control & 25 & 55.9 & 29.0 \\
Anger Expression & 25 & 54.7 & 26.0 \\
*****Woodcock Johnson Ach Test & & & \\
Broad Reading Time 1 & 104 & 9.0 & 3.5 \\
Broad Math Time 1 & 103 & 8.0 & 3.1 \\
Broad Writing Time 1 & 99 & 6.3 & 3.2 \\
Broad Knowledge Time 1 & 95 & 7.2 & 3.3 \\
Skills Time 1 & 86 & 7.7 & 3.1 \\
& & & \\
\hline
\end{tabular}

\footnotetext{
Note:

* The clinically significant cut-off score for the MACI is defined as the higher the base rate score (75 or higher), the greater the probability that the scale has tapped into that syndrome. The MACI consists of 30 subscores.

** Scores in the 14-19 ranges indicate mild depression.

***The higher the score on the LOC, the more the individual externalizes locus of control. A lower score is desirable because it indicates a more internal control.

**** Scale scores for the STAXI that fall between the $25^{\text {th }}$ percentiles or above $75^{\text {th }}$ percentile, fall in what may be considered the normal range.

*****The Woodcock Johnson mean scores reflect grade equivalences. Using grade equivalences allows one to easily note improvements over time while in the program.
} 
The Locus of Control Scale for Children (LOC) consists of one score. The mean score in this sample was 14.5. As compared to normative data for the LOC, for males in the ninth grade was 13.81 (Norwicki \& Strickland, 1973). Using a single sample T-Test is was determined that no mean differences were noted. A lower score is desirable because it indicates more internal control.

The State-Trait Anger Expression Inventory (STAXI) consists of 8 subscores. In Table 10 (page 68-69) the overall $\underline{n}$ for the STAXI was 25 , which was small given the overall sample was 120. The subscale Trait Anger displayed the lowest mean 35, while the subscale Anger Out displayed the largest mean 64.6. Scaled scores ( $\mathrm{t}$ scores) for the STAXI that fall between the $25^{\text {th }}$ and $75^{\text {th }}$ percentile, can be considered within the normal range.

The Woodcock-Johnson Achievement Test consists of 5 subscales. In this sample, residents are functioning at the $9^{\text {th }}$ grade level of reading, $8^{\text {th }}$ grade range for math, $6^{\text {th }}$ grade for written language, $7^{\text {th }}$ grade general information, and $8^{\text {th }}$ grade for overall achievement. $\underline{\text { Treatment Characteristics }}$

Table 11 (page 71) reports types of treatment received by adolescent clients in the residential center. As indicated in Table 3, all students participated in both individual and group therapy, and character education groups (100\%), and 43\% participated in family therapy. Therapists had graduate degrees, and treatment orientation varied with cognitive behavioral being the most common (34\%). The researcher was also interested in determining if any relationship existed between the use of medication and the treatment variables.

A Chi-Square non-parametric test at this point would have been ideal to determine the probability of obtaining the frequencies actually observed. However, a Chi-Square nonparametric test is based on the assumption that frequencies are normally distributed. 
Table 11

Frequency of Treatment Received by Residents in Adolescent Treatment Facility

\begin{tabular}{|c|c|c|}
\hline Variable & Frequency & Percent \\
\hline \multicolumn{3}{|l|}{ Individual Therapy } \\
\hline Yes & 120 & 100 \\
\hline No & 0 & 0 \\
\hline \multicolumn{3}{|l|}{ Family therapy } \\
\hline Yes & 51 & 43.2 \\
\hline No & 67 & 56.8 \\
\hline \multicolumn{3}{|l|}{ Group Therapy } \\
\hline Yes & 120 & 100 \\
\hline No & 0 & 0 \\
\hline \multicolumn{3}{|l|}{ Character Education Groups } \\
\hline Yes & 120 & 100 \\
\hline No & 0 & 0 \\
\hline \multicolumn{3}{|l|}{ Therapist Style } \\
\hline Cognitive & 20 & 17.9 \\
\hline Family Systems/Object Relations & 17 & 15.1 \\
\hline Psychodynamic & 17 & 15.1 \\
\hline Cognitive-Behavioral & 38 & 34.0 \\
\hline Eclectic & 20 & 17.9 \\
\hline \multicolumn{3}{|l|}{ Therapist Degree } \\
\hline $\mathrm{BA}$ & 0 & 0 \\
\hline Masters & 59 & 51.3 \\
\hline Ed.D., Ph.D., Psy.D. & 56 & 48.8 \\
\hline
\end{tabular}

Note: The category Therapist Degree displays less then 120 participants. 
When expected frequencies are large, there is no problem with the assumption of normal distribution. However, as in the case of the present research, the smaller the expected frequencies, the less valid the results. Due to cells in the contingency table which report very low raw observed frequencies ( 5 or below), it is likely that expected frequencies may also be too low for a chi-square to be used effectively.

In an effort to try and answer the question: Is there a relationship between the use of medication and types of treatment? The research conducted a bivariate tabular analysis. This approach was utilized as a method to try and understand the relationship between treatment variables. Table 12 (page 73) is cross-categorized according to two variables: 1) individual \& group therapy vs. no individual \& group therapy (dependent variable) by 2) medication vs. no medication (independent variable).

In addition, the bivariate tabular analysis reflects percentile figures within each of the two rows. Converting the raw observed values into percentages allows the researcher to more easily observe patterns in the data. Raw frequencies were converted into percentages for each cell within the categories of the independent variable. For example, in Table 12, each row was totaled, and then each cell was divided by its row total and multiplied by 100 . This latter procedure was conducted to standardize cell frequencies as if there were 100 observations in each category of the independent variable.

However, this process also comes at a price, converting the raw scores into percentages only allows the researcher to observe patterns in the data. Moreover, no generalization can be made about the population in which these samples were drawn since these frequencies were not submitted to a statistical test of significance. 
Table 12

$\underline{\text { Bivariate Tabular Analysis }}$

Treatment Variables: Percentage of Residents who Received Individual \& Group Therapy vs. No $\underline{\text { Individual \& Group Therapy by Medication versus No Medication }}$

\begin{tabular}{|c|c|c|c|}
\hline & $\begin{array}{c}\text { Individual \& Group } \\
\text { Therapy }\end{array}$ & $\begin{array}{c}\text { No Individual \& } \\
\text { Group Therapy }\end{array}$ & N \\
\hline $\begin{array}{c}\text { Psychotropic } \\
\text { Medication }\end{array}$ & $88.5 \%$ & 0 & 62 \\
\hline $\begin{array}{c}\text { No Psychotropic } \\
\text { Medication }\end{array}$ & $11.4 \%$ & 0 & 8 \\
\hline$\underline{\mathbf{N}}$ & 70 & 0 & 70 \\
\hline
\end{tabular}

\begin{abstract}
${ }^{1}$ Note: These percentages were calculated by dividing the total number of people that received individual \& group therapy and dividing that number by the total $\mathrm{N}$, since everyone included in the sample received individual \& group therapy; then multiplying that fraction by 100 .
\end{abstract}


It is difficult to determine if the observed differences between the medication and no medication groups when compared to the following treatment variables: individual, group, family, therapist degree, and therapist style therapy reflect anything, given the percentage received for individual and group.

Given this caveat, it can be seen in Table 12 (page 73) that within this sample, $88.5 \%$ of those that participated in individual \& group therapy were also treated with some form of psychotropic medication, while the remaining $11.4 \%$ that that also received individual \& group therapy did not receive any psychotropic medications.

Table 13 (page 75 ) reports a cross-categorization of two variables: 1) family therapy vs. no family therapy by 2) medication vs. no medication. It can be seen from the bivariate table that $37.3 \%$ of the sample that received family therapy were also were treated with some form of psychotropic medication. Of interest in Table 5 is that, $50.7 \%$ of the sample that did not receive family therapy was treated with some form of psychotropic medication. However, given that these figures were not submitted to a statistical test of significance it can not be established that the observed differences between the participants that received family therapy and the participants that did not receive family therapy reflects anything other than a chance coincidence.

Table 14 (page 76) reports a cross-categorization of two variables: 1) masters degree vs. doctorate degree by 2) medication vs. no medication. The bivariate table for Table 15 reports that $46.2 \%$ of those residents receiving treatment from a masters level counselor were treated with some form of psychotropic medication; while, $41.7 \%$ of those residents receiving treatment from a doctorate level psychologist did not receive psychotropic medications. 


\section{Table 13}

\section{$\underline{\text { Bivariate Tabular Analysis }}$}

Treatment Variables: Percentage of Residents in Residential Treatment Who Received Family Therapy vs. No Family Therapy by Medication versus No Medication

\begin{tabular}{|c|c|c|c|}
\hline & Family Therapy & $\begin{array}{c}\text { No Family } \\
\text { Therapy }\end{array}$ & $\underline{\mathbf{N}}$ \\
\hline $\begin{array}{c}\text { Psychotropic } \\
\text { Medication }\end{array}$ & $37.3 \%$ & $50.7 \%$ & 59 \\
\hline $\begin{array}{c}\text { No Psychotropic } \\
\text { Medication }\end{array}$ & $5.9 \%$ & $5.9 \%$ & 8 \\
\hline$\underline{\mathbf{N}}$ & 29 & 38 & 67 \\
\hline
\end{tabular}

${ }^{1}$ Note: The percentages for the cells that answer the question: What was the percentage of residents that were not on any psychotropic medication that received family therapy or no family therapy? These percentages were omitted because the figures were miniscule and thus would effect the generalizability of data. 
Table 14

$\underline{\text { Bivariate Tabular Analysis }}$

Treatment Variables: A Comparison of the Percentage of Masters Level Therapists to Doctorate Level Psychologist Who Treated Residents in Residential Placement by Medication versus No $\underline{\text { Medication }}$

\begin{tabular}{|c|c|c|c|}
\hline & Masters Degree & Doctorate Degree & $\underline{\mathbf{N}}$ \\
\hline $\begin{array}{c}\text { Psychotropic } \\
\text { Medication }\end{array}$ & $46.2 \%$ & $41.7 \%$ & 59 \\
\hline $\begin{array}{c}\text { No Psychotropic } \\
\text { Medication }\end{array}$ & $10.4 \%$ & $1.4 \%$ & 8 \\
\hline$\underline{N}$ & 38 & 29 & 67 \\
\hline
\end{tabular}

${ }^{1}$ Note: The percentages for the cells that answer the questions: What was the percentage of residents that were treated by masters level therapist that were not on any psychotropic medication? What was the percentage of residents that were treated by doctorate level therapist that were not on any psychotropic medication? These percentiles were omitted due to because the figures were miniscule and thus would effect the generalizability of data. 
Table 15 (page 78) reports any patterns of relationships between medication vs. no medication received at the residential treatment facility by reported therapeutic orientation/style: CBT, family systems, psychodynamic, cognitive, and eclectic. It can be noted from the bivariate table for Table 15 that of the self-reported cognitive-behavioral therapists, $19.6 \%$ treated residents who also received some form of psychotropic medication. The largest percent was found for cognitively oriented therapists. Thirty percent of those residents treated by cognitively oriented therapist were also on some form of psychotropic medication. Moreover, family systems and psychodynamic therapist each treated $12.1 \%$ of residents who also received some form of psychotropic medication. In addition, $13.6 \%$ of the residents treated by an eclectic therapist were also treated with some form of psychotropic medication. Three percent of residents who received treatment from a psychodynamic therapist were not on any psychotropic medications. Likewise, $1.5 \%$ of the residents treated by cognitive-behavioral and family systems oriented therapists were not on any form of psychotropic medication.

\section{Outcome Characteristics}

Table 16 (page 79) includes means for outcome variables designed to measure progress through treatment and academic achievement at discharge for adolescents in residential treatment. These variables include criteria for measuring progress through the treatment program and academic achievement at discharge. Table 16 (page 79) also includes types of discharge. Of interest in Table 8, are the mean time differences it took residents to complete later levels versus earlier ones. It can also be noted that students averaged 1.9 Type 1 restrictions, 15.8 Type 2, and 11.5 Type 3 restrictions; a factor that could impinge on residents' progress. 
Table 15

Bivariate Tabular Analysis

Treatment Variables: The Percentage of Residents in Residential Treatment that Received Psychotherapy From One of the Five Reported Therapeutic Orientation

\begin{tabular}{|c|c|c|c|c|c|c|}
\hline & CBT & $\begin{array}{c}\text { Family } \\
\text { Systems }\end{array}$ & Psychodynamic & Cognitive & Eclectic & $\underline{\mathbf{N}}$ \\
\hline $\begin{array}{c}\text { Psychotropic } \\
\text { Medication }\end{array}$ & $19.6 \%$ & $12.1 \%$ & $12.1 \%$ & $30.3 \%$ & $13.6 \%$ & 58 \\
\hline $\begin{array}{c}\text { No } \\
\text { Psychotropic } \\
\text { Medication }\end{array}$ & $1.5 \%$ & $1.5 \%$ & $3.0 \%$ & & $6.0 \%$ & 8 \\
\hline$\underline{\mathbf{N}}$ & 14 & 9 & 10 & 20 & 13 & 66 \\
\hline
\end{tabular}

${ }^{1}$ Note: The percentages for the cells that answer the questions: What was the percentage of residents that were treated by cognitive therapist that were not on any psychotropic medication? What was the percentage of residents that were treated by eclectic therapist that were not on any psychotropic medication? These percentages were omitted because the figures were miniscule and thus would effect the generalizability of data. 
Table 16

Mean Scores for Outcome Variables Designed to Measure Progress Through Treatment and Academic Achievement at Discharge for Adolescents in Residential Treatment

\begin{tabular}{|c|c|c|c|}
\hline Variables & $\mathrm{n}$ & Mean & $\mathrm{SD}$ \\
\hline AWOLs (temporary) & 40 & 2.4 & 2.3 \\
\hline Weeks@Level 1 & 93 & 4.4 & 6.5 \\
\hline Weeks@Level 2 & 93 & 11.0 & 10.8 \\
\hline Weeks@Level 3 & 81 & 17.3 & 14.8 \\
\hline Weeks@Level 4 & 46 & 22.0 & 14.6 \\
\hline Progression Score Level 1 & 93 & 1.4 & 6.5 \\
\hline Progression Score Level 2 & 93 & 7.0 & 10.8 \\
\hline Progression Score Level 3 & 81 & 11.3 & 14.8 \\
\hline Progression Score Level 4 & 45 & 14.0 & 14.8 \\
\hline Type 1 Restriction & 38 & 1.9 & 3.9 \\
\hline Type 2 Restriction & 96 & 15.8 & 21.6 \\
\hline Type 3 Restriction & 90 & 11.5 & 15.6 \\
\hline Discharge GPA (based on 100 points) & 114 & 84.1 & 12.0 \\
\hline Discharge Broad Reading (W-J Ach Test) & 72 & 9.3 & 3.2 \\
\hline Discharge Broad Math (W-J Ach Test) & 73 & 8.5 & 3.1 \\
\hline Discharge Broad Writing (W-J Ach Test) & 73 & 6.8 & 3.2 \\
\hline Discharge Broad Knowledge (W-J Ach Test) & 73 & 8.1 & 2.9 \\
\hline Discharge Skills (W-J Ach Test) & 70 & 7.6 & 2.6 \\
\hline Variable & \multicolumn{2}{|c|}{ Frequency } & Percent \\
\hline \multicolumn{4}{|l|}{ Discharge } \\
\hline Planned & \multicolumn{2}{|c|}{27} & 36.5 \\
\hline Diagnostic & \multicolumn{2}{|c|}{4} & 5.4 \\
\hline Other/Deceased & \multicolumn{2}{|c|}{1} & 1.4 \\
\hline AWOLs & \multicolumn{2}{|c|}{7} & 9.5 \\
\hline Agency/Parent Initiated & \multicolumn{2}{|c|}{24} & 32.4 \\
\hline Unsuccessful & \multicolumn{2}{|c|}{7} & 9.5 \\
\hline Self & \multicolumn{2}{|c|}{4} & 5.4 \\
\hline
\end{tabular}

${ }^{1}$ Note: W-J ACH. Scores are based on grade equivalences. 
While not evident from Table 16 (page 79), the achievement scores listed are near expected grade level. Finally, the first three types of discharge can be considered successful, with the remaining unsuccessful. Thus, the successful discharge rate was about $43 \%$. These results need to be interpreted with caution due to the standard error of measure.

\section{Zero-order Pearson Product-Moment Correlations}

Multivariate analysis had been planned to allow simultaneous interpretations of effects. Such analyses, however, were not possible because of missing data in all student records. Accordingly, multiple regression analysis is not included because missing data for a single variable in any given multivariate analysis eliminated the entire participant from the computation when using SAS.

Therefore, the basic relationships (zero-order Pearson Product-Moment Correlations) are presented for (a) Age to Intake and Discharge Scores on Psychometric Measures (Table 17, page 82); (b) Age to Clinical Psychopathology (Table 18, page 86); (c) Intake Demographics Variables to Outcome Variables (Table 19, page 89), (d) Intake Psychometric Measures to Outcome Variables (Table 20, page 93-95), and (e) Treatment Variables to Outcome Variables (Table 21, page 98). These basic relationships were examined as they contributed to answering the research questions. The independent variables Race, Religion, Parents' Marital Status, Diagnosis, Guardian, Therapist Style, Therapist Degree, and Discharge were observed and categorically changed to dichotomous (dummy coded) variables. As a result of dichotomizing variables, the researcher ran the risk of decreasing the variance, thus limiting the understanding of each individual variable.

Despite the above caveat, data were simplified using recoding and data reduction techniques, to agree with the objective of this analytical research, which was to determine what 
variables are related to successful discharge from a residential treatment program for adolescents with behavioral disorders. Respondents' Race was dichotomized into 1 = not Caucasian (other) and 2 = Caucasian categories. Respondents' Religion was dichotomized into $1=$ religious affiliation and $2=$ no religious affiliation categories. Parents' Marital Status was dichotomized into $1=$ married and $2=$ not married categories. Respondents' Diagnosis was dichotomized into $1=$ behavioral disordered and $2=$ not behavioral disordered categories. Respondents' Guardian was dichotomized into $1=$ parents and $2=$ not parents categories. Therapist Style was dichotomized into $1=$ cognitive-behavioral and $2=$ other categories. Therapist Degree was dichotomized into $1=$ Masters and $2=$ Doctoral Degree categories. Discharge was dichotomized into the variable $1=$ successful and $2=$ unsuccessful categories.

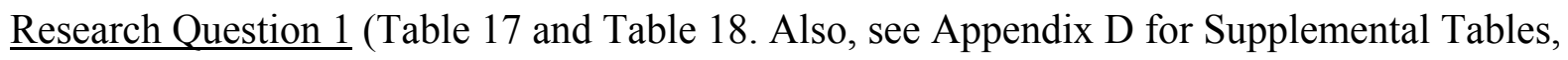
pages 159-167)

How does the age of residents of a Northern Virginia residential treatment facility relate to intake and outcome levels of: (a) depression, (b) internal-external locus of control, (c) state anger, (d) trait anger, (e) angry reaction, (f) anger in (g) anger out, (h) anger control, (i) anger expression, and (j) progression score through treatment levels?

Table 17 (Compressed Table Summary, page 82) addresses the Locus of Control Scale for Children (LOC) and reveals that from intake to discharge students LOC shifts from an external style, where they typically blamed others for their misbehavior to an internal LOC and possibly began taking more responsibility for their own behaviors.

Table 17 (Compressed Table Summary, page 82) reports that the 13-year-old age group moved from, at intake, a score of 16.1 LOC to an 11.8 LOC score at discharge. Likewise, the 14year-old age group moved from a 13.3 LOC score to an $11.6 \mathrm{LOC}$ score at discharge. 
Table 17 (Compressed Table Summary)

Age Related To Intake \& Discharge Psychometric Scores for Research Question 1

Internal-External Locus Of Control for students who had data for both LOC1 (intake) and LOC3 (discharge)

\begin{tabular}{cclccc}
\hline M Age & $\underline{\mathrm{N}}$ & $\underline{\text { M LOC1 (Intake) }}$ & SD & $\underline{\text { M LOC3 (Discharge) }}$ & SD \\
\hline 13.6 & 6 & 16.1 & 5.0 & 11.8 & 6.0 \\
14.1 & 3 & 13.3 & 6.0 & 11.6 & 2.0 \\
15.4 & 3 & 13.3 & 3.0 & 9.7 & 6.0 \\
16.5 & 4 & 13.0 & 5.0 & 10.3 & 5.0 \\
$* 18.0$ & 1 & 21 & & 6 & \\
\hline
\end{tabular}

${ }^{1}$ Note: * The standard deviation scores were omitted for the 18 year old because such analysis was prohibited given the presence of only one score. 
The 15-year-old age group moved from a $13.3 \mathrm{LOC}$ score at intake to a $9.7 \mathrm{LOC}$ score at discharge, and finally the 16-year-old age group moved from a 13.0 LOC score at intake to a 10.3 LOC score at discharge. Higher LOC scores indicate a higher levels of external control; whereas, lower LOC scores indicate more of an internal locus of control.

Additionally, Table 17, Part a: (Appendix D: Supplemental Tables, page 159) reports the Beck Depression Inventory (BDI), which is sensitive to situational depression. Intuitively, it makes sense that younger students have higher BDI scores at intake since they are often homesick and have yet to adjust to their environment. Older students tend to have higher rates of depression at discharge because, often times, these students do not always know to where they will be discharged and often feel an increase in stress related to leaving the facility; as compared to younger students, who almost always have a sense of where they are to be discharged.

Percentiles scores are reported for students who had data for both the State-Trait Anger Expression Inventory (STAXI) at intake and a STAXI at discharge in Table 17, part c:

(Appendix D: Supplemental Tables, page 161). It is important to note that scaled scores, for the STAXI, that fall between the $25^{\text {th }}$ and $75^{\text {th }}$ percentile are considered within the normal range. Furthermore, it should be noted that Spielberger (1991) reports that individuals high in trait anger experience state anger more often, which coincides with the current results. Table 17, Part d:, of the Supplemental Tables found in Appendix D, page 162, reports that the 16.4 year-old at discharge scores at the $60^{\text {th }}$ percentile for trait anger but also scores at the $95^{\text {th }}$ percentile for state anger at discharge. Spielberger (1991) distinguished state anger from trait anger, by indicating that trait anger is the disposition to perceive many situations as frustrating or annoying and to respond in those situations with state anger. Thus, the two constructs are related: persons high in trait anger will experience more frequent state anger. 
In addition, Table 17 Part d:, page 162, reports percentile scores for the Trait subscale for students who had data for both the STAXI at intake and STAXI at discharge. This table reveals that the 13.2 and the 15.0 year old students both decline from intake to discharge, from $39^{\text {th }}$ percentile to $26^{\text {th }}$ percentile for the 13.2 year old, and $54^{\text {th }}$ percentile to $19^{\text {th }}$ percentile for the 15.0 year old. However, it should also be noted that for the second 15.7 year old and the 16.4 year old, their Trait Anger scores at intake are 10 and 26, respectively. Spielberger (1991) suggests that those individuals who score below the $25^{\text {th }}$ percentile may be providing some information into their personality dynamics. For example, low scores generally experience or express very little anger, and have a strong tendency to suppress anger.

For the first 15.7 year old listed in the table his score on the Trait Anger subscale at intake is at the $1^{\text {st }}$ percentile, for Anger In his subscore is at the $18^{\text {th }}$ percentile, and for Anger Out his subscore is at the $15^{\text {th }}$ percentile, which according to Spielberger (1991) could indicate excessive use of denial and repression to protect the individual from experiencing any unwanted angry feelings, due to the extremely low percentile score (below $25^{\text {th }}$ percentile).

Table 17 part $\mathrm{h}$ Supplemental Tables, 166, also reports that the 16.4 year old increased in all areas of anger except Anger Control (Table 17: Supplemental tables Part h), an area in which he declined from the clinical significance level $\left(88^{\text {th }}\right.$ percentile) to the $57^{\text {th }}$ percentile. Additionally, the 13.2 year old decreased from the $39^{\text {th }}$ percentile for Trait Anger (Table 17: Supplemental Tables Part d, page 162) to the $26^{\text {th }}$ percentile at discharge. He further decline from the $35^{\text {th }}$ percentile for Anger In (Table 17: Supplemental Tables Part f, page, 164) at intake to the $26^{\text {th }}$ percentile at discharge.

Most impressively, the 13.2 year old decline from the $91^{\text {st }}$ percentile for Anger Out (Table 17: Supplemental Tables Part g, page 165) at intake to the $63^{\text {rd }}$ percentile, which is no 
longer in the clinically significant range. Likewise, he declined from the $86^{\text {th }}$ percentile (clinically significant) for Anger Control (Table 17: Supplemental Tables Part h, page 166) at intake to the $34^{\text {th }}$ percentile at discharge. Similarly, the 15 year old declined from the clinically significant to clinically non-significant range on State (Table 17: Supplemental Tables Part c, page 161), Trait (Table 17: Supplemental Tables Part d, page 162), Angry Reaction (Table 17: Supplemental Tables Part e, page 163), Anger In (Table 17: Supplemental Tables Part f, page 164), Anger Out (Table 17: Supplemental Tables Part g, page 165), and Angry Expression (Table 17: Supplemental Tables Part i, page, 167) categories.

Table 18 (page 86) reports significant correlations between; MACI subscales and the progression score for Level 3, with Age. The overall $\underline{n}$ was 120, but because of missing data in all student records, the $\underline{n}$ for subscales disclosure, doleful, submissive, unruly, forceful, conforming, oppositional, and impulsive propensity was 74 . Likewise, the MACI subscale unruly, forceful, impulsive propensity at discharge, all reported an $\underline{\underline{n}}$ of 31 .

A negative correlation was found between age and the MACI subscale disclosure $(r=-$ $.23)$ at intake. It appears that younger students tend to report higher scores on the disclosure subscale. Typically high scorers tend to over report problems and symptoms, they are more reactive, symptomatic, and sensitive. They are an open book of emotions and problems. Older students are the opposite; they are quite possibly denying and covering up or withholding information about themselves. 
Table 18

Significant Correlations of Clinical Psychopathology measured by the Millon Adolescent Clinical Inventory and Progression Score for Level 3 with Age (Research Question 1)

\begin{tabular}{|c|c|c|c|c|}
\hline Variable & Psychometric Measure & Correlation & $\mathrm{p}<$ & $\mathrm{n}$ \\
\hline Age & Disclosure (intake) & -.23 & $<.05$ & 74 \\
\hline Age & Doleful (intake) & -.24 & $<.05$ & 74 \\
\hline Age & Submissive (intake) & .32 & $<.01$ & 74 \\
\hline Age & Unruly (intake) & -.34 & $<.01$ & 74 \\
\hline Age & Unruly (discharge) & -.36 & $<.05$ & 31 \\
\hline Age & Forceful (intake) & -.31 & $<.01$ & 74 \\
\hline Age & Forceful (discharge) & -.38 & $<.05$ & 31 \\
\hline Age & Conforming (intake) & .38 & $<.01$ & 74 \\
\hline Age & Oppositional (intake) & -.28 & $<.01$ & 74 \\
\hline Age & Impulsive Propen (intake) & -.28 & $<.01$ & 74 \\
\hline Age & Impulsive Prop (discharge) & -.42 & $<.01$ & 31 \\
\hline Age & Progression Score for Level 3 & -.18 & $<.01$ & 120 \\
\hline
\end{tabular}

${ }^{1}$ It should be noted that (a) There were no significant correlations of depression variable (Beck Depression Inventory) with age (all $\mathrm{p}>.05$ ); (b) There were no significant correlations of Locus of Control with Age (all p > .05); (c) there were no significant correlations of State Anger with Age (all $\mathrm{p}>.05)$; and (d) there were no significant correlations of Trait Anger with Age (all $\mathrm{p}>$ .05 ) 
It is possible that the older students are censoring more information and disclosing less. In essence, as students' age increases, their willingness to self-disclose or to admit typical personal shortcomings quite possibly decreases; while the younger students are less defensive in revealing sensitive aspects of themselves.

In addition, a positive relationship was found between age and the MACI subscale submissive at intake $(\mathrm{r}=.32)$ as well as between age and the MACI subscale conforming at intake $(\mathrm{r}=.38)$. It is possible that submissive/conforming students tend to be overly compliant with both the rules of the facility as well as with the adults that run the facility. This overly conforming attitude is maintained, quite possibly, not because of self-actualization or growth, but rather it may be a manifestation of insecurity, fear reprimands, rejection, and/or embarrassment for making mistakes.

Table 18 (page 86) also reported a negative correlation between age and the MACI subscale forceful at intake $(r=-.31)$ and $r=-.38$ at discharge. It is possible that this correlation reflected movement through the treatment program. As students' progresses through the treatment program, they are less likely to use acting out behaviors as a means to coerce others. However, frequently when students first enter the program they are more likely to believe that they can control others' behavior through force. This is possibly a trait learned through their intimate primary group.

A negative correlation was found between age and the MACI subscale impulsive propensity $(\mathrm{r}=-.28)$ at intake. It is possible that older students are less impulsive; whereas, younger students tended to be more impulsive at intake. Moreover, a negative correlation was also for between age and impulsive propensity $(r=-.42)$ at discharge. Again, older students tend to display less impulsive tendencies. This correlation tends to be somewhat stronger at discharge 
$(r=-.42)$ than at intake $(r=-.28)$; therefore, this effect might be greater than mere maturation, but an effect of the treatment program, in which one of the goals of the program is for students to learn delayed gratification. Older students spend more time thinking before acting.

Table 18 (page 86) also reports a negative correlation between age and the progression score for Level $3(\mathrm{r}=-.18)$. It is possible that younger students spend a greater period of time mastering Level 3 tasks. Also a correlation was noted between age and unruly $(\mathrm{r}=-.36)$ at discharge. It appears that as students become older they tend to spend less time on mastering tasks, and less time on being unruly and disobeying rules.

Research Question 2 (Table 19, page 89)

What relationship exists between intake demographic variables: (a) age, (b) grade, (c) number of siblings, (d) verbal IQ, (e) performance IQ, (f) full scale IQ, (g) discharge GPA, (h) substance abuse history, (i) ethnicity, (j) religious denomination, (k) parents' marital status, and (1) legal guardian with outcome variables: (a) number of AWOL's, (b) weeks at Level 1, (c) weeks at Level 2, (d) weeks at Level 3, (e) weeks at Level 4, (f) progression score for Level 1, (g) progression score for Level 2, (h) progression score for Level 3, (i) progression score for Level 4, (j) Type 1 Restriction, (k) Type 2 Restriction, (l) Type 3 Restriction, (m) discharge GPA, (n) broad reading discharge, (o) broad math discharge, (p) broad writing discharge, (q) broad knowledge discharge, (r) skills discharge, and (s) discharge criteria?

Table 19 (page 89) reports correlations between intake demographic variables and outcome variables designed to measure progress through treatment and academic achievement at discharge for adolescents in residential treatment. All of the relationships reported in Table 19 are significant at the $p<.05$ or $p<.01$ level. 
Table 19

Significant $(p<.05)$ Correlations of Demographic Variables with Outcome Variables Designed to Measure Progress Through Treatment and Academic Achievement at Discharge for Adolescents in Residential Treatment.

\begin{tabular}{|c|c|c|c|c|}
\hline $\begin{array}{l}\text { Intake Demographic } \\
\text { Variables }\end{array}$ & $\mathrm{N}$ & $\begin{array}{l}\text { Outcome } \\
\text { Variables }\end{array}$ & Correlation & $\mathrm{p}<$ \\
\hline No. of Siblings & 36 & AWOLs (temporary) & .42 & $<.01$ \\
\hline Age & 81 & Weeks@level 3 & -.32 & $<.01$ \\
\hline Race & 81 & Weeks@ level 3 & .23 & $<.05$ \\
\hline Age & 81 & Progression Score for level 3 & -.32 & $<.01$ \\
\hline Race & 81 & Progression Score for level 3 & .23 & $<.05$ \\
\hline Age & 96 & \# of Type 2 Restrictions & -.28 & $<.01$ \\
\hline Grade & 96 & \# of Type 2 Restrictions & -.25 & $<.01$ \\
\hline Age & 90 & \# of Type 3 Restrictions & -.33 & $<.01$ \\
\hline Grade & 90 & \# of Type 3 Restrictions & -.34 & $<.01$ \\
\hline Verbal IQ & 85 & Discharge GPA & .27 & $<.01$ \\
\hline Full Scale IQ & 88 & Discharge GPA & .25 & $<.01$ \\
\hline Grade & 72 & W-J Reading@Discharge & .25 & $<.05$ \\
\hline Verbal IQ & 56 & W-J Reading@Discharge & .60 & $<.01$ \\
\hline Performance IQ & 56 & W-J Reading@Discharge & .34 & $<.01$ \\
\hline Full Scale IQ & 59 & W-J Reading@Discharge & .62 & $<.01$ \\
\hline Race & 72 & W-J Reading@Discharge & .26 & $<.05$ \\
\hline Grade & 73 & W-J Math@ Discharge & .30 & $<.01$ \\
\hline No. of Siblings & 63 & W-J Math@Discharge & -.25 & $<.05$ \\
\hline Verbal IQ & 57 & W-J Math@Discharge & .69 & $<.01$ \\
\hline Performance IQ & 57 & W-J Math@Discharge & .29 & $<.05$ \\
\hline Full Scale IQ & 60 & W-J Math@Discharge & .65 & $<.01$ \\
\hline Age & 73 & W-J Writing@Discharge & .24 & $<.05$ \\
\hline Grade & 73 & W-J Writing@Discharge & .37 & $<.01$ \\
\hline Verbal IQ & 57 & W-J Writing@ Discharge & .41 & $<.01$ \\
\hline Full Scale IQ & 60 & W-J Writing@Discharge & .47 & $<.01$ \\
\hline Race & 73 & W-J Writing@ Discharge & .27 & $<.05$ \\
\hline Grade & 73 & W-J Knowledge@Discharge & .22 & $<.05$ \\
\hline Verbal IQ & 57 & W-J Knowledge@Discharge & .66 & $<.01$ \\
\hline Full Scale IQ & 60 & W-J Knowledge@Discharge & .56 & $<.01$ \\
\hline No. of Siblings & 60 & W-J Skills@Discharge & -.29 & $<.05$ \\
\hline Verbal IQ & 54 & W-J Skills@Discharge & .61 & $<.01$ \\
\hline Full Scale IQ & 57 & W-J Skills@Discharge & .51 & $<.01$ \\
\hline Grade & 74 & Discharge, Success of & -.38 & $<.01$ \\
\hline
\end{tabular}

Note: Table organized by outcome variables. 
In this table, it maybe noted that the variable, number of siblings, was positively correlated with the variable temporary absence without leave (AWOLs) $(\mathrm{r}=.42)$. In addition, several negative correlations are reported in Table 19 (page 89) as well. The variable, number of siblings, was negatively correlated with the Woodcock-Johnson discharge scores for both math $(r=-.25)$ and skills $(r=-.29)$ at discharge. It is difficult to determine what contributed to the relationship between the intake variable number of siblings and the outcome variables AWOLs and the discharge scores for Woodcock-Johnson subscales math and skills is relationship.

Of interest in Table 19 is the intake variable, age, which was negatively correlated with weeks at Level $3(r=-.32)$, Progression Score for Level $3(r=-.32)$, number of Type 2 Restrictions $(r=-.28)$, and the number of Type 3 Restrictions $(r=-.33)$. Each of these relationships could be interpreted as, as students become older they are more likely to spend less time on Level 3, progress faster through Level 3, and receive fewer Type 2 Restrictions. It is possible that younger residents could be spending greater periods of time mastering Level 3 tasks; which also will affect the amount of time that it takes those residents to progress through the levels of the program. These findings coincide with the programs expectations. As residents reach higher levels the program demands, "nearly complete compliance" or " $100 \%$ " compliance with rules and expectations.

Age was also positively correlated with the Woodcock-Johnson discharge scores for writing $(r=.24)$. Race was positively correlated with weeks at level $3(r=.23)$, Progression Score for Level $3(\mathrm{r}=.23)$, and discharge scores of the Woodcock-Johnson for both reading $(\mathrm{r}=$ $.26)$ and writing $(r=.27)$ at discharge. It is also difficult to interpret these relationships, since the intake demographic variable Race were observed and categorically changed to dichotomous (dummy coded) variables. The demographic variables Race became: $1=$ not Caucasian and $2=$ 
Caucasian. As a result of dichotomizing variables, the researcher ran the risk of decreasing the variance; which could contribute to the correlations found, thus limiting the understanding of each individual.

In addition, intake variable grade level was positively correlated with the WoodcockJohnson reading $(\mathrm{r}=.25)$, math $(\mathrm{r}=.30)$, writing $(\mathrm{r}=.37)$, and knowledge $(\mathrm{r}=.22)$ scores at discharge. Grade level was negatively correlated with the number of Type 2 Restrictions $(r=-$ $.25)$, Type 3 Restriction $(r=-.34)$, and discharge planning $(r=-.38)$; which could be interpreted as the higher the grade, the less infractions the student receives.

Furthermore, one would expect to see high positive correlations between achievement assessments and IQ. Therefore, verbal IQ was positively correlated with discharge scores of the Woodcock-Johnson for reading $(\mathrm{r}=.60)$, math $(\mathrm{r}=.69)$, writing $(\mathrm{r}=.41)$, knowledge $(\mathrm{r}=.66)$, and skills $(\mathrm{r}=.61)$. Full Scale IQ was positively correlated with discharge scores of the Woodcock-Johnson for reading $(\mathrm{r}=.62)$, math $(\mathrm{r}=.65)$, writing $(\mathrm{r}=.47)$, knowledge $(\mathrm{r}=.56)$, and skills $(\mathrm{r}=.51)$. Performance IQ was positively correlated with the discharge scores of the Woodcock-Johnson for reading $(\mathrm{r}=.34)$ and math $(\mathrm{r}=.29)$. In addition, the researcher also expected to observe positive correlations between GPA and IQ scores. Not surprising, verbal IQ was positively correlated with discharge GPA $(\mathrm{r}=.25)$ and full scale IQ was positively correlated with discharge GPA $(r=.27)$

$\underline{\text { Research Question } 3}$ (Table 20, page 93-95)

What relationship exists between intake psychometric measures: (a) disclosure (MACI), (b) desirability (MACI), (c) debasement (MACI), (d) introversion (MACI), (e) inhibited (MACI), (f) doleful (MACI), (g) submissive (MACI), (h) dramatizing (MACI), (i) egotistic (MACI), (j) unruly (MACI), (k) forceful (MACI), (l) conforming (MACI), (m) oppositional 
(MACI), (n) self-demeaning (MACI), (o) borderline (MACI), (p) identity diffusion (MACI), (q) self-devaluation (MACI), (r) body disapproval (MACI), (s) sexual discomfort (MACI), (t) peer insecurity (MACI), (u) social insensitivity (MACI), (v) family discord (MACI), (w) childhood abuse (MACI), (x) eating dysfunction (MACI), (y) substance abuse proneness (MACI), (z) delinquent predisposition (MACI), (aa) impulsive propensity (MACI), (bb) anxious feelings (MACI), (cc) depressive affect (MACI), (dd) suicidal tendency (MACI), (ee) depression (BDI), (ff) internal-external locus of control (LOC), (gg) state anger (STAXI), (hh) trait anger (STAXI), (ii) angry reaction (STAXI), (jj) anger in (STAXI), (kk) anger out (STAXI), (11) anger control (STAXI), (mm) anger expression (STAXI), (nn) broad reading time 1, (oo) broad math time 1, (pp) broad writing time 1, (qq) broad knowledge time 1, and (rr) skills time 1; with outcome variables: (a) number of AWOL's, (b) weeks at Level 1, (c) weeks at Level 2, (d) weeks at Level 3, (e) weeks at Level 4, (f) Progression Score for Level 1, (g) Progression Score for Level 2, (h) Progression Score for Level 3, (i) Progression Score for Level 4, (j) Type 1 Restriction, (k) Type 2 Restriction, (1) Type 3 Restriction, (m) discharge GPA, (n) broad reading discharge, (o) broad math discharge, (p) broad writing discharge, (q) broad knowledge discharge, (r) skills discharge, and (s) discharge?

Table 20 (pages 93-95) reports correlations between intake psychometric measures and outcome variables designed to measure progress through treatment and academic achievement at discharge for adolescents in residential treatment. All of the relationships reported in Table 20 are significant at the $p<.05$ or $p<.01$ level. In this table, it maybe noted that state anger (STAXI) was found to positively correlate with weeks at Level $3(\mathrm{r}=.57)$. State anger (STAXI) was also found to positively correlate with the Progression Score for Level $3(r=.57)$. 
Table 20

Significant $(p<.05)$ Correlations of Psychometric Measures with Outcome Variables Designed to Measure Progress Through Treatment and Academic Achievement at Discharge for Adolescents in Residential Treatment

\begin{tabular}{|c|c|c|c|}
\hline $\begin{array}{l}\text { Intake Psychometric } \\
\text { Variables }\end{array}$ & $\begin{array}{l}\text { Outcome } \\
\text { Variables }\end{array}$ & Correlation & $\mathrm{p}<$ \\
\hline$\overline{\text { Sexual Discomfort (MACI) }}$ & Weeks@Level 1 & .30 & $<.01$ \\
\hline Desirability (MACI) & Weeks@Level 2 & -.29 & $<.05$ \\
\hline Borderline (MACI) & Weeks@Level 2 & .24 & $<.05$ \\
\hline Identity Diffusion (MACI) & Weeks@Level 2 & .28 & $<.05$ \\
\hline Broad Writing Time $1(\mathrm{~W}-\mathrm{J}$ ACH) & Weeks@Level 2 & -.22 & $<.05$ \\
\hline Desirability (MACI) & Weeks@Level 3 & -.29 & $<.05$ \\
\hline Borderline (MACI) & Weeks@Level 3 & .30 & $<.05$ \\
\hline State Anger (STAXI) & Weeks@Level 3 & .57 & $<.01$ \\
\hline Anger Out (STAXI) & Weeks@Level 3 & .49 & $<.05$ \\
\hline Broad Knowledge Discharge(W-J) & Weeks@Level 3 & .26 & $<.05$ \\
\hline Sexual Discomfort (MACI) & Level 1 Progression Score & .30 & $<.01$ \\
\hline Desirability (MACI) & Level 2 Progression Score & -.29 & $<.05$ \\
\hline Borderline (MACI) & Level 2 Progression Score & .24 & $<.05$ \\
\hline Identity Diffusion (MACI) & Level 2 Progression Score & .28 & $<.05$ \\
\hline Broad Writing Time $1(\mathrm{~W}-\mathrm{J}$ ACH) & Level 2 Progression Score & -.22 & $<.05$ \\
\hline Desirability (MACI) & Level 3 Progression Score & -.29 & $<.05$ \\
\hline Borderline (MACI) & Level 3 Progression Score & .30 & $<.05$ \\
\hline State Anger (STAXI) & Level 3 Progression Score & .57 & $<.01$ \\
\hline Anger Out (STAXI) & Level 3 Progression Score & .49 & $<.05$ \\
\hline Broad Knowledge Time 1(W-J) & Level 3 Progression Score & .26 & $<.05$ \\
\hline Debasement (MACI) & Type 1 Restriction & .61 & $<.01$ \\
\hline Borderline (MACI) & Type 1 Restriction & .48 & $<.05$ \\
\hline Identity Diffusion (MACI) & Type 1 Restriction & .60 & $<.01$ \\
\hline Sexual Discomfort (MACI) & Type 1 Restriction & -.46 & $<.05$ \\
\hline Eating Dysfunction (MACI) & Type 1 Restriction & .58 & $<.01$ \\
\hline Suicidal Tendencies (MACI) & Type 1 Restriction & .52 & $<.05$ \\
\hline Disclosure (MACI) & Type 2 Restriction & .39 & $<.01$ \\
\hline Desirability (MACI) & Type 2 Restriction & -.43 & $<.01$ \\
\hline Debasement (MACI) & Type 2 Restriction & .30 & $<.01$ \\
\hline Doleful (MACI) & Type 2 Restriction & .27 & $<.05$ \\
\hline Submissive (MACI) & Type 2 Restriction & -.40 & $<.01$ \\
\hline Dramatizing (MACI) & Type 2 Restriction & -.31 & $<.01$ \\
\hline Egotistic (MACI) & Type 2 Restriction & -.31 & $<.01$ \\
\hline Forceful (MACI) & Type 2 Restriction & .43 & $<.01$ \\
\hline Conforming (MACI) & Type 2 Restriction & -.48 & $<.01$ \\
\hline Oppositional (MACI) & Type 2 Restriction & .30 & $<.01$ \\
\hline Borderline (MACI) & Type 2 Restriction & $\begin{array}{l}.31 \\
\text { tabl }\end{array}$ & $\begin{array}{c}<.01 \\
\text { ontinue }\end{array}$ \\
\hline
\end{tabular}


Table 20 (continued)

\begin{tabular}{|c|c|c|c|}
\hline $\begin{array}{l}\text { Intake Psychometric } \\
\text { Variables }\end{array}$ & $\begin{array}{l}\text { Outcome } \\
\text { Variables }\end{array}$ & Correlation & $\mathrm{p}<$ \\
\hline Identity Diffusion (MACI) & Type 2 Restriction & .37 & $<<.01$ \\
\hline Self-Devaluation (MACI) & Type 2 Restriction & .34 & $<.01$ \\
\hline Body Disapproval (MACI) & Type 2 Restriction & .32 & $<.01$ \\
\hline Sexual Discomfort (MACI) & Type 2 Restriction & -.27 & $<.05$ \\
\hline Child Abuse (MACI) & Type 2 Restriction & .27 & $<.05$ \\
\hline Eating Dysfunction (MACI) & Type 2 Restriction & .29 & $<.05$ \\
\hline Substance Abuse Proneness (MACI) & Type 2 Restriction & .24 & $<.05$ \\
\hline Anxious Feelings (MACI) & Type 2 Restriction & -.27 & $<.05$ \\
\hline Depressive Affect (MACI) & Type 2 Restriction & .33 & $<.01$ \\
\hline Suicidal Tendencies (MACI) & Type 2 Restriction & .35 & $<.01$ \\
\hline Broad Writing Time 1 (W-J ACH) & Type 2 Restriction & -.22 & $<.05$ \\
\hline Disclosure (MACI) & Type 3 Restriction & .31 & $<.05$ \\
\hline Desirability (MACI) & Type 3 Restriction & -.47 & $<.01$ \\
\hline Debasement (MACI) & Type 3 Restriction & .29 & $<.05$ \\
\hline Introversive (MACI) & Type 3 Restriction & .38 & $<.01$ \\
\hline Doleful (MACI) & Type 3 Restriction & .27 & $<.05$ \\
\hline Dramatizing (MACI) & Type 3 Restriction & -.39 & $<.01$ \\
\hline Egotistic (MACI) & Type 3 Restriction & -.36 & $<.01$ \\
\hline Conforming (MACI) & Type 3 Restriction & -.31 & $<.05$ \\
\hline Borderline (MACI) & Type 3 Restriction & .32 & $<.01$ \\
\hline Identity Diffusion (MACI) & Type 3 Restriction & .36 & $<.01$ \\
\hline Self-Devaluation (MACI) & Type 3 Restriction & .29 & $<.05$ \\
\hline Peer Insecurity (MACI) & Type 3 Restriction & .37 & $<.01$ \\
\hline Depressive Affect (MACI) & Type 3 Restriction & 27 & $<.05$ \\
\hline Self-Devaluation (MACI) & Discharge GPA & -.24 & $<.05$ \\
\hline Anger In (STAXI) & Discharge GPA & .47 & $<.05$ \\
\hline Anger Control (STAXI) & Discharge GPA & .48 & $<.05$ \\
\hline Broad Math Time 1(W-J ACH) & Discharge GPA & .28 & $<.01$ \\
\hline Skills Time 1(W-J ACH) & Discharge GPA & .24 & $<.05$ \\
\hline Peer Insecurity (MACI) & Broad Reading Discharge & .32 & $<.05$ \\
\hline Locus of Control (LOC) & Broad Reading Discharge & -.29 & $<.05$ \\
\hline Broad Reading Time 1 (W-J ACH) & Broad Reading Discharge & .76 & $<.01$ \\
\hline Broad Math Time 1 (W-J ACH) & Broad Reading Discharge & .55 & $<.01$ \\
\hline Broad Writing Time 1 (W-J ACH) & Broad Reading Discharge & .54 & $<.01$ \\
\hline Broad Knowledge Time 1(W-J) & Broad Reading Discharge & .34 & $<.01$ \\
\hline Disclosure (MACI) & Broad Math Discharge & -.33 & $<.05$ \\
\hline Debasement (MACI) & Broad Math Discharge & -.34 & $<.05$ \\
\hline Egotistic (MACI) & Broad Math Discharge & .30 & $<.05$ \\
\hline Oppositional (MACI) & Broad Math Discharge & -.35 & $<.05$ \\
\hline Self-Demeaning (MACI) & Broad Math Discharge & -.41 & $<.01$ \\
\hline Self-Devaluation (MACI) & Broad Math Discharge & -.34 & $<.05$ \\
\hline
\end{tabular}

table continues 
Table 20 (continued)

\begin{tabular}{|c|c|c|c|}
\hline $\begin{array}{l}\text { Intake Psychometric } \\
\text { Variables }\end{array}$ & $\begin{array}{l}\text { Outcome } \\
\text { Variables }\end{array}$ & Correlation & $\mathrm{p}<$ \\
\hline Broad Reading Time 1 (W-J ACH) & Broad Math Discharge & .57 & $<.01$ \\
\hline Broad Math Time $1(\mathrm{~W}-\mathrm{J}$ ACH) & Broad Math Discharge & .78 & $<.01$ \\
\hline Broad Writing Time 1(W-J ACH) & Broad Math Discharge & .48 & $<.01$ \\
\hline Skills Time $1(\mathrm{~W}-\mathrm{J}$ ACH $)$ & Broad Math Discharge & .66 & $<.01$ \\
\hline Broad Reading Time 1 (W-J ACH) & Broad Writing Discharge & .60 & $<.01$ \\
\hline Broad Math Time $1(\mathrm{~W}-\mathrm{J}$ ACH) & Broad Writing Discharge & .51 & $<.01$ \\
\hline Broad Writing Time 1(W-J ACH) & Broad Writing Discharge & .50 & $<.01$ \\
\hline Broad Knowledge Time 1(W-J) & Broad Writing Discharge & 43 & $<.01$ \\
\hline Skills Time $1(\mathrm{~W}-\mathrm{J}$ ACH $)$ & Broad Writing Discharge & .76 & $<.01$ \\
\hline Locus of Control (LOC) & Broad Knowledge Discharge & -.31 & $<.05$ \\
\hline Broad Reading Time 1 (W-J ACH) & Broad Knowledge Discharge & .61 & $<.01$ \\
\hline Broad Math Time $1(\mathrm{~W}-\mathrm{J}$ ACH $)$ & Broad Knowledge Discharge & .56 & $<.01$ \\
\hline Broad Writing Time 1(W-J ACH) & Broad Knowledge Discharge & .48 & $<.01$ \\
\hline Broad Knowledge Time 1(W-J) & Broad Knowledge Discharge & .57 & $<.01$ \\
\hline Skills Time 1(W-J ACH) & Broad Knowledge Discharge & .66 & $<.01$ \\
\hline Dramatizing (MACI) & Skills Discharge & .32 & $<.05$ \\
\hline Egotistic (MACI) & Skills Discharge & .31 & $<.05$ \\
\hline Eating Dysfunction (MACI) & Skills Discharge & -.31 & $<.05$ \\
\hline Broad Reading Time 1 (W-J ACH) & Skills Discharge & .69 & $<.01$ \\
\hline Broad Math Time 1(W-J ACH) & Skills Discharge & .64 & $<.01$ \\
\hline Broad Writing Time 1(W-J ACH) & Skills Discharge & .54 & $<.01$ \\
\hline Skills Time 1 (W-J ACH) & Skills Discharge & .81 & $<.01$ \\
\hline Doleful (MACI) & Discharge, Success of & .35 & $<.05$ \\
\hline Angry Reaction (STAXI) & Discharge, Success of & .94 & $<.01$ \\
\hline Broad Writing Time 1 (W-J ACH) & Discharge, Success of & -.27 & $<.05$ \\
\hline Broad Knowledge Time 1 (W-J) & Discharge, Success of & -.24 & $<.05$ \\
\hline
\end{tabular}

Note: Table organized by outcome variables.

${ }^{1}$ It should be noted that a detailed explanation of each of these scale can be found in Appendix B (pages 135-147).

${ }^{2}$ Time 1 refers to intake administration.

${ }^{3}$ Discharge refers to discharge administration. 
Both debasement $(\mathrm{MACI})(\mathrm{r}=.61)$ and identity diffusion $(\mathrm{MACI})(\mathrm{r}=.60)$ revealed a high positive correlation with the outcome variable Type 1 Restriction. Higher debasement scores could indicate high self-criticalness and a generally negative attitude toward oneself. The positive correlation between identity diffusion and Type 1 Restrictions could infer that negative self-attitudes play a role in earning a higher than average number of Type 1 Restrictions. Moreover, eating dysfunction (MACI) was found to correlate with Type 1 Restriction $(\mathrm{r}=.58)$, which is interesting because one would not expect that this subscale would yield any significant findings given the population sampled. The subscale suicidal tendencies (MACI) was found to positively correlate with Type 1 Restriction $(\mathrm{r}=.52)$.

In addition, there is a high positive correlation between the intake psychometric variable angry reaction (MACI) and discharge $(\mathrm{r}=.94)$. It is also difficult to interpret this relationship, since the outcome variable Discharge was observed and categorically changed to dichotomous (dummy coded) variables $(1=$ successful, $2=$ unsuccessful $)$. As a result of dichotomizing variables, the researcher ran the risk of decreasing the variance; which could contribute to the correlations found, thus limiting the understanding of each individual. Despite this qualification, this relationship could indicate that students who had high levels of anger at the time of intake may have trouble successfully completing the residential treatment program.

Several negative correlations were also reported in Table 20 (pages 93-95). A negative correlation was found between the intake variable sexual discomfort (MACI) and the outcome variable, Type 1 Restriction $(r=-.46)$. In addition, a negative correlation was found between the intake variable, desirability (MACI) and Type 2 Restriction $(r=-.43)$. Likewise, a negative correlation was found between the intake variable desirability (MACI), and Type 3 Restriction ( $r$ $=-.47)$. Higher desirability scores could indicate that the student is motivated to present himself 
in a favorable light; therefore since the student is trying to present himself in a favorable light, and not really making significant changes, then it would make sense that he would likely receive a fewer number of both Type 2 and 3 restrictions.

Moreover, a negative correlation was found between intake variable conforming and Type 2 Restrictions $(r=-.48)$. Submissive/conforming teens tend to be overly compliant with rules and adults, not because of self-actualization, but usually because they are insecure, fear reprimands, rejection, and embarrassment for making mistakes. Therefore, they tend not to earn many restrictions.

As expected, the Woodcock-Johnson was found to correlate with itself when comparing intake versus discharge scores, on scales reading $(\mathrm{r}=.76)$, math $(\mathrm{r}=.78)$, writing $(\mathrm{r}=.50)$, and knowledge $(\mathrm{r}=.57)$. The Woodcock-Johnson broad math at intake was also found to positively correlate with the Woodcock-Johnson math $(\mathrm{r}=.78)$ and skills score at intake and discharge, .64 and .66, respectively.

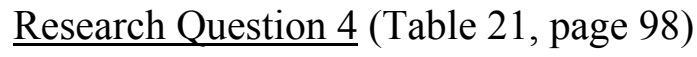

What relationship exists between treatment variables: (a) individual therapy, (b) family therapy, (c) group therapy, (d) therapist's degree, (e) therapist's style, and (f) current medication with outcome variables: (a) number of AWOL's (temporary), (b) weeks at Level 1, (c) weeks at Level 2, (d) weeks at Level 3, (e) weeks at Level 4, (f) Progression Score for Level 1, (g) Progression Score for Level 2, (h) Progression Score for Level 3, (i) Progression Score for Level 4, (j) Type 1 Restriction, (k) Type 2 Restriction, (1) Type 3 Restriction, (m) discharge GPA, (n) broad reading discharge, (o) broad math discharge, (p) broad writing discharge, (q) broad knowledge discharge, ( r) skills discharge, and (s) discharge criteria? 
Table 21

Significant $(p<.05)$ Correlations of Types of Treatment Received with Outcome Variables Designed to Measure Progress Through Treatment and Academic Achievement at Discharge for Adolescents in Residential Treatment

\begin{tabular}{llcc}
\hline Treatment & Outcome & Correlation & $\mathrm{p}<$ \\
Variables & Variables & & \\
\hline Therapist Style & Type 1 Restriction & -.36 & $<.05$ \\
Therapist Style & Discharge GPA & -.20 & $<.05$ \\
& & & \\
\hline
\end{tabular}


Table 21 (page, 98) reports correlations between types of treatment received and outcome variables designed to measure progress through treatment and academic achievement at discharge for adolescents in residential treatment. The correlations reported in Table 21 are significant at the $p<.05$. The independent variable Therapist Style was observed and categorically changed to dichotomous (dummy coded) variables. As a result of dichotomizing variables, the researcher ran the risk of decreasing the variance, thus limiting the understanding of each individual variable.

Despite the above caveat, data was simplified using recoding and data reduction techniques, to agree with the objective of this analytical research which was to determine what variables are related to successful discharge from a residential treatment program for adolescents with behavioral disorders. Therapist Style was dichotomized into $1=$ cognitive-behavioral and 2 $=$ other categories. The results indicated that therapist style is negatively correlated with type 1 restriction $(\mathrm{r}=-.36)$ and discharge GPA $(\mathrm{r}=-.20)$. This relationship could be interpreted as, when noncognitive-behavioral approaches are used with students, the number of Type 1 restriction decreases. However, when cognitive-behavioral are used, discharge GPA increases. 


\section{$\underline{\text { Discussion }}$}

Overall, the results of the current research suggest that those residents who completed the program were more often successfully discharged. These residents, on average, were compliant with the rules of the facility. From the research it appears that students who are successfully discharged from this program are at intake typically: 1) older, 2) less oppositional, 3) engage in less externalizing behaviors, 4) receive fewer type restrictions, and 5) improve achievement scores while at the facility. However, improvement in achievement score could be a product of time spent in a structured program. There is no way of predicting if these gains will continue over time.

The findings of the current research are consistent with research in the field. An extensive review of the literature resulted in several child predictor variables associated with treatment outcome which include: the child's age, sex, race, comorbid issues, history of aggression and juvenile delinquency, poor problem-solving skills, substance use/abuse, the nature of the conduct problems, nature of the referral, and association with delinquent peers (Heimer, 1997; Lahey, Loeber, Hart, Frick, Applegate, Zhang, Green \& Russo, 1995; \& Paetsch \& Bertrand, 1997). McMahon (1994) also reported several predictor variables that have been associated with treatment success. These variables consisted of: (1) the nature of the conduct problems, (2) the age of the adolescent, and (3) their problem solving abilities (McMahon, 1994). Each of these findings further validates the current research.

Earlier studies frequently used child variables taken from intake interview checklists as predictor. What sets the current study apart from other research is the use of well-established psychometric measures in addition to demographic variables as a means to obtain predictor variables. The current study used standardized personality inventories, such as the Millon 
Adolescent Clinical Inventory, the State-Trait Anger Inventory, the Locus of Control Scale for Children, the Beck Depression Inventory for Children, and the Woodcock-Johnson Achievement Test, to generate and measure child predictor variables. A detailed explanation of each of these measures can be found in Chapter 3. Each of these measures has sound reliability; but are not frequently used in residential treatment facilities.

The residential treatment facility reviewed in this study is targeted toward the emotionally disturbed children in the out-of-home system of care. These are children who have failed to respond to any other treatment options and have experienced serious abuse or neglect, multiple failed placements, and school failure. In general, research reveals that the most effective residential programs are highly structured, emphasize the development of basic social skills, and provide individual counseling that directly addresses behavior, attitudes, and perceptions (Chamberlain, 1999). The program understudy met all of the above qualifications. Despite these positive findings, there remained several limitations that impinged on the generalization of results obtained.

\section{Limitations of the Data}

There are limitations of this study that are due to individual methodological problems, while others are inherent to outcome research in residential placement. Limitations of this data set consisted of missing data in all student records. Inevitably, any archival data study will be confronted with practical limitations on the amount and type of data that can be collected. Additional limitations include failure to measure relevant variables such as, missing data.

The results of the present study should be regarded as only an approximate account of the manner in which intake demographic and assessment data, and treatment process variables, relate 
to behavioral outcomes as evidence by changes in discharge assessment and GPA. Despite these obvious limitations, the results of the current study have implications for future research. Future Research

Those residents who completed the program were usually discharged successfully. Premature termination from the program accounted for one out of three of the 120 participants in this study. As a result, a large majority of discharge data was missed due to premature termination of services. Kazdin and Wassell (1998) also reported that a significantly higher percentage of treatment completers improved over those who terminated treatment prematurely.

What can be done to prevent premature termination? Data from the current study shows that students who are successfully discharged are likely at intake to be: 1) older, 2) less oppositional, and 3) engage in less externalizing behaviors. The literature confirms this finding by reporting that several predictors of premature termination of treatment have been identified, such as: history and severity of aggressive, oppositional, and antisocial behavior, and age of the adolescent (Kazdin, Holland \& Crowley, 1997; Kazdin \& Wassell, 1998; \& Kazdin, Siegel \& Bass, 1992).

Mann-Feder (1996) also identified small differences between dropouts and non-dropouts. The amount of familial involvement during placement was the single defining difference between dropouts and non-dropouts. The residents who dropped out of treatment had far less family contact during treatment. Kazdin and Wassell (1998) also reported that the adolescents who terminated treatment early were more likely to originate from families with greater socioeconomic disadvantages, had more difficulty with living circumstances, and showed signs of greater child deviance, as compared to those families of adolescents who completed treatment. 
In the current research, the use of family therapy was difficult to evaluate. Only the families that could get to the treatment facility could receive such services. The program advocated the use of family therapy, but only half of the residents received it. This lack of participation shows how difficult it is to provide treatment in a rural remote area. Even though it is extremely difficult to encourage familial involvement, research conducted on treatment outcome and residential placement strongly suggests the involvement of the family. More important than mere involvement is the amount of contact with the family. The amount of contact a resident has will ultimately affect treatment outcome (Mann-Feder, 1996).

Missing data, premature termination of services, and familial involvement warrant further analysis by researchers and practitioners alike. From the research conducted, it appears that there is a need for qualitative studies, to develop a profile of what type of adolescents with behavioral disorders are the best candidates for future success. Applying empirically validated treatments to the prototypical successfully discharge adolescent will determine which treatment is most efficacious. Subsequently, this treatment can be applied to the more resistant portion of this population. Once a profile has been developed through rigorous empirical research, practical application can begin.

Implication for Practice

The residential treatment program reviewed in this study was effective in focusing on: 1) academic functioning, 2) structuring children's activities and implementing consistent behavior guidelines, 3) enforcing curfews, 4) supervising peer activities that provided extensive recreational events to promote group cooperation and constructive use of leisure time, 5) establishing realistic and clearly communicated consequences for noncompliance, 6) establishing appropriate rewards for desirable behavior, 7) considering pharmacotherapy for children who are 
highly aggressive or impulsive, or both, or those with mood disorders, 8) providing a combination of group and individual therapy, and 9) involving the family of the adolescent in treatment when feasible.

This program was accurate in its estimation of the amount of time that residents would remain on Level 1. However, the results suggested that it took students longer to progress through Levels 2 through 4 than was predicted by the residential treatment program. This discrepancy suggests that program developers significantly underestimated the number of weeks a given resident should expect to remain on a level. An implementation of ongoing program analysis would allow for modifications to the overall behavioral program, thus reducing any discrepancies between performance and expectations.

From the programs description of levels, it can be noted that standards for Level 2 through 4 are more stringent. The program calls for " $100 \%$ " or "nearly complete compliance" with the rules and expectations of the program. One hundred percent compliance increases the amount of time that it will take a given resident to progress through those levels. This could account for the underestimation of progression through Levels 2 through 4.

When conducting archival research, one must come to expect that certain pieces of data are often incomplete. An issue that needs to be addressed is the lack of consistency in the documentation of treatment intervention and significant junctures in treatment. The validity of documentation of information in the patient record is always questionable since information recorded in the chart is biased based on the individual who made the note (Guba \& Lincoln, 1981). To address this problem, periodic reminders to case managers, as well as periodic audits, should be necessary. It is important to maintain the integrity of information obtained in the record, since it may be useful in other areas of program development. 
The range of the number of behavioral infractions received is vast. Due to this range, the overall mean for the sample was raised as well. Ideally, the therapists utilized techniques to modify adolescents' behavior. Therefore, the number of behavioral infractions, such as Type 2 and 3 Restrictions should be incorporated into the treatment program as a criterion for measuring progress in the program, since the number of Type Restrictions received will be a direct manifestation of the adolescents overt behavioral displays. The numbers of behavioral infractions received could be incorporated into the treatment milieu to assess the students' progress. Overall, successfully discharged residents will: 1) grasp the goals of the program, 2) follow the rules, 3) learn delayed gratification, and 4) begin to take responsibility for their own behaviors. 


\section{CHAPTER 5}

\section{Summary}

$\underline{\text { Introduction }}$

The school shootings in the media, such as Columbine, Colorado, Jonesboro, Arkansas, and Santee, California have sparked many researchers' interests to study adolescents with behavioral problems (Garbarino, 1999). Behavioral disorders are the fastest growing disorders of childhood, and account for $2 \%$ to $9 \%$ of all clinic referrals. Childhood behavioral disorders have been found to significantly correlate with later delinquency, criminality, and substance abuse in adolescence and adulthood (Anasari, Gouthro, Ahmad, \& Steele, 1996; Eme \& Kavanaugh, 1995; McMahon \& Wells, 1998).

Adolescents with behavior disorders, who have failed in less restrictive treatment, are placed in residential treatment centers. They clearly constitute a difficult population to treat effectively. Residential treatment for troubled adolescents is expensive, typically assuming a substantial portion of a state's child welfare, mental health and education budgets. Despite high costs, little is known about the effectiveness of residential interventions (Chamberlain, 1999).

Given the use of residential placement and the large amount of Medicaid dollars spent to place adolescents in residential treatment centers, there remains a tremendous need for additional research to examine long-term effectiveness. Chamberlain (1999) cites a need to bridge the gap between research on effectiveness and practical application of empirically validated treatment in residential facilities. Several reviews of residential treatment programs have produced promising findings, but do these studies address what components need to be implemented in residential settings to successfully treat the adolescent with a behavioral disorder?

The increased success of treatment when the family is involved is widely acknowledged 
by therapists. Most therapists are acutely aware of the damage that a family can do to client's therapeutic progress, if the family is not supportive of the treatment goals or are unaware of their impact on the client (Kumpfer, 1999). It is strongly recommended from the literature on residential treatment that the family be involved in the treatment process. The amount of family involvement is also thought to have some bearing on treatment outcome (Mann-Feder, 1996). Whether family therapy should be a necessary component of routine residential treatment remains a controversial issue (Chamberlain, 1999).

The current study conducted an analysis of archival data to assess the contributions of demographic variables, family issues, and peer associations on treatment outcome in a residential treatment setting. Specifically, what demographic characteristics and behavioral disorders, receiving what form of therapeutic intervention, achieve what level of success? The study attempted to answer the following questions:

1. How does the age of residents of a Northern Virginia residential treatment facility, relate to intake and outcome levels of: (a) depression, (b) internal - external locus of control, (c) state anger, (d) trait anger, (e) angry reaction, (f) anger in (g) anger out, (h) anger control and (i) anger expression?

2. What relationship exists among demographic variables: (a) age, (b) grade, (c) number of siblings, (d) verbal IQ, (e) performance IQ, (f) full scale IQ, (g) GPA, (h) substance abuse history, (i) ethnicity, (j) religious denomination, (k) parents marital status, and (1) legal guardianship? How demographic variables related to the following outcome variables: (a) number of AWOL's, (b) weeks at level 1, (c) weeks at level 2, (d) weeks at level 3, (e) weeks at level 4, (f) Progression Score level 1, (g) Progression Score level 2, (h) Progression Score level 3, (i) Progression Score level 4, (j) type 1 restriction, (k) type 2 
restriction, (1) type 3 restriction, (m) current GPA, (n) broad reading discharge, (o) broad math discharge, (p) broad writing discharge, (q) broad knowledge discharge, (r) skills discharge, and (s) discharge criteria?

3. What relationship exists between scales of the Millon Adolescent Clinical Inventory, Beck Depression Inventory, the Locus of Control Scale for children, the State-Trait Anger Expression Inventory, and the Woodcock-Johnson Achievement Test and outcome variables: (a) number of AWOL's, (b) weeks at level 1, (c) weeks at level 2, (d) weeks at level 3, (e) weeks at level 4, (f) Progression Score level 1, (g) Progression Score level 2, (h) Progression Score level 3, (i) Progression Score level 4, (j) type 1 restriction, (k) type 2 restriction, (1) type 3 restriction, (m) current GPA, (n) broad reading discharge, (o) broad math discharge, (p) broad writing discharge, (q) broad knowledge discharge, ( r) skills discharge, and (s) discharge criteria?

4. What relationship exists between the treatment variables of: (a) individual therapy, (b) family therapy, (c) group therapy, (d) therapist's degree, (e) therapist's style, and (f) current medication; and the, outcome variables of: (a) number of AWOL's, (b) weeks at level 1, (c) weeks at level 2, (d) weeks at level 3, (e) weeks at level 4, (f) Progression Score level 1, (g) Progression Score level 2, (h) Progression Score level 3, (i) Progression Score level 4, (j) type 1 restriction, (k) type 2 restriction, (l) type 3 restriction, (m) current GPA, (n) broad reading discharge, (o) broad math discharge, (p) broad writing discharge, (q) broad knowledge discharge, (r) skills discharge, and (s) discharge criteria?

Method

\section{$\underline{\text { Selection of Participants }}$}

The investigator reviewed the records of 120 male adolescents who were admitted to a 
residential treatment facility in Northern Virginia and were served by the facility from January 1999 to January 2001. First, the investigator obtained permission from the Director of the facility to review charts. Secondly, the investigator agreed that none of the charts would be removed from the premises. In addition, permission was obtained from West Virginia University's Institutional Review Board.

The criterion for inclusion in this study was based on residents submitting to some form of psychometric testing, namely, the Beck Depression Inventory (BDI), the Locus of Control Scale for children (LOC), the State-Trait Anger Expression Inventory (STAXI), the Millon Adolescent Clinical Inventory (MACI), and the Woodcock-Johnson Achievement Test (WJ$\mathrm{ACH})$. Participants included adolescents between the ages of 11 to 18.11 and 12 year olds were not systematically administered the clinical measures. The average age of residents at the facility was 15.5 years. Residents represented various racial backgrounds (i.e. white, black, Hispanic, and biracial). Many of the residents came from broken homes, and have not been exposed to structured environments. Approximately $40-50 \%$ of the residents were classified by the facility as behaviorally disordered (BD), and $60 \%$ were classified by the facility as emotionally disordered (ED); some residents met the criteria for more than one disorder.

\section{The Residential Treatment Facility}

The residential treatment facility is located on 126 acres, and is about 20 minutes from the nearest town. At any given time the facility houses $70-80$ residents. The residents were primarily from Virginia; however, there were some residents from West Virginia, Maryland, New Jersey, and Philadelphia.

Adolescents at the facility were referred to the facility by one of three sources: (a) the court, (b) the division of social services, or (c) the school system. Typically, the residents' 
presenting problems were chronic, and often this was the residents' third to fifth placement. Yet, for some residents this may have been the first out-of-home placement.

Therapeutic modalities include weekly individual and group psychotherapy, which was approximately forty sessions per year. Character education groups were another weekly aspect of treatment for all residents. Family therapy was provided to those residents for whom it was feasible for family members to attend. Typically, family therapy was offered once every 4 to 5 weeks to residents. Approximately half of the residents did not receive family therapy.

The facility employs an intensive behavioral management program in which a level system approach is utilized as a measurement of successful completion. Level systems are a multi-level approach in which residents are required to engage in specific behaviors in order to gain privileges. The multi-level system at this facility employs six levels. The more compliant the adolescents are with the rules of the facility, and following through with socially acceptable behaviors, the higher levels they gain.

Measures of the Independent Variable

This study was performed in an ex post facto manner, in which there was very little control over the independent variables. The independent variables in this study are as follows: age, grade, number of siblings, verbal IQ, performance IQ, full scale IQ, GPA, substance abuse history, ethnicity, religious denomination, and parents marital status.

Treatment Characteristics. Treatment variables were additional independent variables. These treatment variables included: whether students received individual, group, and/or family therapy, what orientation was the therapist, what was the degree level of the therapist, and was the resident on any kind of medication, and if so, what type? This aspect of the study was 
designed to be descriptive and shed more light on what characteristics play into successful outcomes.

Measurement of the Dependent Variable

The dependent/outcome variables are overall improvement on behavioral rating scales and they are as follows: number of AWOL's (temporary), weeks at Level 1, weeks at Level 2, weeks at Level 3, weeks at Level 4, Progression Score Level 1, Progression Score Level 2, Progression Score Level 3, Progression Score Level 4, Type 1 Restriction, Type 2 Restriction, Type 3 Restriction, current GPA, broad reading discharge, broad math discharge, broad writing discharge, broad knowledge discharge, skills discharge, and discharge (successful versus not successful). The behavioral rating scales utilized in this study allowed the researcher to determine if the treatment program had an effect on residents' behavioral symptoms, as evidenced by differences between intake and discharge psychometric measures on the following variables: (a) depression, measured by the Beck Depression Inventory; (b) internal/external locus of control, measured by the Locus of Control Scale for children; (c) state anger, (d) trait anger, (e) angry reaction, (f) anger in, (g) anger out, (h) anger control, and (i) angry expression, all measured by the State-Trait Anger Expression Inventory; and (f) clinical psychopathology, measured by the Millon Adolescent Clinical Inventory.

Beck Depression Inventory. The Beck Depression Inventory (BDI-II) is a 21-item selfreport measure. Statements covered on the BDI-II refer to the past two weeks (Beck, et. al, 1996). Beck, Steer, \& Brown (1996) reported the following reliability coefficients for the BDI-II: coefficient alpha ranged between .92 for the outpatient population and .93 for internal consistency. 
Nowicki-Strickland Locus of Control Scale for Children. The Nowicki-Strickland Locus of Control Scale for children (LOC) is a 29-item scale. The LOC scale is used to measure children's perceived level of control over their own lives versus luck or external factors (Nowicki and Strickland, 1973). Test-retest reliability has been reported as being stable and consistent, with internal consistency reliability of .68, sampled at three grade levels: 6,7 , and 8 .

Millon Adolescent Clinical Inventory. The Millon Adolescent Clinical Inventory (MACI) is a 160 -item inventory, 30 -scale. This measure was developed specifically for assessing personality characteristics and clinical syndromes (Millon \& Davis, 1993). The 30-scales of the MACI can be further subdivided into three overall categories: 12 personality patterns scales, eight expressed concern scales, and seven clinical syndrome scales. Procedures were added for correcting various response styles, such as random responding, faking good, or faking bad. Therefore, the final three scales: disclosure, desirability, and debasement are defined as "modifier" scales.

Millon (1993) reports a range of internal consistency reliability coefficient for the 31 scales from .57 to .90 . Test-retest reliability ranged from 0.57 to 0.92 . The correlation between the MACI subscale depressive affect and scores on the Beck Hopelessness scale were both .59 (Millon \& Roger, 1993).

State-Trait Anger Expression Inventory. The State-Trait Anger Expression Inventory (STAXI) is a 44-item self-report inventory. The eight scale scores on the STAXI are as follows: State-Anger, Trait-Anger, Trait-Temperament, Trait-Reaction, Anger-In, Anger-Out, AngerControl, and Anger-Expression. The Trait-Temperament and Trait-Reaction scales consist of two additional subscales of four items from the Trait-Anger scale. Moreover, the Anger-In, Anger- 
Out, and Anger-Control scales consist of three subscales derived from eight items from the Anger-Expression scale (Spielberger, 1988).

The STAXI reports coefficient alphas for the State-Anger and the Trait-Anger that range from .84 to .93 . For the Trait-Temperament scale the reported coefficient alphas range from .84 to .89 . The three anger expression scales reported coefficient alpha that ranges from .73 to .85 (Spielberger, 1988).

Woodcock-Johnson Test of Achievement. The Woodcock-Johnson Test of Achievement (WJ-R) contains two parallel forms containing nine items, each of which measures various aspects of achievement (Woodcock \& Johnson, 1989). The eight areas of cognitive abilities measured in the WJ-R are: long-term retrieval, short-term memory, processing speed, auditory processing, visual processing, comprehension-knowledge, fluid reasoning, and quantitative ability (Woodcock \& Johnson, 1989).

Median reliabilities generally exceed .90 for clusters scores, indicating respectable reliability coefficients for broad cognitive and broad achievement clusters. Concurrent validity studies report correlations in the .60 to .70 range when the WJ-R is compared to other achievement tests. There is adequate concurrent and content, but not construct validity (Woodcock \& Johnson, 1989).

\section{Results}

\section{$\underline{\text { Demographic Characteristics }}$}

The participants were predominantly Caucasian (67\%) and from homes of remarried parents (34\%). Fifty one percent of the sample were involved with family services or were wards of the state. Eighty nine percent of the sample was on some form of psychotropic medications. Fifty four percent of the sample was on probation, and $49 \%$ reported substance abuse. 


\section{Psychometric Characteristics}

Table 2 (pages 70-71) reports intake psychometric scores for residents in residential treatment. For the Millon Clinical Adolescent Inventory (MACI), students' scores tended to reveal higher means for the following subscales: Forceful (71.9), Social Insensitivity (65.1), Family Discord (70.2), Delinquent Predisposition (74.8), and Impulsive Propensity (67.0).

For the Beck Depression Inventory (BDI), mean score in this sample was 13, which is indicative of minimal depressive symptoms. The Locus of Control Scale for Children (LOC) mean score in this sample was 15. The subscale Trait Anger displayed the lowest mean 35, while the subscale Anger Out displayed the largest mean 64.6.The Woodcock-Johnson Achievement Test (WJ-ACH) scores revealed that residents are functioning at the $8^{\text {th }}$ grade level for overall achievement.

\section{Treatment Characteristics}

Table 11 (page 77) reports frequency of treatment received by adolescent clients in residential treatment. All students participated in both individual and group therapy, and 43\% participated in family therapy. Therapists had graduate degrees, and treatment orientation varied with cognitive behavioral being the most common (34\%).

\section{Outcome Characteristics}

Table 16 (page 85) includes means for outcome variables designed to measure progress through treatment and academic achievement at discharge. Of interest in Table 16, are the mean time differences it took residents to complete later levels versus earlier ones. While not evident from Table 16, the achievement scores listed are near expected grade level. Finally, the first three types of discharge can be considered successful, with the remaining unsuccessful. Thus, the successful discharge rate was about $43 \%$. 


\section{$\underline{\text { Zero-order Pearson Product-Moment Correlations }}$}

Multivariate analysis had been planned to allow simultaneous interpretations of effects. Such analyses, however, were not possible because of missing data in all student records. Accordingly, multiple regression analysis is not included because missing data for a single variable in any given multivariate analysis eliminated the entire participant from the computation when using SAS.

Data were simplified using recoding and data reduction techniques. Respondents' race was dichotomized into $1=$ not Caucasian (other) and 2 = Caucasian categories. Respondents' Religion was dichotomized into $1=$ religious affiliation and $2=$ no religious affiliation categories. Parents' Marital Status was dichotomized into $1=$ married and $2=$ not married categories. Respondents' Diagnosis was dichotomized into $1=$ behavioral disordered and $2=$ not behavioral disordered categories. Respondents' Guardian was dichotomized into $1=$ parents and $2=$ not parents categories. Therapist Style was dichotomized into $1=$ cognitive-behavioral and 2 $=$ other categories. Therapist Degree was dichotomized into $1=$ Masters and $2=$ Doctoral Degree categories. Discharge was dichotomized into the variable $1=$ successful and $2=$ unsuccessful categories.


Tables, pages 165-173)

Table 17 (Compressed Table Summary, page 88) addresses the Locus of Control Scale for Children (LOC) and reveals that from intake to discharge students' LOC scores shift from an external style, where they typically blamed others for their misbehavior, to an internal style and possibly began taking more responsibility for their own behaviors. 
Additionally, Table 17 Part a (Appendix D: Supplemental Tables, page 165) shows that younger students have higher BDI scores at intake. Whereas, older students tend to have higher rates of depression at discharge; oftentimes, these students do not know where they are going to be discharged to and feel more stress surrounding leaving. Younger students, however almost always has a sense of where they are to be discharged.

Percentile scores are reported for students who had data for both the State-Trait Anger Expression Inventory (STAXI) at intake and a STAXI at discharge in Table 17 (Appendix D: Supplemental Tables, page 165). Most impressively, the 13.2 year old decline from the $91^{\text {st }}$ percentile for Anger Out (Table 17: Supplemental Tables Part g, page 171) at intake to the $63^{\text {rd }}$ percentile, which is no longer in the clinically significant range. Likewise, he declined from the $86^{\text {th }}$ percentile (clinically significant) for Anger Control (Table 17: Supplemental Tables Part h, page 172) at intake to the $34^{\text {th }}$ percentile at discharge. Similarly, the 15 year old declined from the clinically significant to non-clinically significant range on State, Trait, Angry Reaction, Anger In, Anger Out, and Angry Expression categories.

Table 18 (page 92) reports significant correlations between MACI subscales and the progression score for Level 3, with Age. A negative correlation was found between age and the MACI subscale disclosure $(r=-.23)$ at intake. It appears that younger students tend to achieve higher scores on the disclosure subscale. Older students are the opposite; they are quite possibly denying, covering up, or withholding information about themselves.

Table 18 (page 92) also reports a negative correlation between age and the MACI subscale forceful $(\mathrm{r}=-.31)$ at intake and $(\mathrm{r}=-.38)$ at discharge. It is possible that this correlation reflects movement through the treatment program. As students progresses through the treatment program, they are less likely to try and make others behave the way they want them to. However, 
frequently when students first enter the program they are more likely to believe that they can control others behavior through the use of force.

A negative correlation was found between age and the MACI subscale impulsive propensity $(\mathrm{r}=-.28)$ at intake. It is possible that older students are less impulsive; whereas, younger students tended to be more impulsive at intake. A negative correlation was also found between age and impulsive propensity $(r=-.42)$ at discharge. Older students tend to display less impulsive tendencies. This correlation tends to be somewhat stronger at discharge $(r=-.42)$ than at intake $(\mathrm{r}=-.28)$; therefore, this effect might be greater than mere maturation, but an effect of the treatment program.

Table 18 (page 92) also reports a negative correlation between age and the progression score for Level $3(r=-.18)$. A correlation was also noted between age and unruly $(r=-.36)$ at discharge. As students become older they tend to spend more time on mastering tasks, and less time on being unruly.

Research Question 2 (page 3) (Table 19, page 95)

Table 19 (page 95) reports correlations between intake demographic variables and outcome variables designed to measure progress through treatment and academic achievement at discharge for adolescents in residential treatment. Of interest in Table 19 (page 95) is the intake variable, age, which was negatively correlated with weeks at Level $3(r=-.32)$, Progression Score for Level $3(r=-.32)$, number of Type 2 Restrictions $(r=-.28)$, and the number of Type 3 Restrictions $(\mathrm{r}=-.33)$. Each of these relationships could be interpreted as, as students become older they are more likely to spend less time on Level 3, progress faster through Level 3, and receive less Type 2 Restrictions. 
It is possible that younger residents could be spending greater periods of time mastering Level 3 tasks, which also will affect the amount of time that it takes those residents to progress through the levels of the program. These findings coincide with the programs' expectations. As residents reach higher levels the program demands, "nearly complete compliance" or "100\%" compliance with rules and expectations.

In addition, the researcher also expected to observe positive correlations between GPA and IQ scores. Not surprising, verbal IQ was positively correlated with discharge GPA $(\mathrm{r}=.25)$ and full scale IQ was positively correlated with discharge GPA $(r=.27)$

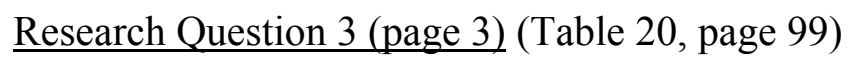

Table 20 (pages 99) reports correlations between intake psychometric measures and outcome variables designed to measure progress through treatment and academic achievement at discharge for adolescents in residential treatment. State anger (STAXI) was also found to positively correlate with the Progression Score for Level $3(\mathrm{r}=.57)$. Both debasement (MACI) (r $=.61)$ and identity diffusion $(\mathrm{MACI})(\mathrm{r}=.60)$ revealed a high positive correlation with the outcome variable Type 1 Restriction. Higher debasement scores could indicate high selfcriticalness and a generally negative attitude toward oneself. The positive correlation between identity diffusion and Type 1 Restrictions could reflect that negative self attitudes plays a role in earning a higher than average number of Type 1 Restrictions.

In addition, there is a high positive correlation between the intake psychometric variable angry reaction $(\mathrm{MACI})$ and discharge $(\mathrm{r}=.94)$. It is also difficult to interpret this relationship, since the outcome variable discharge was categorically changed to dichotomous (dummy coded) variables $(1=$ successful, $2=$ unsuccessful $)$. This relationship could indicate that students who 
had high levels of anger at the time of intake may have trouble successfully completing the residential treatment program.

A correlation was found between the intake variable, desirability (MACI) and Type 2 Restriction $(\mathrm{r}=-.43)$. Likewise, a negative correlation was found between the intake variable desirability $(\mathrm{MACI})$ and Type 3 Restriction $(\mathrm{r}=-.47)$. Higher desirability scores could indicate that the student is motivated to present himself in a favorable light; therefore since the student is trying to present himself in a favorable light, and not really making significant changes, then it would make sense that he would likely receive a greater number of both Type 2 and 3 restrictions.

Moreover, a negative correlation was found between intake variable conforming and Type 2 Restrictions $(r=-.48)$. Submissive/conforming teens tend to be overly compliant with rules and adults, not because of self-actualization, but usually because they are insecure, fear reprimands, rejection, and embarrassment for making mistakes. Therefore, they tend not to earn many restrictions.

Research Question 4 (page 4) (Table 21, page 104)

Table 21 (page, 104) reports correlations between types of treatment received and outcome variables designed to measure progress through treatment and academic achievement at discharge for adolescents in residential centers. Therapist Style was dichotomized into $1=$ cognitive-behavioral and $2=$ other categories. The results indicated that therapist style is negatively correlated with type 1 restriction $(r=-.36)$ and discharge GPA $(r=-.20)$. This relationship could be interpreted as, when noncognitive-behavioral approaches are used with students, the number of Type 1 restrictions decreases. However, when cognitive-behavioral approaches are used, discharge GPA increases. 


\section{$\underline{\text { Discussion }}$}

Overall, the results of the current research suggest that those residents who completed the program were more often successfully discharged. These residents, on average, were compliant with the rules of the facility. From the research it appears that students who are successfully discharged from this program are at intake typically: 1) older, 2) less oppositional, 3) engage in less externalizing behaviors, 4) receive fewer type restrictions, and 5) improve achievement scores while at the facility. However, improvement in achievement scores could be a product of time spent in a structured program. There is no way of predicting if these gains will continue over time.

\section{Limitations of the Data}

Limitations of this data set consisted of missing data in all student records. Inevitably, any archival data study will be confronted with practical limitations on the amount and type of data that can be collected. Additional limitations include failure to measure relevant variables and missing data.

The results of the present study should be regarded as only an approximate account of the manner in which intake demographic and assessment data, and treatment process variables, relate to behavioral outcomes as evidence by changes in discharge assessment and GPA. The data analysis conducted in this study was performed only to allow the researcher to observe patterns in the data. Therefore, it is difficult to determine if the observed differences between variables reflect anything other than mere chance. Despite these obvious limitations, the results of the current study have implications for future research. 


\section{$\underline{\text { Future Research }}$}

Those residents who completed the program were usually discharged successfully. Premature termination from the program accounted for one out of three of the 120 participants in this study. As a result, a large majority of discharge data was missed due to premature termination of services. Kazdin and Wassell (1998) also reported that a significantly higher percentage of treatment completers improved over those who terminated treatment prematurely.

Data from the current study shows that students who are successfully discharged are likely at intake to be: 1) older, 2) less oppositional, and 3) engage in less externalizing behaviors. The literature confirms this finding by reporting that several predictors of premature termination of treatment have been identified, such as: history and severity of aggressive, oppositional, and antisocial behavior, and age of the adolescent (Kazdin, Holland \& Crowley, 1997; Kazdin \& Wassell, 1998; \& Kazdin, Siegel \& Bass, 1992).

Mann-Feder (1996) also identified the amount of familial involvement during placement was the single defining difference between dropouts and non-dropouts. The residents who dropped out of treatment had far less family contact during treatment. Kazdin and Wassell (1998) also reported that the adolescents who terminated treatment early were more likely to originate from families with greater socioeconomic disadvantages, had more difficulty with living circumstances, and showed signs of greater child deviance, as compared to those families of adolescents who completed treatment.

In the current research, the use of family therapy confounded the data. Only the families that could get to the treatment facility could receive such services. The program advocated the use of family therapy, but only half of the residents received it. This lack of participation shows how incredibly difficult it is to provide treatment in a rural remote area. Even though it is 
extremely difficult to encourage familial involvement, research conducted on treatment outcome and residential placement strongly suggests the involvement of the family. More important than mere involvement is the amount of contact with the family. The amount of contact a resident has will ultimately affect treatment outcome (Mann-Feder, 1996).

From the research conducted, it appears that there is a need for qualitative studies, to develop a profile of what type of adolescents with behavioral disorders are the best candidates for future success. Applying empirically validated treatments to the prototypical successfully discharge adolescent will determine which treatment is most efficacious. Subsequently, this treatment can be applied to the more resistant portion of this population. Once a profile has been developed through rigorous empirical research, practical application can begin. 


\section{References}

Ansari, A. A. , Gouthro, S. , Ahmad, K. , \& Steele, C. (1996) Hospital-Based behavior modification program for adolescents: Evaluation and predictors of outcome. Adolescence, 31, 469-476.

Atkins, M. S. , McKay, M. M. , Talbott, E. , \& Arvanitis, P. (1996). DSM-IV diagnosis of conduct disorder and oppositional defiant disorder: Implications and guidelines for school mental health teams. School Psychology Review, 25 (3), 274-283.

Beutler L.E. (1998). Identifying empirically supported treatments: what if we didn't? Journal of Consulting and Clinical Psychology, 66, 1: 113-20.

Boivin, M., Dodge, A. K., \& Coie, D. J. (1995). Individual-group behavioral similarities and peer status in experimental playgroups of boys: The social misfit revisited. Journal of Personality and Social Psychology, 69, 269-279.

Borduin, M. C., Mann, J. B., Cone, T. L., Henggler, W. S., Fucci, R. B., Blaske, M. D., \& Williams, A. R. (1995). Multisystemic treatment of serious juvenile offenders: Long-term prevention of criminality and violence. Journal of Consulting and Clinical Psychology, 63, 569-578.

Brendgen, M., \& Vitaro, F. (1998). Affiliation with delinquent friends: Contributions of parents, self-esteem, delinquent behavior. Journal of Early Adolescence, 18 (3), 244-266.

Bureau of Justice Statistics (1998). Substance Abuse and Treatment of Adults on Probation. Washington, DC: U.S. Department of Justice. 
Chamberlain, P., Reid, B. J. (1998). Comparison of two community alternatives to incarceration for chronic juvenile offenders. Journal of Consulting and Clinical Psychology, 66, 624633.

Chamberlain, P., (1999). Residential Care for Children and Adolescents with Oppositional Defiant Disorder and Conduct Disorder. Handbook of Disruptive Behavior Disorders, 495-506.

Chambliss, D., L. \& Hollon, S., D. (1998). Defining empirically supported therapies. Journal of Consulting \& Clinical Psychology, 66, 7-18.

Chaplin, James Patrick. (1985). Dictionary of Psychology. New York: Laurel

Christ, G. A. M., Lahey, B. B., Frick, J. P., Russo, F. M., McBurnett, K., Loeber, R., Stouthamer-Loeber, M., \& Green, S. (1990). Serious conduct problems in the children of adolescent mothers: Disentangling confounding correlations. Journal of Consulting and Clinical Psychology, 58, 840-844.

Centers for Disease Control and Prevention. (1998). Youth risk behavior surveillance, United States, August 1997. Atlanta: Epidemiology Program Office: Publisher.

Coie, D. J. , \& Jacobs, R. M. (1993). The role of social context in the prevention of conduct disorder. Development \& Psychopathology, 5, 263-275.

Cohen, Albert K. (1955). Delinquent Boys: The Culture of the Gang. Glencoe, IL: Free Press.

Conduct Problems Prevention Research Group (1992). A developmental \& clinical model for the prevention of conduct disorder: The Fast Track Program. Development \& Psychopathology, 4, 509-527. 
Day, H. D. , Franklin, M. J. , \& Marshall, D. D. (1998). Predictors of aggression in hospitalized adolescents. The Journal of Psychology, 132 (4), 427-434.

DeFrancesco, J., J. (1995). Conduct disorder: the crisis continues. APA Monitor.

DeMar, J. (1997) A school-based group intervention to strengthen personal and social competencies in latency-age children. Social Work in Education, 19, 219-231.

Dishion, J. T., McCord, J., \& Poulin, F. (1999). When interventions harm: Peer groups and problem behavior. American Psychologist, 54,_755-764.

Division of Criminal Justice Services. (1999). A statistical report of the department of military affairs and public safety, West Virginia, September 1999. WV Juvenile Probation: Author.

Dodge, A. K. (1990). Nature versus nurture in childhood conduct disorder: It is time to ask a different question. Developmental Psychology, 26, 698-701.

Edwards, W. J. (1996). A measurement of delinquency differences between a delinquent and nondelinquent sample: What are the implications? Adolescence, 31, 973-989.

Eme, R., F. \& Kavanaugh, L. (1995). Sex differences in conduct disorder. Journal of Clinical Child Psychology, 24, 406-427.

Enger, J., M. \& Howerton, D., L. (1994). Internal/external locus of control, self-esteem, and parental verbal interaction of at-risk black male adolescents. Journal of Social Psychology, 134, 269-276.

Epstein, M. H., Cullinan, D., Quinn, K., \& Cumblad, C. (1994). Characteristics of children with emotional and behavioral disorders in community-based programs designed to prevent placement in residential facilities. Journal of Emotional \& Behavioral Disorders, 2, 5157. 
Farrington, D., P. (1978). The family background of aggressive youths. In L., A., Hersov, Berger, M. \& Shaffer, D. (eds.). Aggression and antisocial behavior in childhood and adolescence, 73-93. Oxford, England: Pergamon.

Fishbein, D. H. (1990). Biological perspectives in criminology. Criminology, 18 (1), 27-73. Frauenglass, S. \& Routh, D. (1997). Family support decreases influence of deviant peers on Hispanic adolescents'. Journal of Clinical Child Psychology, 26, 15-23.

Frick, J. P. , Lahey, B. B. , Loeber, R. , Stouthamer-Loeber, M. , Christ, G. , M. , \& Hanson, K. (1992). Familial risk factors to oppositional defiant disorder and conduct disorder: Parental Psychopathology and maternal parenting. Journal of Consulting \& Clinical Psychology, 60 (1), 49-55.

Garbarino, J. (1999). Lost boys: Why our sons turn violent and how we can save them. New York: The Free Press.

Garrett, C. J. (1985). Effects of residential treatment on adjudicate delinquents: A meta-analysis. Journal of Research in Crime and Delinquency, 22, 287-308.

Glasser, W. (1984). Control Theory, New York: Harper and Collins.

Guba, E. G. , \& Lincoln, Y. S. (1981). Effective evaluation: Improving the usefulness of evaluation results through responsive and naturalistic approaches. San Francisco: Jossey-Bass.

Hagan, J. (1997). Defiance and despair: Subcultural and structural linkages between delinquency and despair in the life course. Social Forces, 76,_119-134.

Henggeler, W. S., Melton, B. G., Brondino, J. M., Scherer, G. D., \& Hanley, H. J. (1997) Multisystemic therapy with violent and chronic juvenile offenders and their families. The 
role of treatment fidelity in successful dissemination. Journal of Consulting and Clinical Psychology, 65,_821-833.

Henggeler, S. W., Schoenwald, S. K., Borduin, C. M., Rowland, M. D., \& Cunningham, P. B. (1998). Multisystemic treatment of antisocial behavior in children and adolescents. New York: Guilford.

Henggeler, W. S., Schoenwald, K. S., \& Pickrel (1995). Multisystemic therapy: Bridging the gap between university- and community-based treatment. Journal of Consulting Clinical Psychology, 63, 709-717.

Henggeler, W. S., Smith, H. B., \& Schoenwald, K. S. (1994). Key theoretical and methodological issues in conducting treatment research in the juvenile justice system. Journal of Clinical Child Psychology, 23,_143-150.

Heimer, K. (1997) Socioeconomic status, subcultural definitions, and violent delinquency. Social Forces, 75, 799-833.

Hunt, D. , Butler, L., Noy, J., \& Rosser, M. (1979). Assessing conceptual level by the paragraph completion method. Toronto: OISE.

Hyde, S. (1994) Residential Care: Some High-Risk Youth Benefit, But More Study Needed. Online Article: http://www.druglibrary.org/schaffer/govpubs/gao/gao27.htm.

Jesness, C., F. (1972). Manual for the Jesness Inventory. Palo Alto: Consulting Psychologists Press.

Kazdin, E. A. (1991). Effectiveness of psychotherapy with children and adolescents. Journal of Consulting and Clinical Psychology, 59, 785-798. 
Kazdin, E. A. (1993). Psychotherapy for children and adolescents: Current progress and future research direction. American Psychologist, 48, 644-657.

Kazdin, E. A. (1998). Identifying and developing empirically supported child and adolescent treatments. Journal of Consulting and Clinical Psychology, 66,_19-36.

Kazdin, E. A., Bass, D., Ayers, A. W., \& Rodgers, A. (1990). Empirical and clinical focus of child and adolescent psychotherapy research. Journal of Consulting and Clinical Psychology, 58, 729-740.

Kazdin, E. A., Holland, L., \& Crowley, M. (1997). Family experience of barriers to treatment and premature termination from child therapy. Journal of Consulting and Clinical Psychology, 65, 453-463.

Kazdin, E. A., Siegel, C. T., \& Bass, D. (1992). Cognitive problem solving skills training and parent management training in the treatment of antisocial behavior in children. Journal of Consulting and Clinical Psychology, 60, 733-747.

Kazdin, E. A., Siegel, C. T., \& Bass, D. (1990). Drawing on clinical practice to inform research on child and adolescent psychotherapy: Survey of practitioners. Professional Psychology: Research and Practice, 3, 189-198.

Kazdin, E., A., \& Wassell, G. (1998). Treatment completion and therapeutic change among children referred for outpatient therapy. Professional Psychology: Research and Practice, 29, 332-340.

Kazdin, E. A., \& Weisz, R. J. (1998). Identifying and developing empirically supported child and adolescent treatments. Journal of Consulting and Clinical Psychology, 66, 19-36. 
Klein, K. , Forehand, R. , Armistead, L. , \& Long, P. (1997). Delinquency during the transition to early adulthood: Family and parenting predictors from early adolescence. Adolescence, $32,61-80$.

Kumpfer, K. (1999). Preventing school violence by promoting mental health. SAMHSA News, 9, 25-35.

Lahey, B. B., Loeber, R., Hart, L. E., Frick, J. P., Applegate, B., Zhang, Q., Green, M. S., \& Russo, F. M. (1995). Four-year longitudinal study of conduct disorder in boys: Patterns and predictors of persistence. Journal of Abnormal Psychology, 104, 83-93.

Levenson, H. (1981). Differentiating among internality, powerful others and chance. In H. Lefcourt (Ed), Research with locus of control construct. New York: Academic Press.

Loeber, R., \& Farrington, P. D. (1994). Problems and solutions in longitudinal and experimental treatment studies of child psychopathology and delinquency. Journal of Consulting and Clinical Psychology, 62, 887-900.

Loeber, R. and Stouthamer-Loeber, M. (1986). Family Factors as Correlates and Predictors of Conduct Problems and Juvenile Delinquency. In M. Tony and N. Morris (eds.), Crime and Justice, Vol. 7 Chicago: University of Chicago Press.

Mann-Feder, V. R. (1996). Adolescents in therapeutic communities. Adolescence, 31, 17-28.

Mash, J. E., \& Barkley, A. R. (Eds.). (1999). Treatment of childhood disorders (2 ${ }^{\text {nd }}$ ed.). New York: The Guilford Press.

Matthys, W. (1997). Residential behavior therapy for children with conduct disorder. Behavior Modification, 21 (4), 512-533. 
McCord, J. (1993). Conduct disorder and antisocial behavior: Some thoughts about processes. Development \& Psychopathology, 5, 321-329.

McMahon, J. R. (1994). Diagnosis, assessment, and treatment of externalizing problems in children: The role of longitudinal data. Journal of Consulting and Clinical Psychology, 62,_901-917.

McMahon \& Wells (1998). Conduct disorders. In E. J. Mash \& R. A. Barkley (Eds.), Treatment of childhood disorders (pp. 73-132). New York: Guilford Press.

Miller, E. G., \& Prinz, J. (1990). Enhancement of social learning family interventions for childhood conduct disorder. Psychological Bulletin, 108, 291-307.

Millon, T. \& Davis, R., D. (1993). The millon adolescent personality inventory and the millon adolescent clinical inventory. Journal of Counseling \& Development, 71, 570-575.

Moore, J. K., Osgood, W. D., Larzelere, E. R., \& Chamberlain, P. (1994). Used of pooled time series in the study of naturally occurring clinical events and problem behavior in a foster care setting. Journal of Consulting and Clinical Psychology, 62, 718-728.

Netherton, D. S., Holmes, D., \& Walker, E. C. (Eds.). (1999). Child \& adolescent psychological disorders: A comprehensive textbook. New York: Oxford University Press.

Nieves, N. (1991). Childhood psychopathology and learning disabilities: Neuropsychological relationships. In J. Obrzut \& G. Hynd (Eds.). Neuropsychological Foundations of Learning Disabilities: A Handbook of Issues, Methods, and Practice (pp. 113-147). San Diego, CA: Academic Press, Inc.

Norwicki, S. \& Strickland, R., B. (1973). A locus of control scale for children. Journal of Consulting \& Clinical Psychology, 62, 718-728. 
Paetsch, J. J., \& Bertrand, D. L. (1997). The relationship between peer, social, and school factors, and delinquency among youth. The Journal of School Health, 67,_27-32.

Patterson, R. G., \& Forgatch, S. M. (1995). Predicting future clinical adjustment from treatment outcome and process variables. Psychological Assessment, 7,_275-285.

Paul, G.L. (1967). Outcome research in psychotherapy. Journal of Consulting Psychology, 31, $109-118$.

Putnins, L. A. (1997). Victims' awareness programs for delinquent youth: Effects on moral reasoning maturity. Adolescence, 32,_709-814.

Quay, C. H., \& Hogan, E. A. (Eds.). (1999). Handbook of disruptive behavior disorders. New York: Plenum Publishers.

Quinsey, L., V., Harris, T., G., Rice, E., M. \& Cormier, A., C. (1998). Violent offenders: appraising and managing risk. American Psychological Association. Washington, D. C.

Reid, J. B. (1993). Prevention of conduct disorder before and after school entry: Relating interventions to developmental findings. Development \& Psychopathology, 5, 243-262.

Reiss, A. J. , \& Roth, J. A. (Eds.). (1993).Understanding and preventing violence. Washington, D.C.: National Academy Press.

Richters, J., E. \& Cicchetti, D. (1993). Mark twain meets DSM III-R: conduct disorder, development and the concept of harmful dysfunction. (Special Issue: Toward a developmental perspective on conduct disorder). Development and Psychopathology, 5, $5-29$. 
Rosenstein, S. D., Horowitz, A. H. (1996). Adolescent attachment and psychopathology. Journal of Consulting and Clinical Psychology, 64, 244-253.

Rutter, M. (1994). Family discord and conduct disorder: Cause, consequences, or correlate? Journal of Family Psychology, 8, 170-186.

Scherer, G. D. , Brondino, J. M. , Henggeler, W. S. , Melton, B. G. , \& Hanley, H. J. (1994). Multisystemic Family Preservation Therapy: Preliminary findings from a study of rural and minority serious adolescent offenders. Journal of Emotional and Behavioral Disorders, 2 (4), 198-206.

Schoenwald, S., K. \& Henggeler, S., W. (1998). Changing the natural and service ecologies of adolescents and their families. In M. H. Epstein, K., Kutash, \& Duchnowski, A. (eds.). Community based programming for children with serious emotional disturbances and their families, 485-511. Austin, Texas.

Sells, P. S. (1998). Treating the tough adolescent: A family-based, step-by-step guide. New York: The Guilford Press.

Spielberger, D. C. (1991). State-trait anger expression inventory. Professional Manual. Odessa, Fl: Psychological Assessment Resources, Inc.

Spivack, G., Spotts, J., \& Haines, P. E. (1967). Manual for the Devereux adolescent behavior rating scale. Devon, PA: The Devereux Foundation.

Sutherland (1947). Principles of Criminality ( $6^{\text {th }}$ ed.). New York: Lippincott.

Swanson, H.L. (1993). Effect of stimulant medications on children with attention deficit disorder: A "review of reviews." Exceptional Children, 60, 154-162. 
Swanson, H. L. (1991). Operational definitions and learning disabilities: An overview. Learning Disability Quarterly, 14, 242-54.

Tankersley, M. , \& Kamps, D. (1996). Social interventions for head start children with behavioral risks: Implications and outcomes. Journal of Emotional \& Behavioral Disorders, 4 (3),_171-181.

Teplin, L. A., Abram, K. M. , McClelland, G. M., Dulcan, M. K. \& Mericle, A. A. (2002). Psychiatric Disorders in Youth in Juvenile Detention. Archives of General Psychiatry, December 2002.

Thomas, G. (1994). Introduction - A View from the Trench (17), 1-31. Co-published simultaneously in Child \& Youth Services. The Haworth Press, Inc.

U.S. Department of Justice: Federal Bureau of Investigation. (1997). Crime in the United States: Uniformed crime report, November 1998. U.S. Government Printing Office: Publisher

Wagner, B. M. , \& Cohen, P. (1996). Parent/adolescent relationships. Journal of Adolescents Research, 11 (3), 347-375.

Wahler, G. R. (1990). Who is driving the interactions? A commentary on "Child and parent effects in boys' conduct disorder”. Developmental Psychology, 26, 702-704.

Walker, H. M., \& Kavanagh, K. (1998). First step to success: An early intervention approach for preventing school antisocial behavior. Journal of Emotional and Behavioral Disorders, 6, 66-81. 
Webster-Stratton, C. (1993). Strategies for helping early school-aged children with conduct disorder and oppositional defiant disorder: The importance of home school partnership. School Psychology Review, 22 (3), 437-457.

Wechsler, D. (1974). Manual for the Wechsler Intelligence Scale for Children-Revised. San Antonio, TX: Psychological Corporation.

Weiss, B., \& Weisz, R. J. (1995). Relative effectiveness of behavioral versus nonbehavioral child psychotherapy. Journal of Consulting and Clinical Psychology, 63, 317-320.

Weiss, B., \& Weisz, R. J., Han, S. S., Granger, A. D., \& Morton, T. (1995). Effects of psychotherapy with children and adolescents revisited: A meta-analysis of treatment outcome studies. Psychological Bulletin, 117, 450-468.

Weisz, R. J., Donenberg, R. G., Han, S. S., \& Weiss, B. (1995). Bridging the gap between laboratory and clinic in child and adolescent psychotherapy. Journal of Consulting and Clinical Psychology, 63,_688-701.

Weisz, R. J., Han, S. S., \& Valeri, M. S. (1997). More of what? Issues raised by the fort bragg study. American Psychologist, 52, 541-545.

Weisz, R. J., Walter, R. B., Weiss, B., Fernandez, A. G., \& Mikow, A. V. (1990). Arrests among emotionally disturbed violent and assaultive individuals following minimal versus lengthy intervention through North Carolina's Willie M Program. Journal of Consulting and Clinical Psychology, 58, 720-728.

Woodcock, R.W., \& Mather, N. (1989, 1990). WJ-R tests of achievement: Examiner's manual. In R.W. Woodcock \& M.B. Johnson, Woodcock-Johnson psycho-educational batteryrevised. Allen, TX. 


\section{Appendix A}

Data Record Sheet

\begin{tabular}{|c|c|}
\hline Adolescent Characteristic & Coding Instruction \\
\hline 1. Religion & $\begin{array}{l}\text { Protestant }=1, \text { Catholic }=2, \text { Other }=3, \text { None }= \\
4\end{array}$ \\
\hline 2. Race & $\begin{array}{l}\text { African American }=1 \text {, Caucasian }=2, \text { Biracial } \\
=3 \text {, Asian American }=4, \text { Hispanic }=5\end{array}$ \\
\hline 3. Diagnosis & $\begin{array}{l}\mathrm{BD}=1, \mathrm{ED}=2, \mathrm{LD}=3, \mathrm{LD} \& \mathrm{ED}=4, \mathrm{BD} \& \\
\mathrm{ED}=5, \mathrm{LD}, \mathrm{BD}, \& \mathrm{ED}=6\end{array}$ \\
\hline 4. Marital Status/Parents & $\begin{array}{l}\text { Married }=1, \text { Divorced }=2, \text { Separated }=3, \\
\text { Widowed }=4, \text { Never Married }=5, \text { Unknown }= \\
6, \text { Remarried }=7\end{array}$ \\
\hline 5. Current Meds & $\begin{array}{l}\text { Antipsychotics }=1, \text { Antidepressants }=2, \\
\text { Antianxiety }=3, \text { Mood Stabilizers }=4, \\
\text { Stimulants }=5: \\
1,2=9 \\
1,2,4,5=10 \\
1,2,3=11 \\
1,4=12 \\
2,1,5=13 \\
1,2,4=14 \\
3,5=15 \\
2,4=16 \\
2,5=17 \\
1,4,5=18 \\
3,4,5=19 \\
3,4=20 \\
4,5=21 \\
2,4,5=22 \\
5,1,3,2=23 \\
4,2,3=24 \\
1,5=25 \\
3,4,5,1=26 \\
\text { Other }=35\end{array}$ \\
\hline 6. Probation & $\mathrm{Yes}=1, \mathrm{No}=0$ \\
\hline 7. Legal Guardian & $\begin{array}{l}\text { Family Services }=1, \text { Permanent Foster Care }=2 \\
\text { Relative }=3 \text {, Parents }=4 \text {, Mother only }=5, \\
\text { Father only }=6\end{array}$ \\
\hline 8. Substance Use & $\mathrm{Yes}=1, \mathrm{No}=2$ \\
\hline
\end{tabular}




\begin{tabular}{|l|l|}
\hline $\begin{array}{l}\text { 9. Counseling (Individual) } \\
\text { 10. Counseling (Group) }\end{array}$ & $\begin{array}{l}\text { Yes }=1, \text { No }=0 \\
\text { Yes }=1, \text { No }=0\end{array}$ \\
\hline 11. Counseling (Family) & Yes $=1$, No $=0$ \\
\hline 12. Therapist Style & $\begin{array}{l}\text { Cognitive Behavioral }=1, \text { Family } \\
\text { Systems } / \text { Object Relations }=2, \text { Psychodynamic } \\
=3, \text { Cognitive Behavioral }=4, \text { Eclectic }=5\end{array}$ \\
\hline 13. Therapist Degree & BA $=1$, Masters $=2$, Ed.D, PhD, Psy.D $=3$ \\
\hline 14. Discharge Type & $\begin{array}{l}\text { Planned }=1, \text { Dx }=2, \text { Other/Deceased }=3, \\
\text { AWOL }=4, \text { Agency/Parent Initiated }=5, \\
\text { Unsuccessful }=6, \text { Self }=7\end{array}$ \\
\hline
\end{tabular}




\section{Appendix B \\ Description of Psychometric Measures}

\section{Outcome:}

1. Amount of improvement noted by decrease in overall behavioral rating scales (The Beck Depression Inventory, the Locus of Control Scale for children, the Millon Adolescent Clinical Inventory, and the State-Trait Anger Expression Inventory).

2. Internal/External Locus of Control - each are measured by the Locus of Control Scale for children.

a. Internal Locus of Control - The degree to which the individual attributes events, which he/she believes are contingent upon his/her own behavior. Then we label this a belief in internal locus of control (Norwicki \& Strickland, 1973).

b. External Locus of Control - The degree to which the individual believes that reinforcement follows some action that is not contingent upon his/her own behavior, but rather is due to luck, fate, or other environmental factors. Then we label this a belief in external locus of control (Norwicki \& Strickland, 1973).

3. The State-Trait Anger Expression Inventory (STAXI) measures the experience and expression of anger (Spielberger, 1988). Anger is defined as having two major components (a) state anger; and (b) trait anger.

a. Trait Anger - Trait anger is defined as "the disposition to perceive a wide range of situations as annoying or frustrating and the tendency to respond to such situations with more frequent elevations in state anger" (Spielberger, 1988, p.1). 
b. State Anger - State anger is defined as "an emotional state marked by subjective feelings that vary in intensity from mild annoyance or irritation to intense fury and rage" (Spielberger, 1988, p.1).

c. Angry Reaction - Angry reaction is a trait anger subscale that measures "individual differences in the disposition to express anger when criticized or treated unfairly by other individuals" (Spielberger, 1988, p.1).

d. Angry Temperament - Angry temperament is a trait subscale that measures: a general propensity to experience and express anger without specific provocation" (Spielberger, 1988, p.1).

e. Angry Expression - is defined as maintaining three components: (a) anger-out; (b) anger-in; (c) anger control, "that provides a general index of the frequency with which anger is expressed, regardless of the direction expressed" (Spielberger, 1988, p.1).

f. Anger Out - Anger -out "involves the expression of anger toward other people or objects in the environment" (Spielberger, 1988, p.1).

g. Anger In - "The second component of anger expression is anger direct inward that is, holding in or suppressing angry feelings" (Spielberger, 1988, p.1).

h. Anger Control - "Individual differences in the extent to which a person attempts to control the expression of anger" (Spielberger, 1988, p.1).

4. Clinical Psychopathology - Clinical pathology in this study was measured by the Million Adolescent Clinical Inventory (MACI). The MACI is a measure of general and specific kinds of pathology. The MACI is made up of 30 scales. Therefore, any elevated MACI scale has the potential to slow down advancements through the level system; hence, effecting 
successful outcome in the treatment program. The first 12 scales "make up the personality patterns reflect the way in which personality traits and features combine to form a pattern. The following 8 scales focus on feelings and attitudes about issues that tend to concern most troubled adolescents. The following 7 scales "relate to disorders that manifest themselves in relatively specific form; that is, the symptomatology will cluster into clear-cut and welldefined clinical syndromes, such as anxiety and depression. They are usually the initial focus of treatment, standing out as relatively dramatic and notable behavior, thoughts, or feelings that call attention to the person as one who requires professional help." The intensity of their experience is reflected in the score elevations for each scale (Millon, 1993, p. 7, 12, 17). "Procedures were added for correcting various distortion effect (e.g., random responding, faking good, faking bad). Three "modifier" scales disclosure, desirability, and debasement)" (Millon, 1993, p. 3).

a. Introversive - "Introversive adolescents lack the capacity to experience life as either painful or pleasurable. Introversive teenagers who are characterized by a diminished capacity to experience both pain and pleasure do not seem to be interested in personal enjoyment or social satisfaction, nor do they evidence much discomfort when faced with personal difficulties or social discomfort. Introversive adolescents neither strive for rewards nor seek to avoid punishment” (Millon, 1993, p. 7). This personality pattern is similar to the DSM-IV Axis II schizoid personality disorder.

b. Inhibited - These adolescents "expect life to be distressing, with few rewards and much anguish. The inhibited type is also disposed to feel apprehensive and angst. They tend to drift into isolating circumstances and self-alienated behavior. There is a hyperalertness to anticipate pain, with a consequent inattention to joy" (Millon, 1993, p.8). 
c. Doleful - "There has been a significant loss, a sense of giving up, and a loss of hope that joy can be retrieved. Similar to the DSM-IV axis II depressive personality type, the Dole personality type experiences pain as permanent, with pleasure no longer considered even possible. A significant loss, a disconsolate family, a barren environment, and hopeless prospects can all shape the Doleful character style” (Millon, 1993, p. 8).

d. Submissive - "Adolescent who exhibit the Submissive pattern, similar to the DSM-IV axis II the dependent personality, have learned that feeling good, secure, and confident (feelings associated with pleasure or the avoidance of pain) comes almost exclusively from their relationships with others. Behaviorally, these adolescent display a strong need for external support and attention. Experiencing low self-esteem and failure with peers may lead these individuals to forgo attempts at self-assertion and self-gratification. They learn early that rewarding experiences are not readily achieved alone but are secured by leaning on others" (Millon, 1993, p. 8).

e. Dramatizing "Adolescent who exhibit the Dramatizing pattern, similar to the DSM-IV axis II the histrionic personality. They achieve their goals of maximizing protection and nurturance by busily engaging in a series of manipulative, seductive, gregarious, and attention-getting maneuvers. Dramatizing types appear on the surface to be quite dissimilar from their passive counterparts. These teenagers often have an insatiable, sometimes indiscriminate, hunger for stimulation and affection. Their cleaver and oftenartful social behavior gives the appearance of inner confidence and independent selfassurance. However, beneath this guise lies a fear of genuine autonomy and a need for repeated signs of acceptance and approval" (Millon, 1993, p. 9). 
f. Egotistic - "There is a primary reliance on self rather than others. They have learned that maximum pleasure and minimum pain are achieved by turning exclusively to themselves. Egotistic pattern, involves the acquisition of a self-image of superior worth, learned largely in response to admiring and dotting parents. Rewarding oneself or possessions a real or inflated sense of self-worth. Displaying confidence, narcissistic arrogance, and an exploitive egocentricity in social contexts, these individuals exhibit what is called the passive-independent style in the theory because they feel that they posses all that is important-themselves. Adolescent who exhibit the Egotistic pattern, similar to the DSM-IV axis II the narcissistic personality, they maintain an air of arrogant self-assurance and exploit others to their own advantage without much thought or even conscious intent” (Millon, 1993, p. 9).

g. Unruly - "Unruly adolescents exhibit the outlook, temperament, and socially unacceptable behavior of the DSM-IV axis II antisocial personality disorder. They act to counter anticipated deceit and derogation at the hands of others. They do this by actively engaging in a hostile and duplicitous manner and by engaging in illegal behavior through which they seek retributions or the exploitation of others. Skeptical regarding the motives of others, these adolescents desire autonomy and seek revenge for what they feel are past injustices" (Millon, 1993, p. 9-10).

h. Forceful - "The Forceful personality style (similar to the DSM sadistic disorder) is characterized by viewing pain (stress, fear, cruelty) rather than pleasure as the preferred mode of relating to others. This adolescent assumes an active role in controlling, dominating, and intimidating others. Acts that humiliate, demean, and abuse others are experienced as pleasurable. The Forceful personality style includes adolescents who are 
generally hostile and pervasively combative, and they appear indifferent to or even pleased by the destructive consequences of their intimidating, contentious, and abusive behavior" (Millon, 1993, p.10).

i. Conforming - "This personality pattern is similar to the DSM obsessive-compulsive personality disorder. These adolescents display a distinct other-directedness and a consistency in social propriety and interpersonal respect. Their histories usually indicate that they have been subjected to constraint and discipline, but only when they transgressed parental strictures and expectations. Beneath the compliant and otheroriented veneer are intense desires to revel and to assert their own self-oriented feelings and impulses. To avoid intimidation and punishment, they have learned to deny the validity of their own wishes and emotions and to adopt the values and precepts set forth by others. Conforming adolescents are likely to have been coerced into accepting standards imposed on them by others. Their prudent, controlled, and perfectionist ways derive from a conflict between repressed anger toward others and a fear of shame, guilt, and social disapproval. Behind these adolescents' front a propriety and restraint lurk intense, angry feelings that may occasionally break through their controls" (Millon, 1993, p. 10).

j. Oppositional - "Oppositional (similar to the DSM-III passive-aggressive personality and the DSM-IV negativistic personality), vacillate between others and self, sometimes behaving obediently and sometimes reacting defiantly. Feeling intensely, yet unable to resolve their ambivalence, they weave an erratic course from voicing their selfdeprecation and guilt for failing to meet the expectations of others, to expressing stubborn negativism and resistance over having submitted to the wishes of others. These 
adolescents involve themselves in endless wrangles and experience disappointment as they fluctuate between deference and obedience and defiance and aggressive negativism. Their behavior displays an erratic pattern of explosive anger or stubbornness intermingled with guilt and shame" (Millon, 1993, p. 11).

k. Self-Demeaning - " these adolescents interpret events and engage in relationships in a manner that is not only at variance with the function of this deeply rooted polarity (survival) but us contrary to the associations these emotions usually acquire through learning. To the Self-Demeaning adolescent, pain may have become preferable to pleasure, passively accepted if not encouraged in intimate relationships. It is often intensified by purposeful self-denial and acceptance of blame and may be aggravated by acts that engender difficulties and by thoughts that exaggerate past misfortunes and anticipate future one. Focusing on their very worst features, many assert that they deserve to be shamed and humbled. To compound their pain and anguish, these adolescents may actively and repetitively recall their past misfortunes and transform otherwise fortunate circumstances into problematic ones. Typically acting in an unpresuming and self-effacing way, they often intensify their deficits and place themselves in an inferior or abject position. The pain of physical brutality or the anguish of verbal abuse may have been followed repeatedly by love and intimacy, leading to the learned assumption that provocation is a necessary precursor to ultimate acceptance and tenderness" (Millon, 1993, p. 11).

1. Borderline Tendency - "The Borderline Tendency Personality Pattern corresponds to the theory's emotional dysfunctional and maladaptive ambivalent orientation. Conflicts exist across the board, between pleasure and pain, active and passive, and self and others. 
Adolescents with this personality pattern seem unable to take a consistent, neutral, or balanced position among these polar extremes, tending to fluctuate from one end to the other. They experience intense endogenous moods with recurring periods of dejection and apathy, often interspersed with spells of anger, anxiety, or euphoria. Among the features that distinguish them from less severe personality covariants is the instability and liability of their moods. Additionally, many express and may act on recurring selfmutilating and suicidal thoughts. Some appear to be overly preoccupied with securing affection. Many have difficulty maintaining a consistent sense of identity" (Millon, 1993, p. 12).

m. Identity Diffusion - "This transformation from unexamined childhood to adult identity, at times chaotic and troubling, is the of the Identity Diffusion scale. Factors such as rewarding parent-child relationships and competent same-sex role models must exist to facilitate the effective development of identity. Adolescents who lack suitable role models or who have experienced confusing or angry messages from parents and peers will find this shift overwhelming and frightening. Development of an identity does not demand the rejection of parental values but rather the examination and integration those values along with the values of the larger world that the adolescent is entering" (Millon, 1993, p. 13).

n. Self-Devaluation - "Early adolescence, however, ushers in a painful period of comparison of self against ideals that seem far beyond what the adolescent has considered previously. It is the disparity between these two, and the struggles to resolve them, that are the focus of the Self-Devaluation scale. This struggle is closely tied to the adolescent's efforts to develop his or her own identity. What we see is the adolescent 
formulating a tentative sense of who he or she is. It is in this area, perhaps more than any other, that the adolescent's strengths will often intensify conflicts, yet ultimately help him or her grow and resolve difficulties. Dissatisfaction with self becomes a highly personal marker of unhappiness and not merely an index common to most adolescents" (Millon, 1993, p. 13-14).

o. Body Disapproval - " Wishes and dreams regarding appearance now stand in sharp relief against an emerging physical self. The manner in which the adolescent views him/herself rests, in part, on facets of objective body build, but this physique is judged in the context of a myriad of experiences and societal norms. This judgmental process is highly complex, a product of parental attitudes, personal fears, peer reactions, and one's own critical self-awareness. Negative family attitudes can create and intensify facial and body-image dissatisfaction, even among adolescents who are experiencing typical growth changes. Unfortunately, for many adolescents, dissatisfaction with their appearance often remains equally immutable" (Millon, 1993, p. 14).

p. Sexual Discomfort - "The ability to integrate these sexual impulses into the framework of one's self-image will have a distinct bearing on how the teenager will feel about and form sexual relationships. The effective transition to sexual awareness ands comfort is not a product merely of maturation and parental acceptance. After a tremulous start, most adolescents do achieve a meaningful sexual expression, one combining both friendship and intimacy. The ease and rate of this transition is gauged by the Sexual Discomfort scale, reflecting problematic parental attitudes, cultural beliefs, and the impact of peers, all of which contribute to sexuality and its acceptance. Immature attitudes and a 
troublesome sense of guilt and shame are tapped to aid the clinician in helping teenagers with these problems" (Millon, 1993, p. 14-15).

q. Peer Insecurity - "Adolescents see the peer group as a source of support while they try to distance themselves from parental values and domination. Although peer group affiliation does not encompass all aspects of a teenager's life, it does make up and influence a significant portion of social behavior. Adolescents with poor self-esteem are caught in a particularly desperate bind. Expecting rejection, they often remain timid and passive observation on the sidelines of life. This scale, measures the adolescent's degree of success in finding a comfortable, rewarding position in his/her peer group" (Millon, 1993, p. 15).

r. Social Insensitivity - " The most salient behavioral characteristic of this type of individual is a generalized indifference to the feelings and reactions of others. This differs from overt hostility; rather, it shows a casual indifference to the presence of discomfort and pain in others. Often uncaring and seemingly unmoved by needs for reciprocal social relationships, this person may choose isolation, apathy, or insensitivity. Such as individual may eschew ordinary restraints and actively espouse views that are contrary to the rights of others" (Millon, 1993, p. 15-16).

s. Family Discord - "The teenager's relationship to his/her family, along with perceptions of what it should be, is the focus of this scale. This scale assesses the adolescent's feelings and perceptions, not what is objectively real" (Millon, 1993, p. 16).

t. Childhood Abuse - " This scale was designed to uncover abuse in the adolescent's background. This scale measures only the adolescent's perception and recollection of these events; it does not necessarily affirm the reality of these experiences. Adolescents 
with this history will report shame or disgust over having been subjected to experiences of being abused either verbally, physically, or sexually, ostensibly by parents, siblings, more distant relatives, or family friends"(Millon, 1993, p. 17).

u. Eating Dysfunction - This scale measures the likelihood that an adolescent suffers from an eating disorder (Millon, 1993).

v. Substance-Abuse Proneness - "Through the Substance-Abuse Proneness scale, the MACI seeks to provide an understanding of why substance abuse occurs and what purpose it serves for an adolescent with specific personality patterns" (Millon, 1993, p. $18)$.

w. Delinquent Predisposition - "Adolescents who a problems gain attention by the distress they inflict on others and through a disregard for ordinary societal constraints. This scale seeks to answer the question: What is the nature of this inability or unwillingness to comply with societal regulation? How does this habit of disregard develop and what paths are best followed in search of remediation?(Millon, 1993, p. 19).

x. Impulsive Propensity - "Impulsive behavior is distributed along a continuum, and society and individual families establish clear markers along this continuum concerning what is or is not acceptable" (Millon, 1993, p. 19).

y. Anxious Feelings - "Anxiety is a universal emotion. However, it is considered a serious psychological disorder if it occurs frequently, persists for long periods of time, cannot be explained by realistic stressors, and upsets the individual's ability to relate socially or to function adequately. Anxious adolescents often report feeling either vaguely apprehensive or specifically phobic. They are tense, indecisive, and restlessness, and they tend to complain of a variety of physical discomforts, such as tightness, excessive 
perspiration, ill-defined muscular aches, and nausea. Some anxious adolescents have multiple somatic complaints, often presented in a dramatic, vague, or exaggerated way. Others have a history that may be best considered hypochondriacal; they interpret minor physical discomfort or sensations as signifying a serious ailment. Typically, somatic complaints are employed to gain attention" (Millon, 1993, p. 20).

z. Depressive Affect - " The majority of depressed adolescents remain involved in everyday life but are preoccupied with feelings of discouragement or guilt, a lack of initiative, apathy, low self-esteem, futility, and self-deprecation. During these periods of dejection, there may be tearfulness, suicidal ideation, a pessimistic outlook, social withdrawal, poor appetite or overeating, chronic fatigue, poor concentration a loss of interest in pleasurable activities, and a decreased effectiveness in performing ordinary and routine tasks. Depending on the adolescent's characteristic personality style, there may be a shy, introverted, and seclusive pattern, characterized by sluggish immobility or an irritability, complaining, and whining tone" (Millon, 1993, p. 20).

aa. Suicidal Tendencies - " A continuum may be said to exist that includes thoughts about intentional self-injury or death (suicidal ideation), intentional self-injury (self-destructive behavior), unsuccessful suicidal behavior (suicide attempts), and finally, successful attempts (suicide). Any elevation on the Suicidal Tendency scale should be taken seriously.(Millon, 1993, p. 20).

bb. Disclosure - "Procedures were added for correcting various distortion effect (e.g., random responding, faking good, faking bad). Three "modifier" scales disclosure, desirability, and debasement)" (Millon, 1993, p. 3). 
cc. Desirability - "Procedures were added for correcting various distortion effect (e.g., random responding, faking good, faking bad). Three "modifier" scales disclosure, desirability, and debasement)" (Millon, 1993, p.3).

dd. Debasement - "Procedures were added for correcting various distortion effect (e.g., random responding, faking good, faking bad). Three "modifier" scales disclosure, desirability, and debasement)" (Millon, 1993, p. 3). 
$\underline{\text { Behavioral Management System }}$

Appendix C

\begin{tabular}{|l|l|}
\hline \multicolumn{2}{|c|}{ Notice of Demerits } \\
\hline Students Name: & \multicolumn{2}{|l|}{} \\
\hline Date: & \multicolumn{2}{|c|}{ Time: } \\
\hline $\begin{array}{l}\text { Provide a written } \\
\text { description of the } \\
\text { behavior below: }\end{array}$ & \multicolumn{2}{|c|}{ CODE } \\
\hline & \\
\hline & \\
\hline
\end{tabular}


Behavioral Management System

Appendix C

$\underline{\text { ASSIGNED QUIET TIME - TIME OUT }}$

\begin{tabular}{|c|c|c|c|c|c|c|}
\hline Date & Code & $\begin{array}{c}\text { Description of } \\
\text { Behavior }\end{array}$ & \multicolumn{5}{c|}{ Initials } \\
\hline & & & Staff & Time & Student & Time \\
\hline & & & & & & \\
\hline & & & & & & \\
\hline & & & & & & \\
\hline & & & & & & \\
\hline
\end{tabular}

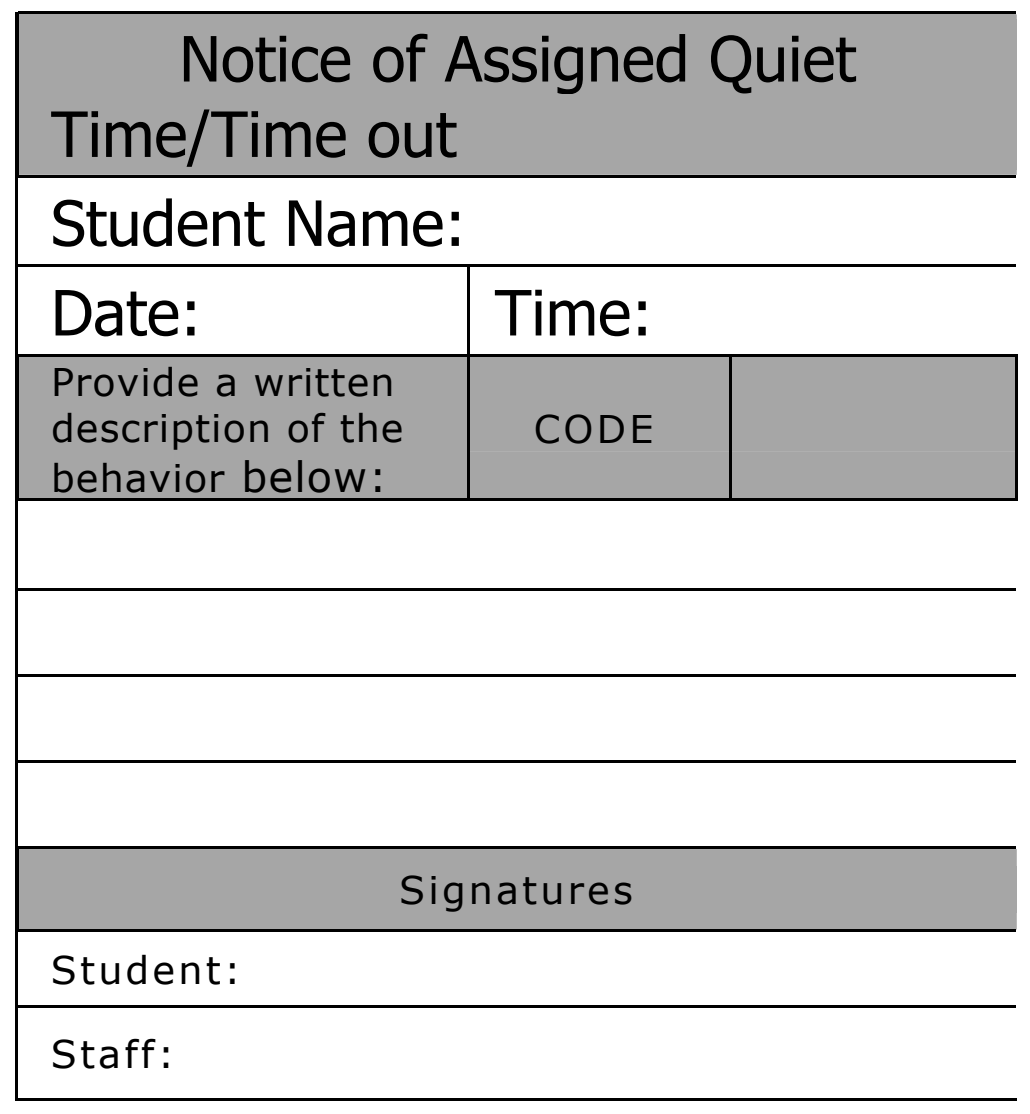


$\underline{\text { Behavioral Management System }}$

Appendix C

\section{DETENTION}

\begin{tabular}{|c|c|c|c|c|c|c|c|}
\hline \multirow[t]{2}{*}{ Date } & \multirow[t]{2}{*}{ Code } & \multirow{2}{*}{$\begin{array}{l}\text { Description of Behavior } \\
\text { Detention \& } \underline{\text { OR }} \text { Method Served }\end{array}$} & \multicolumn{5}{|c|}{ Initials } \\
\hline & & & Staff & Time & Student & Time & Balance \\
\hline & & & & & & & \\
\hline & & & & & & & \\
\hline & & & & & & & \\
\hline & & & & & & & \\
\hline
\end{tabular}

\section{Notice of Detention}

Student Name:

Date:

Provide a written

description of the behavior

below:
Time:

\section{CODE}

\section{SIGNATURES}

Student:

Staff: 
$\underline{\text { Behavioral Management System }}$

Appendix C

Punishment Sheet

(Demerits/Fines/Time Outs/ Etc)

\begin{tabular}{|c|c|c|c|c|c|c|c|c|}
\hline \multicolumn{9}{|c|}{ Notice of Punishment (s) } \\
\hline $\begin{array}{l}\text { Student } \\
\text { Name: }\end{array}$ & & & Date: & & & & & \\
\hline Code & $\begin{array}{l}\text { Description } \\
\text { of } \\
\text { Behavior }\end{array}$ & Time & $\begin{array}{l}\text { Student's } \\
\text { Initials }\end{array}$ & $\begin{array}{l}\text { Time } \\
\text { Out/ } \\
\text { Variance }\end{array}$ & $\begin{array}{l}\text { Amount } \\
\text { of Fine }\end{array}$ & Detention & $\begin{array}{l}\text { Student's } \\
\text { Initial } \\
\text { (Served) } \\
\end{array}$ & $\begin{array}{l}\text { Staff's } \\
\text { Initial } \\
\text { (Served) }\end{array}$ \\
\hline & & & & & & & & \\
\hline & & & & & & & & \\
\hline & & & & & & & & \\
\hline & & & & & & & & \\
\hline & & & & & & & & \\
\hline & & & & & & & & \\
\hline & & & & & & & & \\
\hline & & & & & & & & \\
\hline
\end{tabular}


$\underline{\text { Behavioral Management System }}$

Appendix C

\section{Restriction Record Sheet} TYPE 1 RESTRICTION

\begin{tabular}{l|l|l}
\hline Student Name: & Level: & Date:
\end{tabular}

This above named student was placed on Type 1 restriction for seven days on this date due to the behaviors described below.

Money received from the student as a result of placement on restriction

\begin{tabular}{l|l} 
Staff Signature: & Student Signature:
\end{tabular}

The student has earned the demerits listed below while on this restriction. Days on which Group $\mathrm{C}$ behavior was maintained are circled. Please check the applicable level below.

\begin{tabular}{|c|c|c|c|c|}
\hline \multirow[t]{2}{*}{$\checkmark$} & Level & Group C Criteria & Fine & Detention \\
\hline & Level I & Not Applicable & Not Applicable & 2 Hours \\
\hline & Level II & Less than 9 Demerits & Not Applicable & 2 Hours \\
\hline & Level III & Less than 7 Demerits & $\$ 1.00$ & 2 Hours \\
\hline & Level IV & Less than 5 Demerits & $\$ 2.00$ & 2 Hours \\
\hline & Level V & Less than 4 Demerits & $\$ 3.00$ & 2 Hours \\
\hline & Level VI & Less than 3 Demerits & $\$ 5.00$ & 2 Hours \\
\hline \multicolumn{5}{|c|}{ First Week } \\
\hline \multicolumn{5}{|l|}{ Day/Date } \\
\hline \multicolumn{5}{|l|}{ Demerits } \\
\hline \multicolumn{5}{|c|}{ Second Week } \\
\hline \multicolumn{5}{|l|}{ Day/Date } \\
\hline \multicolumn{5}{|l|}{ Demerits } \\
\hline Detention & & Fine Paid: & $\$$ & \\
\hline
\end{tabular}

If student does not complete the restriction within fourteen days, the case manager will review the student's progress with the Unit Director to determine whether additional intervention is necessary to help the student to establish and maintain appropriate behavior. 
$\underline{\text { Behavioral Management System }}$

Appendix C

\section{Restriction Record Sheet} TYPE 2 RESTRICTION

\begin{tabular}{l|l|l}
\hline Student Name: & Level: & Date:
\end{tabular}

This above named student was placed on Type 2 restriction for seven days on this date due to the behaviors described below.

Money received from the student as a result of placement on restriction

\begin{tabular}{l|l} 
Staff Signature: & Student Signature:
\end{tabular}

The student has earned the demerits listed below while on this restriction. Days on which Group $\mathrm{C}$ behavior was maintained are circled. Please check the applicable level below.

\begin{tabular}{|c|c|c|c|c|}
\hline \multirow[t]{2}{*}{$\checkmark$} & Level & Group C Criteria & Fine & Detention \\
\hline & Level I & Not Applicable & Not Applicable & 2 Hours \\
\hline & Level II & Less than 9 Demerits & Not Applicable & 4 Hours \\
\hline & Level III & Less than 7 Demerits & $\$ 3.00$ & 4 Hours \\
\hline & Level IV & Less than 5 Demerits & $\$ 6.00$ & 4 Hours \\
\hline & Level V & Less than 4 Demerits & $\$ 9.00$ & 4 Hours \\
\hline & Level VI & Less than 3 Demerits & $\$ 15.00$ & 4 Hours \\
\hline \multicolumn{5}{|c|}{ First Week } \\
\hline \multicolumn{5}{|l|}{ Day/Date } \\
\hline \multicolumn{5}{|l|}{ Demerits } \\
\hline \multicolumn{5}{|c|}{ Second Week } \\
\hline \multicolumn{5}{|l|}{ Day/Date } \\
\hline \multicolumn{5}{|l|}{ Demerits } \\
\hline Detention & & Fine Paid: & $\$$ & \\
\hline
\end{tabular}

If student does not complete the restriction within fourteen days, the case manager will review the student's progress with the Unit Director to determine whether additional intervention is necessary to help the student to establish and maintain appropriate behavior. 
$\underline{\text { Behavioral Management System }}$

Appendix C

\section{Restriction Record Sheet} TYPE 3 RESTRICTION

\begin{tabular}{l|l|l}
\hline Student Name: & Level: & Date:
\end{tabular}

This above named student was placed on Type 3 restriction for seven days on this date due to the behaviors described below.

Money received from the student as a result of placement on restriction

\begin{tabular}{l|l} 
Staff Signature: & Student Signature:
\end{tabular}

The student has earned the demerits listed below while on this restriction. Days on which Group $\mathrm{C}$ behavior was maintained are circled. Please check the applicable level below.

\begin{tabular}{|c|c|c|c|c|}
\hline \multirow[t]{2}{*}{$\checkmark$} & Level & Group C Criteria & Fine & Detention \\
\hline & Level I & Not Applicable & Not Applicable & 2 Hours \\
\hline & Level II & Less than 9 Demerits & Not Applicable & 4 Hours \\
\hline & Level III & Less than 7 Demerits & $\$ 3.00$ & 4 Hours \\
\hline & Level IV & Less than 5 Demerits & $\$ 6.00$ & 4 Hours \\
\hline & Level V & Less than 4 Demerits & $\$ 9.00$ & 4 Hours \\
\hline & Level VI & Less than 3 Demerits & $\$ 15.00$ & 4 Hours \\
\hline \multicolumn{5}{|c|}{ First Week } \\
\hline \multicolumn{5}{|l|}{ Day/Date } \\
\hline \multicolumn{5}{|l|}{ Demerits } \\
\hline \multicolumn{5}{|c|}{ Second Week } \\
\hline \multicolumn{5}{|l|}{ Day/Date } \\
\hline \multicolumn{5}{|l|}{ Demerits } \\
\hline Detention & & Fine Paid: & $\$$ & \\
\hline
\end{tabular}

If student does not complete the restriction within fourteen days, the case manager will review the student's progress with the Unit Director to determine whether additional intervention is necessary to help the student to establish and maintain appropriate behavior. 
$\underline{\text { Behavioral Management System }}$

Appendix C

\section{$\underline{\text { PETITION FOR ADVANCEMENT IN LEVELS }}$}

Identifying Information:

Today's Date

Student Name:

Admission Date:

Current Level:

Prerequisite Information:

1. Restrictions over the last six weeks:

2. Groupings earned over last eight weeks:

\begin{tabular}{|l|l|l|l|}
\hline \multicolumn{1}{|c|}{ Week } & From & To & Grouping Earned \\
\hline Current Week & & & \\
\hline Last Week & & & \\
\hline Next Previous Week & & & \\
\hline Next Previous Week & & & \\
\hline Next Previous Week & & & \\
\hline Next Previous Week & & & \\
\hline Next Previous Week & & & \\
\hline Next Previous Week & & & \\
\hline
\end{tabular}

3. Percentage of merits earned over the last six weeks:

\begin{tabular}{|l|l|l|l|}
\hline \multicolumn{1}{|c|}{ Week } & From & To & Grouping Earned \\
\hline Current Week & & & \\
\hline Last Week & & & \\
\hline Next Previous Week & & & \\
\hline Next Previous Week & & & \\
\hline Next Previous Week & & & \\
\hline Next Previous Week & & & \\
\hline Next Previous Week & & & \\
\hline Next Previous Week & & & \\
\hline
\end{tabular}

4. Accomplishment at current level which support advancement:

5. Student input regarding advancement, where appropriate: 
$\underline{\text { Behavioral Management System }}$

\section{PETITION FOR ADVANCEMENT IN LEVELS}

Page 2

Signature:

Case Manager

Student

6. Unit Staff input regarding advancement:

7. Unit Staff Decision regarding advancement (Levels II through VI):

Utilization Review Committee decision regarding advancement (Level VI):

Date

Signature, Unit Director (Level II through V)

Signature, Chairman, Utilization Review Committee 


\section{Appendix D}

\section{Supplemental Tables}

Table 17

$\underline{\text { Age Related To Intake and Discharge Psychometric Scores for Research Question } 1}$

a. Depression scores for students who had data for both the Beck Depression Inventory (intake) and the Beck Depression Inventory (discharge)

\begin{tabular}{ccc}
\hline Age & Beck Depression Inventory (Intake) & Beck Depression Inventory (Discharge) \\
\hline 13.2 & 12 & 3 \\
13.8 & 45 & 3 \\
15.7 & 1 & 1 \\
15.7 & 9 & 1 \\
16.4 & 1 & 21 \\
\hline
\end{tabular}

table continues 


\section{Appendix D}

\section{Supplemental Tables}

Table 17 (table continued)

b. Internal-External Locus Of Control for students who had data for both LOC1 (intake) and LOC3 (discharge). (Compressed Table Summary can be found in body of text)

\begin{tabular}{ccc}
\hline Age & LOC1 (Intake) & LOC3 (Discharge) \\
13.2 & 17 & 8 \\
13.3 & 18 & 18 \\
13.7 & 12 & 12 \\
13.8 & 24 & 7 \\
13.8 & 11 & 5 \\
13.9 & 15 & 21 \\
14.0 & 10 & 10 \\
14.2 & 10 & 11 \\
14.3 & 20 & 14 \\
15.0 & 10 & 7 \\
15.7 & 14 & 6 \\
15.7 & 16 & 16 \\
16.4 & 14 & 14 \\
16.5 & 18 & 4 \\
16.6 & 14 & 13 \\
16.8 & 6 & 10 \\
18.0 & 21 & 6 \\
\hline
\end{tabular}

table continues 


\section{Appendix D}

\section{Supplemental Tables}

Table 17 (continued)

c. STAXI percentile scores for students who had data for both the STAXI (intake) and STAXI (discharge)

\begin{tabular}{ccc}
\hline Age & State Anger (Intake) & State Anger (Discharge) \\
\hline 13.2 & 35 & 75 \\
15.0 & 56 & 35 \\
15.7 & 35 & 35 \\
15.7 & 35 & 35 \\
16.4 & 35 & 95 \\
\hline
\end{tabular}

table continues 


\section{Appendix D}

\section{Supplemental Tables}

Table 17 (continued)

d. STAXI percentile scores for students who had data for both the STAXI (intake) and STAXI (discharge)

\begin{tabular}{lcc} 
Age & Trait Anger (Intake) & Trait Anger (Discharge) \\
13.2 & 39 & 26 \\
15.0 & 54 & 19 \\
15.7 & 1 & 10 \\
15.7 & 10 & 10 \\
16.4 & 26 & 60 \\
\hline
\end{tabular}

table continues 


\section{Appendix D}

\section{Supplemental Tables}

Table 17 (continued)

e. STAXI percentile scores for students who had data for both the STAXI (intake) and STAXI (discharge)

\begin{tabular}{ccc}
\hline Age & Angry Reaction (Intake) & Angry Reaction (Discharge) \\
\hline 13.2 & 48 & 48 \\
15.0 & 60 & 24 \\
15.7 & 3 & 24 \\
15.7 & 12 & 12 \\
16.4 & 35 & 84 \\
\hline
\end{tabular}

table continues 


\section{Appendix D}

\section{Supplemental Tables}

Table 17 (continued)

f. STAXI percentile scores for students who had data for both the STAXI (intake) and STAXI (discharge)

\begin{tabular}{ccc}
\hline Age & Anger In (Intake) & Anger In (Discharge) \\
\hline 13.2 & 35 & 26 \\
15.0 & 76 & 43 \\
15.7 & 18 & 7 \\
15.7 & 81 & 81 \\
16.4 & 26 & 57 \\
\hline
\end{tabular}

table continues 


\section{Appendix D}

\section{Supplemental Tables}

Table 17 (continued)

g. STAXI percentile scores for students who had data for both the STAXI (intake) and STAXI (discharge)

\begin{tabular}{ccc}
\hline Age & Anger Out (Intake) & Anger Out (Discharge) \\
\hline 13.2 & 91 & 63 \\
15.0 & 43 & 22 \\
15.7 & 15 & 33 \\
15.7 & 87 & 83 \\
16.4 & 22 & 63 \\
\hline
\end{tabular}

table continues 


\section{Appendix D}

\section{Supplemental Tables}

Table 17 (continued)

h. STAXI percentile scores for students who had data for both the STAXI (intake) and STAXI (discharge)

\begin{tabular}{ccc}
\hline Age & Anger Control (Intake) & Anger Control (Discharge) \\
\hline 13.2 & 86 & 34 \\
15.0 & 57 & 86 \\
15.7 & 57 & 98 \\
15.7 & 93 & 93 \\
16.4 & 88 & 57 \\
\hline
\end{tabular}

table continues 


\section{Appendix D}

\section{Supplemental Tables}

Table 17 (continued)

i. STAXI percentile scores for students who had data for both the STAXI (intake) and STAXI (discharge)

\begin{tabular}{ccc}
\hline Age & Angry Expression (Intake) & Angry Expression (Discharge) \\
\hline 13.2 & 44 & 57 \\
15.0 & 72 & 13 \\
15.7 & 18 & 1 \\
15.7 & 72 & 69 \\
16.4 & 8 & 61
\end{tabular}

${ }^{1}$ Note: Table 10 reports percentiles for students who had data for both the STAXI (intake) and STAXI (discharge). It is important to not that scaled scores that fall between the $25^{\text {th }}$ and $75^{\text {th }}$ percentile all can be considered within the normal range, all other scores a considered clinically significant. 


\section{Biographical Sketch}

Taji Tortorello was born in October, 1973 in Long Branch, New Jersey. After moving with her mother to several areas across the country she settled in Miami Florida, where she graduate from Miami Sunset High School. After high school, Taji began college at Oakwood College in Huntsville, Alabama. After one year she transferred to Kean University in Elizabeth, New Jersey. She completed her M.S. in Clinical/Community Psychology at Francis Marion University in Florence, South Carolina. Taji enjoys running/speed-walking and movies. She looks forwarded to the challenge of completing her Doctorate degree. 


\section{Vita}

Name:

Date of Birth:

Academic Summary:

B.A.

$$
\begin{aligned}
& \text { Kean University } \\
& \text { Date: May, } 1996 \\
& \text { Major: Psychology }
\end{aligned}
$$

M.S. Francis Marion University

Date: December, 1998

Major: Clinical/Community Psychology

Ph.D. West Virginia University

Expected Date:

Major: Counseling Psychology 